University of Louisville

ThinkIR: The University of Louisville's Institutional Repository

Electronic Theses and Dissertations

$12-2010$

\title{
Walking biomechanics of end stage knee OA and TKA patients.
}

Danielle Biton

University of Louisville

Follow this and additional works at: https://ir.library.louisville.edu/etd

\section{Recommended Citation}

Biton, Danielle, "Walking biomechanics of end stage knee OA and TKA patients." (2010). Electronic Theses and Dissertations. Paper 113.

https://doi.org/10.18297/etd/113

This Doctoral Dissertation is brought to you for free and open access by ThinkIR: The University of Louisville's Institutional Repository. It has been accepted for inclusion in Electronic Theses and Dissertations by an authorized administrator of ThinkIR: The University of Louisville's Institutional Repository. This title appears here courtesy of the author, who has retained all other copyrights. For more information, please contact thinkir@louisville.edu. 


\title{
WALKING BIOMECHANICS OF END STAGE KNEE OA AND TKA PATIENTS
}

\author{
By \\ Danielle Biton \\ Maitrise in Mechanical Engineering, University of Grenoble, France, 1996 \\ DEA in Biomechanics, University of Paris, France, 1997
}

\author{
A Dissertation \\ Submitted to the Faculty of the \\ Graduate School of the University of Louisville \\ in Partial Fulfillment of the Requirements \\ for the Degree of
}

Doctor of Philosophy

Department of Mechanical Engineering

University of Louisville

Louisville, Kentucky

December 2010 
Copyright 2010 by Danielle Biton

All rights reserved 



\title{
WALKING BIOMECHANICS OF END STAGE KNEE OA AND TKA PATIENTS
}

\author{
By \\ Danielle Biton \\ Maitrise in Mechanical Engineering, University of Grenoble, France, 1996 \\ DEA in Biomechanics, University of Paris, France, 1997 \\ A Dissertation Approved on
}

November 23, 2010

by the following Dissertation Committee:

Dissertation Director 


\section{ACKNOWLEDGEMENTS}

This work received support from the National Institute for Nursing Research (Grant \# 1RO1 NR080).

I would like to thank my adviser, Dr. Peter Quesada, for his guidance, support, invaluable advice throughout the time of my dissertation, and for always being there for me when I needed assistance.

I wish to thank Drs. Ellen Brehob, Robert Topp, Julius Wong, and Michael Voor, who served on my dissertation advisory committee, for their insightful suggestions to improve my dissertation. I would especially like to thank Dr. Michael Voor for the opportunity to work on bone remodeling prior to this project, which I particularly enjoyed.

I appreciate the constant support of my parents and parents in law. I am tremendously grateful for the motivational support, and tons of chocolate, from my sisters in France, who even though separated by a great distance, were always there for me. I wish to thank my kids, Timmy and Emilie, for their unending laughs, love, and silliness that cheered me up. I would especially like to thank my husband for his patience, understanding, and relentless support.

Finally, I am grateful for Mary Welps, who helped me relieve my aches and pains during the last few months of my dissertation preparation, and helped me see the light at the end of the tunnel! 


\begin{abstract}
WALKING BIOMECHANICS OF END STAGE KNEE OA AND TKA PATIENTS Danielle Biton
\end{abstract}

December 15, 2010

\begin{abstract}
Osteoarthritis (OA) of the knee is associated with decline in functional capacity and ultimately leads to Total Knee Arthroplasty (TKA) in many of these patients. Exercise regimens prior to surgery may potentially enhance pre and post TKA functional performance. However, assessment of such performance should involve biomechanical factors that characterize the mechanisms with which tasks are performed, and not just the quantity of task performed. The present overall study investigated walking biomechanics of end stage knee OA and TKA patients. Throughout the three sub-studies that comprised the overall investigation, particular emphasis was placed on heelstrike and the loading response phase of gait, in addition to functional ability parameters.

The first sub-study investigated gait biomechanics and fatigue during a 6 minute walk for patients with end stage knee OA. Results demonstrated that even if patients were able to maintain their gait velocity throughout the walk, subtle but statistically significant differences at the ankle were present after the 6 minute walk. Knee OA patients may be experiencing higher loading conditions at the knee after $6 \mathrm{~min}$. In order to adapt to fatigue, knee OA patients appear to adopt ankle strategies alleviating the load from a painful knee, rather than knee strategies, causing greater instability and reduced


performances. A single walking trial for gait analysis may be insufficient to assess gait compensations due to fatigue in daily activities.

In light of the initial results on end stage knee OA walking biomechanics, the second sub-study included investigation of the effects of a 4 to 6 weeks exercise program on TKA outcomes. Results demonstrated that exercise therapy was effective at improving function and reducing pain to a certain extent pre-surgery. However, assessment of the walking biomechanics raised the question of whether improving physical ability improved knee OA condition or caused further knee joint degeneration and possibly the onset of $\mathrm{OA}$ in the opposite leg. Control patients exhibited a more careful gait pattern with lower speed and gait parameters reflecting potentially lower impact at heelstrike which may be more beneficial for knee OA conditions. The exercisers' walking characteristics showed evidence of an overstriding gait pattern with potentially reduced shock absorption mechanisms that can lead to lower leg injuries.

The third sub-study investigated walking biomechanics of prehab and non prehab subjects one month after surgery and results suggested that the effects of the pre-surgery exercise program did not remain post-surgery. Even if patients in the exercise group had increased physical ability performances and experienced less pain just prior to surgery compared to the control group, one month after surgery there was no difference between the groups. The lack of a significant effect of the exercise program on gait changes post surgery may indicate that the exercise regimen prior to surgery requires an additional component such as gait retraining. Adding a gait retraining component to the prehab protocol may improve the rate of recovery and help patients to maintain the prehab benefits even post TKA surgery. 


\section{TABLE OF CONTENTS}

Page

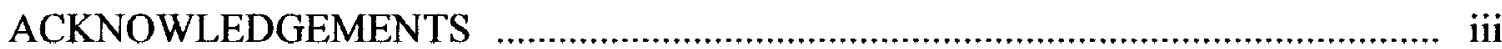

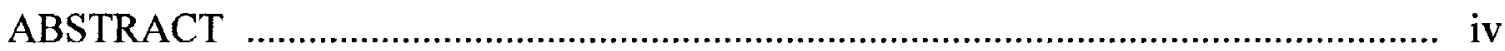

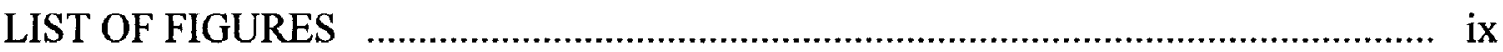

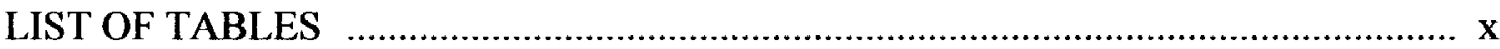

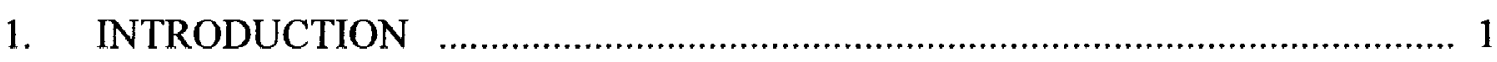

$1.1 \quad$ Prevalence of Knee OA

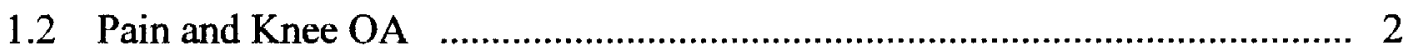

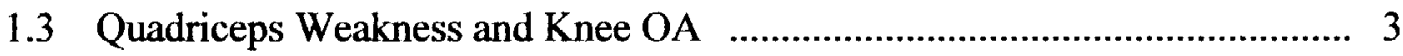

1.4 Measures of Functional Ability

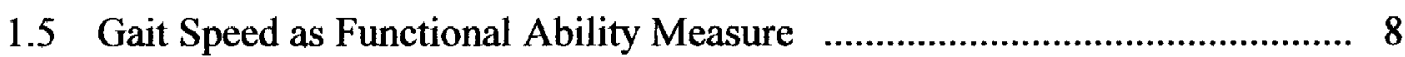

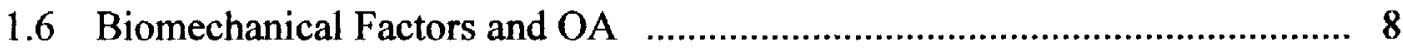

1.7 Heelstrike and the Loading Response Phase of Gait ............................... 9

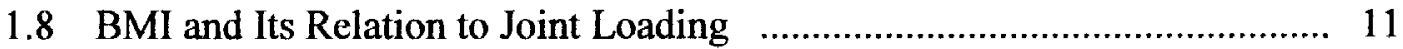

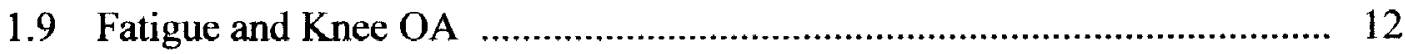

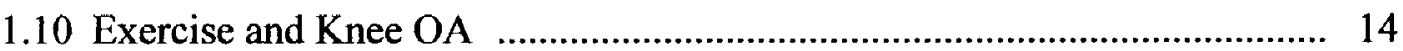

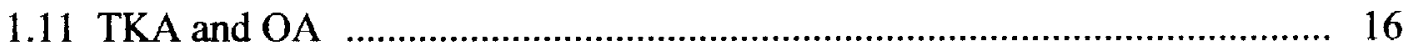

1.12 Gait Characteristics and Functional Capacity among TKA Patients $\ldots . . . . . .16$

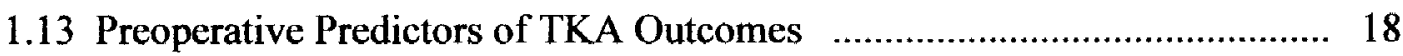

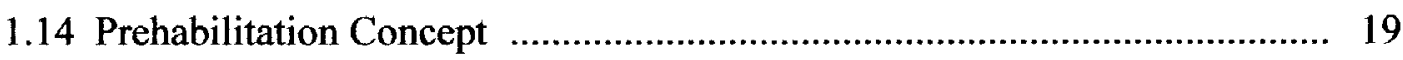

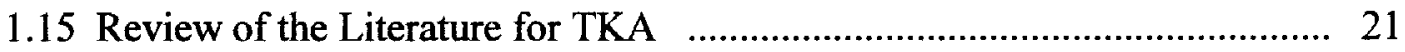

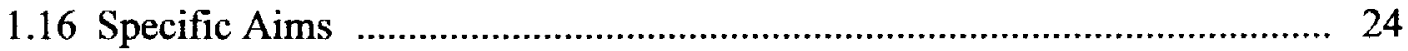




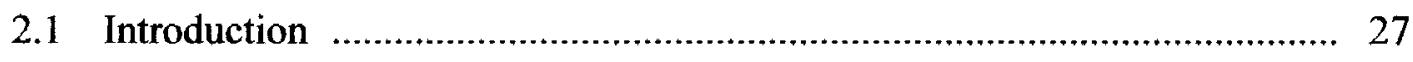

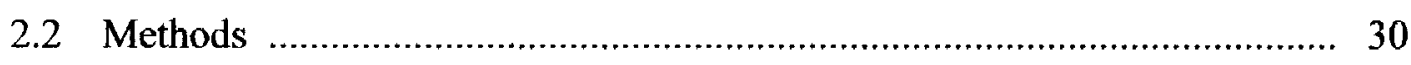

2.2 .1 Population .................................................................... 30

2.2.2 Experimental Protocol ……………………................................... 31

2.2.3 Data Processing ....................................................................... 34

2.2.4 Data summarization ………….................................................... 36

2.2.5 Statistical Analysis …………………………............................. 38

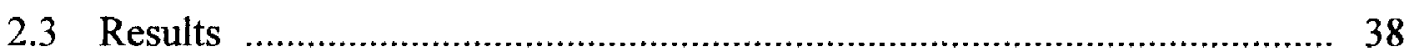

2.3.1 Functional Ability Parameters ………………........................... 38

2.3.2 Gait Characteristic Parameters ………………………………….... 39

2.3.2.1 Gait Speed …................................................................. 39

2.3.2.2 Ankle Trajectory and Pre-Heelstike Vertical Velocity ..... 40

2.3.2.3 Knee Kinematics .............................................................. 40

2.3.2.4 Ankle Kinematics ........................................................ 41

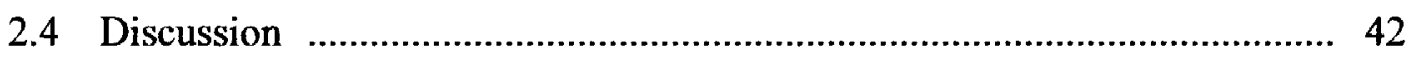

2.5 Conclusion ...................................................................................... 48

3. EXERCISE EFFECTS ON PROLONGED GAIT AMONG END STAGE KNEE OA PATIENTS ............................................................................ 50

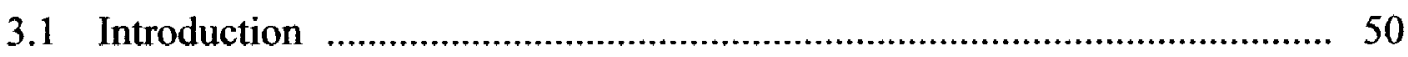

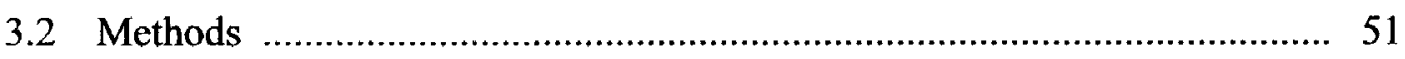

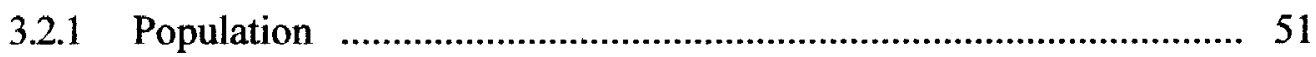

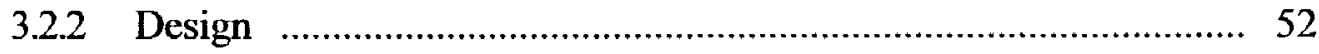

3.2.2.1 Exercise Treatment Group ………………………….... 52

3.2.2.2 Control Group ............................................................. 54

3.3 Statistical Analysis ....................................................................... 54

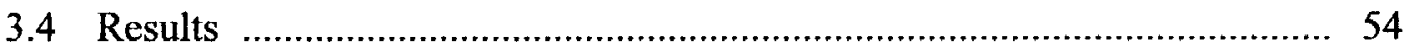

3.4.1 Functional Ability Parameters and Gait Parameters at the Beginning of the Walk ............................................................. 54

3.4.2 Parameter Changes between Start and End of the Walk ................. 60

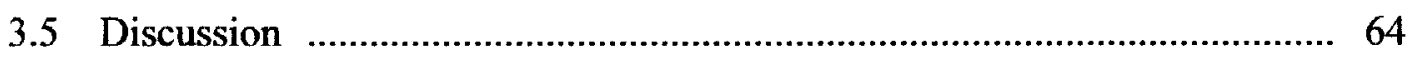


3.6 Conclusion

4. PREHABILITATION EFFECTS ON PRONGUED GAIT AMONG TKA PATIENTS 72

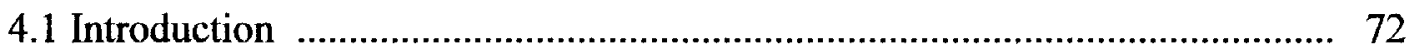

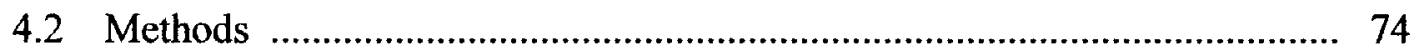

4.2.1 Design .......................................................................... 75

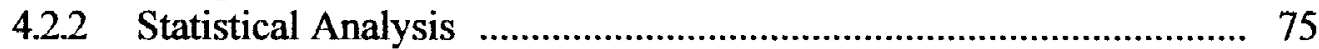

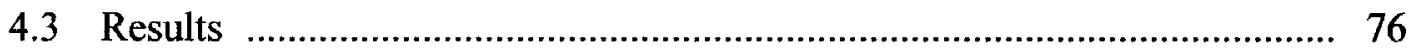

4.3.1 Functional Ability Parameters and Gait Parameters at the Beginning of the Walk ........................................................... 76

4.3.2 Parameter Changes between Start and End of the Walk ............... 76

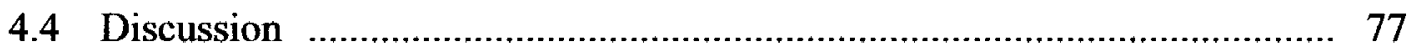

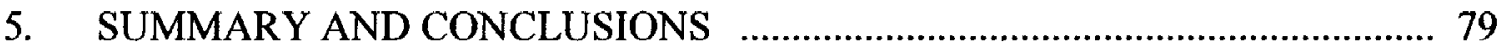

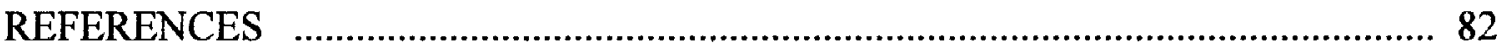

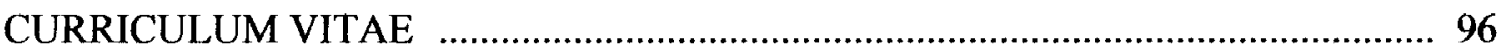




\section{LIST OF FIGURES}

FIGURE

PAGE

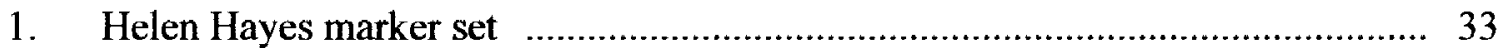

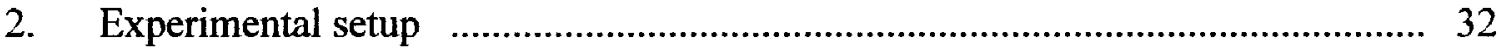

3. Ankle vertical trajectory and vertical velocity profile, definition of

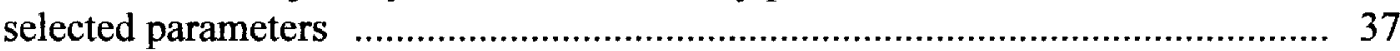

4. Knee joint angle and definition of selected knee parameters ………................ 37

5. Ankle joint angle and definition of selected ankle parameters ........................... 37

6. Ankle vertical trajectory and vertical velocity profile .................................... 40

7. Knee joint angle and definition of selected knee parameters _.............................. 41

8. Ankle joint angle and definition of selected ankle parameters ....................... 42

9. Mean variation of D6 between $\mathrm{T} 0$ and $\mathrm{T} 1$ for control and exercise group ......... 56

10. GS_start mean variations between $\mathrm{T} 0$ and $\mathrm{T} 1$ for control and exercise group .... 58

11. Żank mean variations between $\mathrm{T} 0$ and $\mathrm{T} 1$ for control and exercise group .......... 59

12. TLRKA_start mean variation between $\mathrm{T} 0$ and $\mathrm{T} 1$ for control and exercise group ……................................................................................. 60

13. LRAA mean variations at $\mathrm{T} 0$ and $\mathrm{T} 1$ between start and end of walk .................. 62

14. IKA mean variations at $\mathrm{T} 0$ and $\mathrm{T} 1$ between start and end of walk ................... 64 


\section{LIST OF TABLES}

TABLE

PAGE

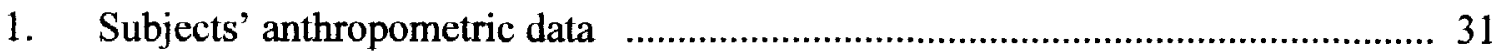

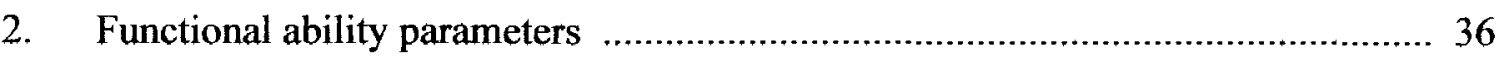

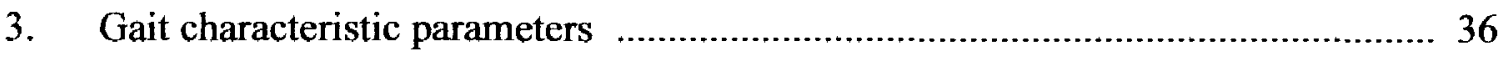

4. Knee pain, distance covered in 6 minute and body mass index values $\ldots \ldots \ldots \ldots . . . . .38$

5. Summary of gait characteristic parameters (mean, $S t$ dev, and $P$ values) at the beginning and end of the 6 minute walk

6. Tests of between subject effects significance for D6, KP, and gait parameters at the beginning of the walk

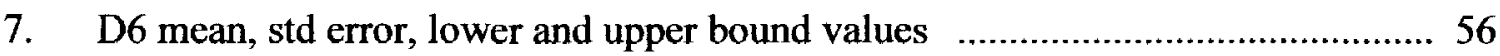

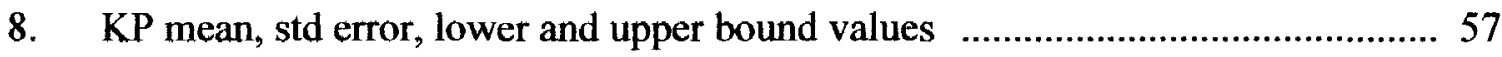

9. GS_start mean, std error, lower and upper bound values ................................ 58

10. Żank_start mean, std error lower and upper bound values .............................. 59

11. TLRKA_start mean, std error, lower and upper bound values ..........................6 60

12. Tests of between subjects effects significance for fatigue indicators ................ 61

13. LRAA_change mean, std error, lower and upper bound values ........................62 62

14. LRAA mean, st error, lower and upper bound values f ................................... 62

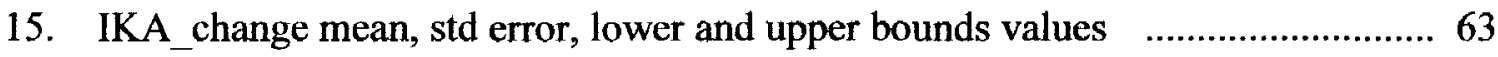

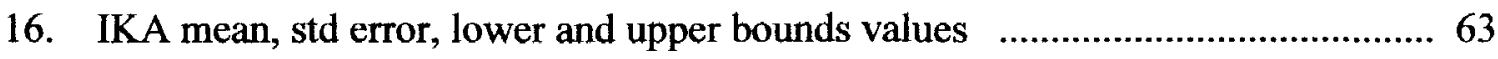

17. Tests of between subject effects significance for D6, KP, and gait parameters at the beginning of the walk

18. Tests of between subjects effects significance for fatigue indicators 


\section{CHAPTER 1}

\section{INTRODUCTION}

\subsection{Prevalence of Knee OA}

Osteoarthritis (OA) is the most common form of arthritis. According to a report published by the American Academy of Orthopaedic Surgeons (Praemer et al. 1999), arthritis affects more than 32 million Americans, or almost 1 in 8 . It is a common, progressive health problem among adults (Phipps et al. 1994, Verbrugge et al. 1995). Current estimates indicate that there are over 27 million Americans affected by clinically symptomatic OA (Block and Shakoor 2009, Lawrence et al. 2008). It is estimated that $80 \%$ of all adults age 65 years and older exhibit radiographic evidence of OA (Burckhardt et al 1990). The prevalence is expected to rise dramatically as the population is aging in the next few decades (Kalb et al.1999). It is estimated that by the year 2020, 60 million Americans, or $18 \%$ of the population, will have to deal with the daily impact of OA on their life. A majority of these adults have OA related pain and OA related disability. $\mathrm{OA}$ in the knees and hips, which affects the weight bearing joints, has a greater clinical impact due to its greater disabling effects. Among U.S. adults 30 years of age and older, $\mathrm{OA}$ in the knee occurs in approximately $6 \%$ and $\mathrm{OA}$ in the hip in roughly $3 \%$ (Felson et al. 1998). Symptomatic knee OA affects an estimated 10-12\% of the adult population aged 55 years and older (Peat et al. 2001). The knee is the most commonly affected joint (Brady et al. 2000) and knee OA is a leading cause of disability and functional limitations in adults (Guccione et al. 1994, Oliveria et al. 1995). 


\subsection{Pain and Knee OA}

Pain in the affected joint is the most common symptom of $\mathrm{OA}$ and contributes to significant declines in functional ability including getting off of the floor, going up and down stairs and walking (McAlindon et al. 1993, Messier et al. 1992). The physiological reaction to pain introduces two obstacles to effective walking: deformity and muscular weakness (Perry 1992). Muscle weakness occurs secondary to the pain of joint swelling causing reduced activity. There is a feedback mechanism designed to protect the joint structure from destructive pressure. Patients display the cumulative effect of this protective reflex as disuse atrophy. During gait analysis, less available strength and increased protective posturing are expected when the joints are swollen.

A tool used for measuring pain is the visual analogue scale (VAS). It is a simple item which is easy to use and removes third person interpretation. The Visual Analogue Scale has been demonstrated to correlate well with physician assessments of pain (Jensen et al. 1986), and to have high test-retest reliability (Price et al. 1983). Consequently it is a valid and reliable tool for measuring pain intensity (Dixon et al. 1981, Kremer et al. 1981, Downie et al. 1978, Ohnhaus et al. 1975).

Pain is a symptom systematically reported in knee OA. Analgesic treatment is common to reduce pain and try to improve ability of daily living. However use of analgesics in knee $\mathrm{OA}$ is thought to result in the loss of the protective pain reflex, leading to an increased load on the joint and a more rapid progression of the disease. Clinical observations both supporting and refuting the occurrence of such mechanisms have been reported in the literature (Ronningen et al. 1979, Newman et al. 1985, Rashad et al. 1989, Hodgkinson et al. 1973, Doherty et al. 1986). Schnitzer et al. (1993) suggested that 
reduction in pain tends to normalize gait but at the same time increase several of the parameters that can be associated with loading of the knee.

Rapid motion of a knee with intrinsic joint pathology increases tissue tension and, therefore, pain. This leads to limited knee flexion in the loading response phase. Loading response knee flexion is avoided by the same mechanisms used for quadriceps weakness. The purpose is to escape the shear force that accompanies joint motion. A second objective is to reduce the compressive force from a contracting quadriceps. Articular surface damages are the common causes. Knee OA patients normally experience pain which is thought to change their motor response and influence their walking pattern in order to minimize knee loading.

\subsection{Quadriceps Weakness and Knee OA}

Investigators have observed a decline in leg strength, particularly in the quadriceps of the knee affected with OA (Lewek et al. 2004, Hassan et al. 2001, Hurley et al. 1998, 1997). Strength in older adults with knee OA has been observed to be reduced by up to

one third compared to age matched controls (Fisher et al. 1991). The relationship between joint pain and decline in muscle strength are beginning to be recognized as more complex than simply disuse due to joint pain contributing to muscle atrophy and muscle weakness surrounding the joint (Sharma et al. 1999, Hurley et al. 1999). Understanding of the role of the quadriceps is important to understand weakness repercussion on gait functions. The function of the quadriceps is to support a flexed knee. When there is insufficient strength to meet the demand, a variety of substitutions are used to preserve weight bearing stability (Perry et al. 1992). When analyzing gait pattern, absent loading response knee flexion is the most common sign of gait adaptation due to quadriceps 
weakness. During loading response, knee flexion is avoided as a deliberate action to protect a weak quadriceps from the strain of decelerating a rapidly flexing knee (Perry et al. 1992). Premature ankle platarflexion blocks tibial advancement, so initial contact by the heel does not stimulate the normal rocker action. Patients use this substitution to preserve a good walking speed and endurance.

Quadriceps weakness has long been recognized as a feature of knee OA (Hurley et al. 1998). However, the question of whether quadriceps weakness is a cause or an effect of knee OA presents some controversy. It is unclear if quadriceps weakness develops after or prior to onset of knee OA. Women with reduced quadriceps strength have a greater risk of developing OA (Brandt et al. 1999). Sharma et al. (2003) concluded that greater quadriceps strength at baseline was associated with increased likelihood of OA progression in malaligned and lax knees. In a review paper, Teichtahl et al. (2003) highlighted the fact that, although a strong quadriceps has the potential to reduce the risk of developing OA, a strong quadriceps is also a risk factor for disease progression in people with malaligned and lax arthritic knees. It has been well established that individuals with knee OA have weaker quadriceps than age matched control subjects without knee OA (O'Reilly et al.1998, Slemenda et al. 1997, Fisher and Pendergast 1997, Baker et al. 2004). The weakness associated with knee OA is largely thought to be the result of disuse atrophy secondary to joint pain. Slemenda at al. (1998) presented results suggesting otherwise. Quadriceps weakness occurred in knee OA when pain was absent. Also, weakness was present in women prior to the onset of radiographic evidence of knee OA (Slemenda et al. 1997, 1998). Other studies have suggested that quadriceps weakness 
increases the risk of disability in person with knee OA (O'Reilly 1998 and McAlindon 1993).

Quadriceps contraction occurs before heelstrike and thereby absorbs impulse loads transmitted through the knee joint. In an attempt to remove the effect of pain on causing weakness Baker et al. (2004) performed an analysis among asymptomatic subjects. The association with muscle weakness was attenuated and remained significant only in patients with mixed disease. These results are in contradiction with Slemenda et al. (1997). Baker et al. 2004 results suggest that pain, in large part, is responsible for decreased strength. The latest statement can be reflected in 2 ways. First, painful knees cannot elicit a maximal contraction due to pain during testing, or second, painful knee OA comes first and cause disuse, muscle atrophy and muscle weakness. Once muscle weakness is present, it can set up a vicious cycle of decreased joint stability and altered proprioception that, in turn, alters the biomechanics of the joint causing further deterioration of the diseased joint. Baker et al. 2004 also found results suggesting that weakness propels severity. Weakness has less effect on disease incidence than on disease progression and/or severity. Weakness was not associated with medial patellofemoral disease suggesting that quadriceps weakness alters the balance of quadriceps contraction, leading to excessive lateral loading. The authors concluded that results in individuals without symptom suggest that pain may contribute to weakness and that the association of OA and weakness may reflect their mutual association with pain.

\subsection{Measures of Functional Ability}

OA related declines impair individuals and lead to difficulty ascending and descending stairs, rising from a chair, standing comfortably, walking, and completing 
other activities of daily living (Jordan et al. 1997, Messier et al. 1992). Thus, physical function was identified by a consensus of research experts in $\mathrm{OA}$ as one of the most important dimensions to be measured when evaluating intervention effectiveness (Bellamy et al. 1997). Locomotor ability, which is defined as the aptitude of a person to walk, is one of the most important physical functions. Locomotor ability can be quantified in many different ways. Gait parameters and fatigability while performing walking, are some examples of pertinent walking functional ability quantifications. Locomotor ability reflects changes in physical function (Barr et al.1994). Declines in functional capacity, measured both objectively and by self-report, have been reported to be a consistent symptom associated with OA of the knee (Sharma et al. 1999, Topp et al 2001).

Among patients over the age of 55, OA is one of the most disabling conditions (Brady et al. 2000). People with symptomatic knee OA have the clinical symptoms of pain, stiffness and decreased range of motion, causing an increased morbidity and a diminished quality of life. Because of its prevalence and the frequent disability that accompanies the disease in the knee and the hip, $\mathrm{OA}$ accounts for more trouble with climbing stairs and walking than any other disease (Guccione et al. 1994). Ettinger et al. (1994) reported that $50 \%$ of men with knee OA have difficulty ambulating and $44 \%$ have difficulty transferring. Of the women in their study with knee $\mathrm{OA}, 71 \%$ and $67 \%$ reported difficulty with ambulating and transferring, respectively.

Measures of functional ability include 6 minute walking test and assessment of walking speed. The secondary role of knee OA treatments (exercise regimen or TKA) is to restore function. Walking is the most important function for normal daily living and 
activity and this function is altered in patients with knee OA. The distance covered in 6 minutes is used as a way of quantifying locomotor ability. Thus, the distance covered in 6 minutes was recognized as an appropriate variable when analyzing outcomes of TKA. A time-constant walking test such as the 6 minute walk test is capable of measuring the performance of all older adults who are ambulatory, regardless of ability level. Previous investigators have assessed the functional ability of TKA patient's pre- and postoperatively using this protocol with minimal reports of injury (Hurwitz et al. 2000, Fransen et al. 2001). Sub maximal exercise has been shown to be effective in detecting a training effect in older adults following aerobic training (Stevenson et al. 1991), and poses less of a health risk to the older adult than a maximal exercise test. The 6-minute walk test has good test-retest reliability and has been demonstrated to be a valid indicator of sub maximal and maximal aerobic capacity among older adults (Stillwell et al. 1996). The distance covered in 6 minutes is perceived as an adequate measure of physical function and locomotor ability by patients and was recommended for this purpose in research projects (Langenfeld et al. 1990, Harada et al. 1999). Ouellet et al. (2002) found, using the distance covered in 6 minutes that patients with knee OA walked shorter distance than control normal subjects. They walked $72 \%$ before TKA and $58 \% 2$ months after TKA of the control values. Validity, reliability, and responsiveness of the 6 minute walk test have been reported in patients with rheumatoid arthritis and OA (Guyatt et al. 1985, Peterson et al. 1993, Price et al. 1988). Reduced functional capacity of people with knee $\mathrm{OA}$ is a major characteristic of the disease and distance covered in 6 minute appears to be a good index of functional ability. 
According to patients and rehabilitation specialists, locomotor ability is of the highest relevance when looking at outcomes of TKA surgery for patients with OA of the knee, since most patients reported difficulties walking. Moreover, this locomotor activity reflects changes in physical function (Barr et al. 1994).

\subsection{Gait Speed as Functional Ability Measure}

Several authors have demonstrated that free walking velocity is a consistent indicator of overall functional status. Ouellet et al. (2002) found a significantly reduced speed for knee OA patients before and 2 months after TKA compare to normal control subject. Among impairment in functional ability, gait speed has been widely studied among patients with $\mathrm{OA}$ of the knee, and is recognized as a significant parameter when analyzing gait deficiency. Gait speed was recognized as an important parameter when analyzing walking pattern. Gait of knee OA patients is characterized by a reduced

velocity compared to normal control subject. Speed was hypothesized to be a strategy to reduce mechanical loading on the knee by patients with less severe knee OA.

Rapid motion of a knee with intrinsic joint pathology increases tissue tension and, therefore, pain. This leads to limited knee flexion in the loading response phase. Loading response knee flexion is avoided by the same mechanisms used for quadriceps weakness. The purpose is to escape the shear force that accompanies joint motion. A second objective is to reduce the compressive force from a contracting quadriceps.

\subsection{Biomechanical Factors and $\mathrm{OA}$}

However, alone, measures of functional ability often offer limited information on how the task is performed. The initiation and progression of knee OA has been related to mechanical factors (Andriacchi et al. 2004). The initiation of OA occurs when the 
cartilage experiences a traumatic or chronic condition which shifts the load bearing contact location of the knee to a location not conditioned and not capable of adapting to the new loading condition during load-bearing activities such as walking (Andriacchi and Mundermann 2006). Andriacchi (2006) provides a framework for explaining the role of kinematics and loads on the progression of knee OA: "The initiation phase is caused by abnormal kinematics while loading drives the progression phase." Radin (2004) explains that the characteristic of $\mathrm{OA}$ is joint failure driven by mechanical factors. In $\mathrm{OA}$, the affected joint tissue is excessively loaded. Loads that are applied too quickly damage joints and the supporting musculoskeletal structures, causing microdamage. Accumulation of microdamage causes degeneration of the joint structure. Individuals who have acquired cumulative microdamage have less effective shock-absorbing mechanisms. When the shock absorbers fail to function effectively, the result is cumulative microdamage leading to remodeling in the cartilage and the bone (Radin et al. 1995). In OA, the tissues are trying to heal but the damage is greater than the reparative capacity. The result is a loss of the articular cartilage surface.

\subsection{Heelstrike and the Loading Response Phase of Gait}

Recent studies have suggested that the mechanical environment of the knee during ambulation has a profound influence on the severity (Mundermann et al. 2004), progression (Miyazaki et al. 2002), and treatment outcomes for knee OA. Schipplein and Andriacchi (1991) demonstrated that high loads occur at the knee at heelstrike with the knee near full extension. Gill and O'Connor (2003) established the gait determinants responsible for producing large impulses at heelstrike. The authors reported that usual gait variables mask subtle variations that are responsible for large variations of heelstrike 
impulse loading. They suggested the use of late swing ankle vertical height and preheelstrike ankle vertical velocity, as indicators of knee loading conditions. With these variables they were able to distinguish between people who "glide" into the ground at heelstrike avoiding high loads and those who "dig" into the ground at heelstrike and experience high loads. By ignoring these important gait variables one would be ignoring the mechanical origin of knee $\mathrm{OA}$.

Astephen and Deluzio (2005) isolated the loading response phase as a very important predictor of knee OA characteristics and suggested that there are important gait pattern differences just after heelstrike in patients with severe knee OA. Loading response is the initial phase of the gait cycle that immediately follows heelstrike. Subjects are shifting their body mass from double support stance to single limb support stance (Perry 1992). Loading response represents one of the most demanding tasks during the gait cycle, requiring a great deal of coordination, shock absorbency and limb stability (Perry 1992), all of which can be greatly compromised by knee OA. The knee and ankle provide valuable shock absorption mechanisms to protect the knee joint from the deleterious forces of full floor contact with the heel. Impact knee angle is believed to have a considerable influence on the body's ability to attenuate impact loading (Lafortune et al. 1996). Impact forces are mainly determined by ankle and knee angles at touchdown and impact velocity (Gerritsen et al. 1995). Hence, leg position at heelstrike is critical for understanding compensation used by end stage knee OA patient regarding loading of a painful knee.

Restrained ankle plantar flexion and knee flexion during the loading response phase of gait have the advantage to provide valuable shock absorption. During this time, the 
quadriceps functions eccentrically to restrain, but not completely prevent knee flexion. Loading response knee flexion disrupts knee stability. Strength of the quadriceps is critical to establish a secure limb. Quadriceps weakness has been documented as a characteristic of knee OA patients. The relationship between joint pain and decline in muscle strength are beginning to be recognized as more complex than simply disuse due to joint pain contributing to muscle atrophy and muscle weakness surrounding the joint (Sharma et al. 1999, Hurley et al. 1999).

Gait parameters of interest when studying end stage knee OA patients appear to be those related to heelstrike phenomenon and the loading response phase of gait. Leg position at heelstrike, knee flexion and ankle plantarflexion during loading response, ankle height in late swing and vertical velocity of the ankle just prior heelstrike are of particular interest. They give a picture of the lower leg shock absorption capacity.

\subsection{BMI and Its Relation to Joint Loading}

Similar loading pattern during gait have been observed for obese patients and knee Osteoarthritis patients (Andriacchi and Mundermann 2006) suggesting that increased weight initiates a pathway to cartilage degeneration prior to the emergence of knee OA symptoms. Overweight is a strong risk factor for disabling knee OA (Kauffman et al. 2001, Manninen et al. 1996, McAlindon et al. 1996). Several studies have demonstrated that individuals with an increased BMI are at risk of developing knee OA (Schouten et al. 1992, Hochberg et al. 1995, Mannien et al. 1996, McAlindon et al. 1996, Felson et al. 1997). Kauffman et al. (2001) demonstrated that individuals with knee OA and increased BMI have gait patterns that deviated from normal. Knee loading is related to body mass, 
and thus, biomechanical stresses are magnified in overweight subjects. The overweight subjects modified their gait pattern to minimize joint loading.

\subsection{Fatigue and Knee OA}

An increased fatigue is reported by OA patients. Muscle fatigue refers to a class of acute effects that impair performance (Enoka 1994). "A decrease in the muscle's producing capability, over prolonged (sustained or intermittent) contractions, is a typical manifestation of muscle fatigue" (Caffier et al. 1992, Hagberg et al. 1981). Because joint movement is achieved by contractions of multiple muscles in action, fatigue-induced impairment of joint performance depends on the differences in fatigue responses of various muscles. In addition the forces generated by the muscles, and hence their contributions to torque, also change depending on joint positions due to physiological and architectural factors.

An increased fatigue is reported by patients with OA. However, to date this fatigue has not been characterized and quantified. When fatigue is related to a disease like osteoarthritis, affecting daily living activities, it is usually assessed by questionnaires. Questionnaires are not able to identify physiological changes associated with fatigue. The role of mechanical factors in the pathomechanics of osteoarthritis is well recognized. Syed et al. (2000) hypothesized that the changes in gait pattern due to fatigue in obese knee OA patients will lead to an altered knee kinematic pattern at heelstrike and consequently decrease the shock absorption. This scenario will result in an increased rate of loading causing articular cartilage damage (Radin et al. 1991). Knee OA patients exhibit significant quadriceps weakness (Slemenda et al. 1997, Nordesjo et al. 1983, Fisher et al. 1991)). Fatigue due to muscle weakness leads to shorter periods of eccentric 
contraction and thus in decreased shock absorbency. Thus, it is reasonable to anticipate that fatigue will affect loading pattern in knee OA patients.

Gait alteration and loading pattern changes due to fatigue have been characterized in other population. Van Lent et al. (1994) reported that mild fatigue (10 minute) did not affect the gait pattern of control persons but did affect the gait pattern of patients with ACL ruptures. Compensatory mechanisms appeared while patients did not complain about being tired. However, muscle activity and gait patterns showed significant signs of fatigue. Johnston et al. (1998) results clearly supported the hypothesis that fatigue can significantly decrease balancing ability. They suggested that fatigued individuals may be at increased risk of injury. Perhaps, ligamentous laxity noted to occur with fatigue contributes to an increased incidence of injury. These results suggest that rehabilitation programs should not only concentrate on muscle strengthening but also on endurance. Mizrahi et al. (1997) indicated that failure of the EMG to detect fatigue is a sign that fatigue is coming from deterioration of coordinated muscle action with loss of synergistic control of muscles rather than failure of the individual muscle. The results of their study on fatigue during running showed that the amplitude of the acceleration is steadily increasing with running time in the fatigue group. Thus they concluded that the human musculoskeletal system becomes less capable to handle heel-strike induced shock waves when there is fatigue. The latest results emphasize the fact that fatigue may promote osteoarthritis. Verbitsky et al. (1998) find similar results but they also found a relationship with stride rate while velocity is preserved. In the fatigued group, subjects were maintaining a constant velocity but a decreased stride rate associated with an increase in heelstrike initiated shock waves. Bobbert et al. (1992) suggested that fatigue 
in the runner may lead to modification of landing phase mechanics. Studies on knee OA patients have focused on deviation in gait pattern compared with normal able-bodied control subjects, but none have investigated preferred gait pattern selected by knee OA patients under mild fatigued condition and the consequences these choices may have on gait function, the musculoskeletal system and progression of the disease.

\subsection{Exercise and Knee OA}

For managing pain, exercise is among the most common conservative management approaches. It is important to recognize the involvement of muscle in OA because muscle can be exercised to improve strength, endurance, and skill, even in very old people. Therefore, rehabilitation programs that address muscle dysfunction can prevent or alleviate some of the problems associated with OA. In their review article, Fransen et al. (2002) demonstrated the accruing evidence of exercise benefits for osteoarthritic patients. Furthermore, regular participation in physical activity has been recognized for several years as being beneficial in the management of knee OA (Hochberg et al. 1995, American college of rheumatology subcommittee on osteoarthritis guidelines 2000, Hurley 2003). A substantial number of clinical trials have indicated that various exercise interventions can enhance measures of functional capacity among patients with OA of the knee. Most exercise interventions such as walking programs (Messier et al. 1997, Minor et al. 1989, Peterson et al. 1993), muscle strengthening programs (Fisher et al. 1997, Peterson et al. 1993, Fisher et al. 1993), aquatic programs (Messier et al. 1997), and general therapy (Fisher et al. 1993), have demonstrated global improvements in pain reduction, walking speed, distance, muscle strength, and gait kinematics. 
A number of comprehensive reviews in the area have made similar conclusions regarding the benefits of exercise among $\mathrm{OA}$ patients and indications for future inquiry in the area. Petrella et al. (2000) and Van Baar et al. (1999) reviewed 33 studies and noted significant effects of exercise treatment on joint pain, functional outcome measures, and self-perceived measures of functioning among OA patients. Hurley (2003) reviewed the literature focusing on strength training for individuals with knee $\mathrm{OA}$, and raised some considerations to include balance and functional retraining activities to rehabilitation programs. Primarily, exercise can increase muscle strength (Fisher et al. 1991, 1993, 1997, Hurley et al. 1993, Fransen et al. 1997, 2001, Hurley et al. 1998, O'Reilly et al. 1997, Rogind et al. 1998, Ettinger et al. 1997, Deyle et al. 2000). Many different regimens, involving static and dynamic contractions, weights, and manual or other forms of resistance, have been employed to reach these improvements. These studies showed that exercise programs are safe for knee OA patients and that muscle strength benefits are greater than the risk encountered when exercising. They demonstrated that strength increase is associated with reduced pain and disability, without acerbating knee damage (Peat et al. 2001, Fisher et al. 1991, 1993, 2001, Fransen et al. 1997, 2001, Hurley et al. 1998, O'Reilly et al. 1997, Rogind et al. 1998, Ettinger et al. 1997, Deyle et al. 2000). Also, incorporated into rehabilitation programs, exercise aimed at improving reaction time, balance and coordination, can improve functional joint stability and proprioception (Hurley et al. 1998), restore shock absorption capacity, and protect against further joint damage (Johansson et al. 1991, O'Connor et al. 1985, 1998). 


\subsection{TKA and OA}

Conservative treatments for knee $\mathrm{OA}$, including exercise as well as weight loss and medication, commonly delay but do not eliminate the need for surgical treatment. They do not provide cures for the disease, nor do they address the physiological cause of the symptoms. Commonly, these treatments provide only limited relief of the symptoms and surgical interventions are recommended (Brady et al. 2000). Knee replacement is one of the most common orthopaedic procedures performed. In $2001,172,335$ primary knee replacement and 16,896 revisions were performed (Orthopedic Network News 2002). Previous reports suggest that TKA improves functional status, relieves pain, and results in relatively low morbidity (Callahan 1994). As a result of conservative treatment limitations, the rate of TKAs is increasing. In 1990, over 129,000 TKAs were performed (NCHS 1992), while in 1998 266,000 TKAs were performed in the United States. Total knee arthroplasty (TKA) addresses the actual problem and replaces the nonfunctional joint with a prosthetic device. This procedure has been proven to be efficient in relieving pain and improving functional ability and quality of life (Fortin et al. 1999, Harris et al. 1990, Liang et al. 1990, Rissanen et al. 1995, Tierney et al. 1994, Van Essen et al. 1998, Williams et al. 1997). However, TKA commonly involves prolonged rehabilitation (Dieppe et al. 1999, Callahan et al. 1994).

\subsection{Gait Characteristics and Functional Capacity among TKA Patients}

Gait characteristics, which are important indicators of functional capacity, have been observed to differ in knee OA patients from normal subjects even after postoperative recovery from a TKA. Two months after TKA the locomotor capacity is far below the preoperative level (Ouellet et al. 2002). Two years after TKA, gait analysis 
shows a slow gait, with a "stiff knee gait pattern" and an unphysiological gait pattern (Benedetti et al. 2003). The free gait velocity in TKA patients is reported to be lower than in normal controls (Lee et al 1999, Berman et al. 1987, Chen et al. 1991, Kroll et al. 1989). Using a normal model accounting for velocity (Lee et al. 1999), cadence is faster and step length is shorter in TKA patients than in normal controls. Lee et al. (1999) also demonstrated that step time and single support time are shorter and double support time is longer in TKA patients compared with normal subjects. Initial vertical ground reaction forces are significantly lower for TKA patients than in normal subjects (Lee et al. 1999). The author concluded that TKA patients are believed to walk in such a manner as to soften the shock when the heel hits the ground. Brinkman et al. (1985) demonstrated a reduced knee speed and range of motion among TKA patients postoperatively compared to normal controls. Ouellet et al. (2002) found also a reduced excursion of motion for the TKA knee associated with a more flexed hip and a less plantar flexed ankle. Wilson et al. (1996) found a decreased knee range of motion in posterior stabilized prostheses, and two groups of flexion and extension knee moments, with an increased quadriceps and hamstring muscle activity. The abnormal characteristics of flexion-extension moments found during TKA gait were thought to be associated to abnormal phasing of quadriceps and hamstring (Andriacchi 1993). As possible causes for remaining abnormalities in gait of TKA patients, Andriacchi et al. (1982) suggested that there were lasting abnormal patterns learned preoperatively. In more recent studies, several authors agree with the hypothesis that the retention of pre surgery gait patterns accounts for the abnormal sagittal moment patterns observed post surgery (Smith et al. 2004, Hilding et al. 1996, Wilson et al. 1996). Assuming that knee pain and muscle weakness associated with OA 
contribute to changes in gait characteristics preoperatively (Perry 1998), it seems likely that post-TKA gait abnormalities, including deficits in knee speed and range of motion, may also be attributed to preoperative knee pain and muscle weakness. Post-TKA muscle weakness may contribute to additional compensatory gait mechanisms, the result of which would be a gait pattern generated by "inadequate, excessive, inappropriately timed, or out-of-phase muscle actions" (Perry 1998). Furthermore, this remaining abnormal knee prosthetic biomechanics might have implications in long term failure of prosthesis (banks et al. 1997, Hilding et al. 1999).

\subsection{Preoperative Predictors of TKA Outcomes}

Measures of functional capacity have been shown to be significant predictors of outcomes following TKA. Prior to surgery, such knowledge is helpful in identifying patients at risk of poor locomotor recovery, identifying their expected level of independence, and predicting the need of postoperative locomotor rehabilitation and home support in the first months following TKA.

Anouchi et al. (1996) observed among TKA patients that preoperative knee flexibility, pain and functional capacity significantly predicted postoperative flexibility, pain and functional capacity respectively. In a similar descriptive study Sharma et al. (1996) studied TKA patients 1 month prior to and 3 months following their TKA procedure. All subjects were 55 years and older with OA of the knee. Significant predictors of postoperative TKA functional capacity have included preoperative pain and functional capacity but not preoperative knee strength. In another study, Escalante et al. (1997) attempted to identify predictors of length of stay following TKA and THA surgeries. The authors reported that preoperative functional capacity was an important 
determinant of the rate of recovery of functional independence and length of stay following TKA and THA surgeries. They concluded that interventions, which optimize preoperative functional capacity among TKA and THA patients, could potentially enhance postoperative functional capacity and decrease postoperative length of stay.

In more recent studies, Fortin et al. (2002) found that improvements in pain and function at 2 years following TKA were similar to those observed at 6 months. Subjects with the worst function and pain at the time of surgery had comparatively worse function 2 years after surgery. They concluded that performing surgery earlier in the course of functional decline may be associated with better outcome. Fortin et al. (1999) found similar results with THA and TKA surgeries. Also, Parent et al. (2003) found that the preoperative profile of a patient at risk for poor postoperative locomotor recovery 2 months after TKA would be a patient with a high intensity pain, a restriction in flexion amplitude, a deficit in knee strength, and a poor preoperative locomotor ability measured by the 6 minute walk test. In addition, the preoperative gait power profiles, on the non operated side, would be characterized by low concentric push off work by the plantar flexors and low concentric action of the hip flexors during early swing.

A large number of studies have found association between capability variables (6 minute gait distance, gait speed, stride length) and measures of locomotor ability, in elderly people (Harada et al. 1999, Chandler et al. 1998), in persons with OA (Peterson et al. 1993, Rejeski et al. 1995), and in persons with TKA (Finch et al. 1998).

\subsection{Prehabilitation Concept}

The theory of prehabilitation states that by improve the functional capacity of the body in preparation for an anticipated stressful event such as orthopaedic procedure, the 
functional capacity after surgery will be improved. Marcia et al. (2002) explain the foundation behind this theory.

The human body reacts positively to physical activity by performing more efficiently (Administration on aging, 2001). In response to physical activity, muscles, bones and joints rebuild and repair. Conversely, without physical activity, muscle weaken, bones become porous, and joints become less mobile resulting in dysfunction (Deschenes et al. 2001, Michael 2000). Weak muscles, frail bones, and joints are responsible for functional limitations such as difficulty climbing stairs, getting in and out of a chair, and walking.

Hence, weight-bearing activities are crucial to improving or maintaining physical functioning of the human body (Jorgensen et al. 2000, Bamman et al. 1998). Stressor of inactivity is associated with TKA procedure and thus put patients at risk for limited physical functioning due to lack of activity.

The human body has the potential to regain what was lost due to the immobilization. Strength training before immobilization has been found to retard the loss of strength (Akima et al. 2000, Bamman et al. 1997, Keays et al. 2000). Furthermore, the human body has the capacity to become stronger at any age, and even with many medical conditions. Physical activity has the potential for improving functional capacity, which prepares the body for external stressors.

Measure of functional capacity before orthopaedic surgery may directly affect postoperative functional capacity (Fortin et al. 1999). Patients with lower preoperative physical function do not improve as much in function and pain relief postoperatively compared to patients with a higher physical function preoperatively. Thus, it seems 
appropriate to attempt to enhance an individual's functional capacity prior to encountering the stressor of TKA surgery through prehabilitation in an attempt to reduce postoperative pain as well as improve performance of functional ability.

The concept of prehabilitation has been employed by athletes in an effort to reduce the risk of injuries and help accelerate their rebound from any injuries. When applied properly the concept of prehabilitation results in fewer injuries and faster rehabilitation among athletes (Caraffa et al. 1996, Griffin et al. 1996, Heidt et al. 2000, Jones et al. 1994, smith et al. 1994).

Similarly, by applying the concept of prehabilitation to improve the patient's functional ability before encountering the stressor, such as TKA surgery, the individual would be more likely to withstand the stress better than one who is physically inactive.

\subsection{Review of the Literature for TKA}

Only 3 studies have examined effect of exercise programs prior to TKA on surgery outcomes. These studies used different treatment interventions, different outcome measures, and different sample sizes. They were all randomized controlled trial studies. We will review the specificities of each of them.

In the first study, Weidenhielm et al. (1993) used a population scheduled for unicompartmental knee replacement. The findings of this study cannot be extrapolated for total knee replacement as the degree of severity of knee OA and the surgical procedures are not the same. Patients had moderate OA of the knee. The sample size was 20 patients for the control group and 19 patients for the treatment group. The intervention program prior to surgery consisted of warm up, knee joint mobility exercises, and muscle strengthening of the lower limb. This 5 weeks physiotherapy program aimed at 
preserving or improving range of motion and increasing strength. Before surgery the treatment group showed slight improvements in pain, perceived stability of the knee during walking, faster self selected and maximal walking speeds compared to the control group. However muscle strength, range of motion and oxygen cost were unchanged. After surgery, no differences were identified between groups. The conclusion of this study was that there were no benefits from preoperative physical exercise on the outcome of TKA surgery.

In the second study, D'Lima et al. (1996) studied the effect of 5 weeks of strength or aerobic training versus a control condition among 30 patients scheduled for TKA. Patients were evaluated with questionnaires only: Arthritis Impact Measurement Scale (AIMS), Quality of Well Being Instrument scale (QWBS), Hospital for Special Surgery Knee Rating (HSSKR). These self-reported instruments indicated no effect for either of the 2 modes of preoperative exercise training over the control condition. However, both groups, aerobic and strength training, tolerated their exercise program extremely well.

In the third study, Rodgers et al. (1998) examined the effect of 6 weeks of physical therapy among 10 subjects scheduled for TKA. The exercise program consisted of lower limb stretching, mobilizing and strengthening. Only the treatment group was testing at baseline 6 weeks prior surgery. All the subjects were tested just prior to surgery and postsurgery. The authors reported no difference in isokinetic strength decrease after surgery between groups. However, muscle area did not decrease significantly for the treatment group, but it did decrease for the control group after surgery. The conclusion of this study was that preoperative physical therapy preserved thigh muscle area after surgery but the 
usefulness of a prehabilitation program in knee replacement surgery couldn't be demonstrated.

Similarly for Total hip replacement (THA), Whitney et al. (2002) reported that 31 THA patients, who engaged in strength training exercises preoperatively, were able to walk greater distances postoperatively than the THA controls. These investigators concluded that preoperative exercise might promote recovery and mobility after THA. These conclusions are also supported by the findings of Wijgman et al (1994) who reported that preoperative physical therapy improved the Harris Hip Scores among 31 THR patients at the time of discharge and 14 days after surgery.

Previously cited studies have been limited by a number of methodological flaws, which may have contributed to their findings, that preoperative exercise had inconclusive effects on postoperative recovery among TKA patients. The proposed study will address these flaws.

Pertinent choice of outcome measures must be done with regards to the concept of specificity. The major flaw in all the studies looking at effects of preoperative exercise on TKA outcomes is the choice of outcome measures. The three studies cited disregarded the concept of specificity of training. Thus, the outcome measures chosen were not related to the interventions used and would not be expected to change following intervention.

Weidenhielm et al. (1993) used an intervention program focused on knee mobilizing exercises and lower limb strengthening, and choose oxygen cost of walking and knee ROM, as outcome variables, which are not directly related to the exercise program. D'Lima et al. (1996) used two intervention programs based on basic 
strengthening exercises and ergometry exercises. It is unlikely that the effects will translate to a change in function as measures by questionnaires such as the impact measurement scale. Specific functional exercise need to be targeted to achieve this aim. Rodgers et al. (1998) asserted that the measurement scales used in D'Lima et al. (1996) study are probably not sensitive enough to detect changes in strength and other parameters following physiotherapy as they have not been design for that purpose. Rodger et al. (1998) acknowledge also, that the choice of an isokinetic measurement tool may not detect changes in strength adequately after an isotonic training program.

Outcome measures assessing more global parameters such as physical function are more sensitive to changes after a physiotherapy program, which compromises other components in addition to muscle strengthening. Wang et al. (2002) used measures of gait parameters and general endurance as outcome variables for exercise program on total hip arthroplasty and showed that they were pertinent outcomes measures that can quantify changes in this population.

In the present study we propose also to use gait parameters and general endurance parameters that have been proven to be adequate measures for exercise program on the outcomes for TKA. In addition we propose to examine parameters related to the loading response phase that were shown to have a strong relationship with the progression of OA and functional impairment.

\subsection{Specific Aims}

The present overall study investigated the walking biomechanics of end stage knee OA and TKA patients. This work was divided into 3 sub-studies. 
The first sub-study aim was to evaluate biomechanical and functional effects of a moderate duration walk among patients with severe knee OA scheduled for TKA surgery. The hypothesis tested was based on the presumption that a 6 minute walk represents a fatiguing activity for end stage knee OA patients. We hypothesized that end stage knee OA patients will exhibit an altered gait pattern after a 6 minute walk compared with the initial gait pattern at the beginning of the walk. Based on the fact that biomechanical factors are an important characteristic of knee OA, gait kinematics were analyzed with particular interest in phenomenon happening around heelstrike and loading response phase of gait, at the knee and ankle joints, initially and after a 6 minute walk. Pain, distance covered in 6 minute and body mass index were recorded to relate to function.

The $2^{\text {nd }}$ sub-study aim was to determine whether an exercise program prior to surgery improves outcomes of patients seeking relief from knee $\mathrm{OA}$. The hypothesis tested in the $2^{\text {nd }}$ sub-study was based on the first sub-study hypothesis stating that gait adaptations appear after a 6 minute walk and on the hypothesis that exercise improves function in knee OA patients. We hypothesized that a 4 to 8 week exercise program will modify the gait pattern and measures of functional ability adopted by end stage knee OA patients at the beginning of the 6 minute walk as well as the compensatory mechanisms at the end of the walk compared to the initial walking trial. Gait variables used in the first sub-study were used in the second sub-study.

The aim of the $3^{\text {rd }}$ sub-study was to assess the benefits of a prehabilitation program on post-TKA outcomes. The hypothesis tested in the $3^{\text {nd }}$ sub-study was based on the first and second sub-studies stating that gait adaptations are present after a 6 minute walk and exercise improves knee OA patients' outcomes. The hypothesis tested in the $3^{\text {rd }}$ sub-study 
was that at one month after TKA surgery, gait characteristics related to shock absorbency and functional status parameters (knee pain and distance covered in 6 minute) would be significantly improved for patients participating in the prehabilitation protocol compared with patients in the control group who had only usual care. 


\section{CHAPTER 2}

\section{BIOMECHANICHAL EFFECTS OF PROLONGED}

\section{GAIT AMONG END STAGE KNEE OA PATIENTS}

\subsection{Introduction}

Osteoarthritis $(\mathrm{OA})$ is the most common form of arthritis. Current estimates indicate that there are at least 27 million Americans affected by clinically symptomatic OA (Lawrence et al. 2008). The prevalence is expected to rise dramatically as the population ages during the next few decades. A majority of these adults have OA related pain and disability. Knee $\mathrm{OA}$ has a greater clinical impact since it affects a weight bearing joint. People with symptomatic knee OA have pain, stiffness and decreased range of motion which contribute to limited functional ability.

Functional ability measures include 6 minute walking test and assessment of walking speed. The distance covered in 6 minutes is perceived as an adequate measure of physical function and locomotor ability by patients and has been recommended for this purpose in research projects (Langenfeld et al. 1990, Harada et al. 1999). Several authors have demonstrated that free walking velocity is a consistent indicator of overall functional status. Among impairment in functional ability, gait speed has been widely studied among patients with knee $\mathrm{OA}$, and is recognized to be a significant parameter when analyzing knee OA gait deficiency. However, alone, measures of functional ability often offer limited information on how the task is performed. 
The initiation and progression of knee $\mathrm{OA}$ has been related to mechanical factors (Andriacchi et al. 2004). Andriacchi (2006) provides a framework for explaining the role of kinematics and loads on the progression of knee OA: "The initiation phase is caused by abnormal kinematics while loading drives the progression phase." Radin (2004) explains that the characteristic of $\mathrm{OA}$ is joint failure driven by mechanical factors. Recent studies have suggested that the mechanical environment of the knee during ambulation has a profound influence on the severity (Mundermann et al. 2004), progression (Miyazaki et al. 2002), and treatment outcomes for knee OA. Schipplein and Andriacchi (1991) demonstrated that high loads occur at the knee at heelstrike with the knee near full extension. Gill and O'Connor (2003 a and b) established the gait determinants responsible for producing large impulses at heelstrike. The authors reported that usual gait variables mask subtle variations that are responsible for large variations of heelstrike impulse loading. They suggested the use of late swing ankle vertical height and preheelstrike ankle vertical velocity, as indicators of knee loading conditions. With these variables they were able to distinguish between people who "glide" into the ground at heelstrike avoiding high loads and those who "dig" into the ground at heelstrike and experience high loads. By ignoring these important gait variables one would be ignoring the mechanical origin of knee $\mathrm{OA}$.

Astephen and Deluzio (2005) isolated the loading response phase as a very important predictor of knee $\mathrm{OA}$ characteristics and suggested that there are important gait pattern differences just after heelstrike in patients with severe knee OA. Loading response represents one of the most demanding task during the gait cycle, requiring a great deal of coordination, shock absorbency and limb stability (Perry 1992), all of which 
can be greatly compromised by knee $\mathrm{OA}$. The knee and ankle provide valuable shock absorption mechanisms to protect the knee joint from the deleterious forces of full floor contact with the heel. Impact knee angle is believed to have a considerable influence on the body's ability to attenuate impact loading (Lafortune et al. 1996). Impact forces are mainly determined by ankle and knee angles at touchdown and impact velocity (Gerritsen et al. 1995). Hence, leg position at heelstrike is critical for understanding compensation used by end stage knee OA patient regarding loading of a painful knee.

Restrained ankle plantar flexion and knee flexion during the loading response phase of gait have the advantage to provide valuable shock absorption. During this time, the quadriceps functions eccentrically to restrain, but not completely prevent knee flexion. Loading response knee flexion disrupts knee stability. Strength of the quadriceps is critical to establish a secure limb. Quadriceps weakness has been documented as a characteristic of knee OA patients. The relationship between joint pain and decline in muscle strength are beginning to be recognized as more complex than simply disuse due to joint pain contributing to muscle atrophy and muscle weakness surrounding the joint (Sharma et al. 1999, Hurley et al. 1999).

Gait parameters of interest when studying end stage knee OA patients appear to be those related to heelstrike phenomenon and the loading response phase of gait. Leg position at heelstrike, knee flexion and ankle plantarflexion during loading response, ankle height in late swing and vertical velocity of the ankle just prior heelstrike are of particular interest. They give a picture of the lower leg shock absorption capacity.

An increased fatigue is reported by patients with OA. However, this fatigue has not been characterized and quantified. Syed et al. (2000) hypothesized that the changes in 
gait pattern due to fatigue in obese knee $O A$ patients will lead to an altered knee kinematic pattern at heelstrike and consequently decrease the shock absorption. This scenario will result in an increased rate of loading causing articular cartilage damage (Radin et al. 1991). Knee OA patients exhibit significant quadriceps weakness (Slemenda et al. 1997, Nordesjo et al. 1983, Fisher et al. 1991)). Fatigue due to muscle weakness leads to shorter periods of eccentric contraction and thus in decreased shock absorbency.

The hypothesis tested in the present study was based on the presumption that a 6 minute walk represents a fatiguing activity for end stage knee $\mathrm{OA}$ patients. We hypothesized that end stage knee OA patients will exhibit an altered gait pattern after 6 minute walk compared with initial gait pattern at the beginning of their walk. Gait kinematics were analyzed with particular interest to phenomenon happening around heelstrike and loading response phase of gait, at the knee and ankle joints, initially and after a 6 minute walk. Pain, distance covered in 6 minute and body mass index were recorded to relate to function. A better understanding of gait alterations due to prolonged walk might help identify mechanical factors related to the initiation and propagation of the disease and help design gait rehabilitation strategies and suggest meaningful outcome measures when evaluating rehabilitation protocol and TKA surgery effectiveness.

\subsection{Methods}

\subsubsection{Population}

The study population consisted of 26 community-residing subjects, aged 50 years or older, scheduled for unilateral TKA for treatment of end stage knee OA. There were 12 men and 14 women in the sample. The subjects ranged in age from 50 to 75 years and 
had a mean age of 62.5 years $( \pm 7.4)$. Their mean height was $170.5 \mathrm{~cm}( \pm 10.1)$ and their mean weight was $94.2 \mathrm{~kg}( \pm 23.0)$. Subjects' anthropometric data are presented in Table1.

\begin{tabular}{|c|c|c|}
\hline Age (years) & Height $(\mathrm{cm})$ & Weight $(\mathrm{kg})$ \\
\hline $62.5( \pm 7.4)$ & $170.5( \pm 10.1)$ & $94.2( \pm 23.0)$ \\
\hline
\end{tabular}

Table 1. Subjects' anthropometric data.

Subjects were recruited on a volunteer basis from an orthopaedic practice. Subjects were excluded if they reported any of the pre-established exclusion criteria. Patient without significant neuromuscular or musculoskeletal pathology other than ostheoarthritis, and who agreed to participate was asked to sign a consent form approved by the IRB.

\subsubsection{Experimental Protocol}

Each subject, who was eligible and agreed to participate, performed a preoperative baseline 6 minute walk, 4 to 8 weeks prior to their scheduled TKA. Motion data during each 6 minute walk were acquired with an 8-camera optoelectronic motion tracking system (Hawk system; Motion Analysis Corp.). This type of system digitally records image plane coordinates of reflective markers and determines their three-dimensional coordinates in a global coordinate system (i.e. the data capture volume) at each sampling interval. The spatial distribution of the cameras was made to obtain reliable motion data of the lower body and obtain at least one complete stride even for subjects with larger step lengths. The cameras were arranged such that the data capture volume corresponds with a portion of the path along which subjects were performing six-minute walks. Whereas the path for these walks was a "loop," each trial included several passes through the data capture volume. The experimental set up is presented in Figure 1. 


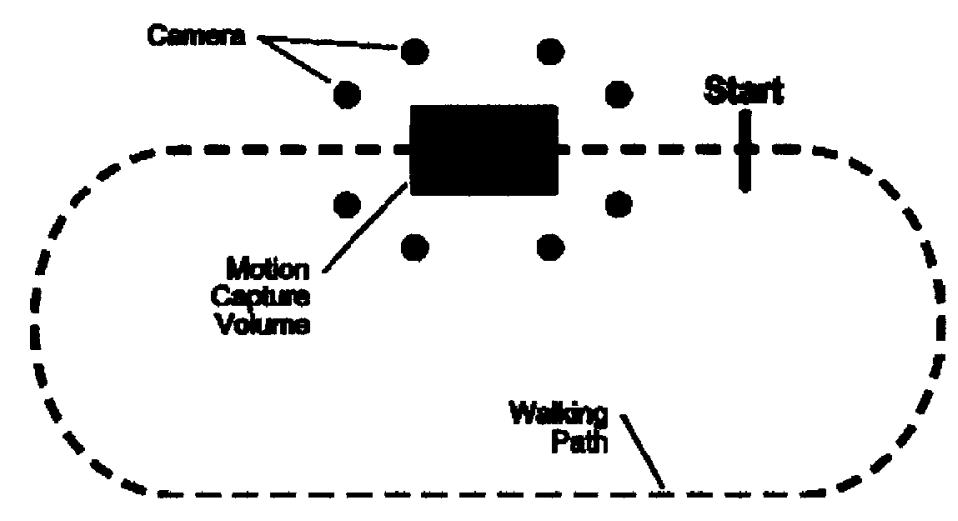

Figure 1. Experimental setup.

Prior to performing each session's six-minute walk, each subject had reflective, spherical markers placed as described by the Helen Hayes marker set (Figure 2) on each side of the body at the second metatarsal heads, heels, lateral malleoli, lateral femoral epicondyles, and anterior superior iliac spines. Two additional markers were located, one at the sacrum and the other as an offset for reconstruction purposes, on the left shoulder blade. Wands with markers at the ends were located at the mid-tibias and mid-thighs. Two markers were added to the standard Helen Hayes marker set, one in each side of the outer hip to make reconstruction easier.

The markers placed on the bony landmarks were used to calculate anatomical coordinate systems for the pelvis, thigh, shank and foot. The motion analysis system was calibrated prior to each testing session. One trial in a standing $\mathrm{T}$-pose position (static trial), was recorded in order to calculate the location of the joint centers. Data were recorded at $100 \mathrm{~Hz}$.

After a short set up and adaptation routine, subjects were requested to cover as much distance as they can in 6 minutes, in a100 to 180 feet long walkway constituted by two semi circles linked by two straight lines (Figure 1). Thus, patients should not experience pain due to a sharp turn angle. 


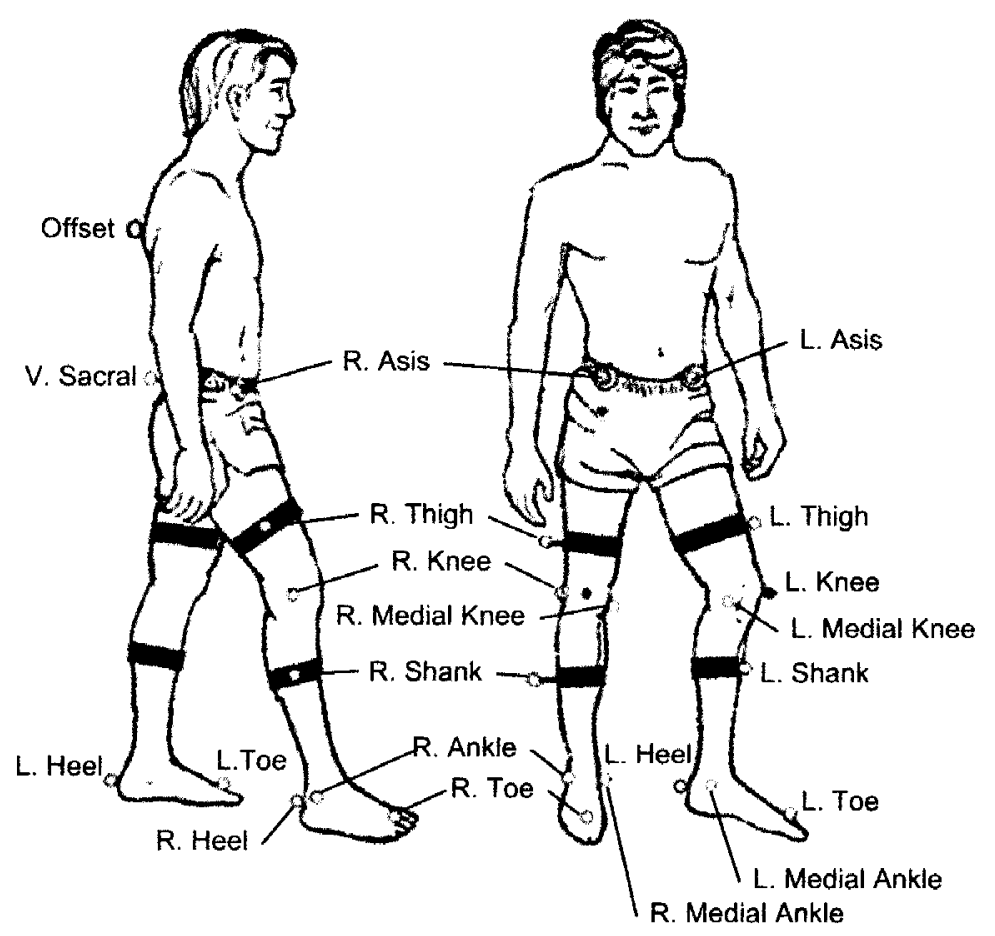

Figure 2. Helen Hayes marker set.

Patients were wearing their own preferred comfortable low rise shoes. When needed, a walking aid was used, except on the motion analysis acquisition part of the walkway. In this case, the walking aid was taken from the patient before entering the motion analysis capture volume, and given back when exiting the motion analysis capture volume. At each cycle, motion data were recorded along one of the straight lines of the walkway.

Subjects started walking and were instructed that they may stop during the test if they experience fatigue or pain and may resume walking once they feel they are capable. No verbal encouragement was offered to the subject during this evaluation. 


\subsubsection{Data Processing}

The motion data recorded were tracked to obtain the $3 \mathrm{D}$ coordinates of the markers using a tracking analysis software package (EVaRT, Motion analysis Corp.).The 3D marker trajectories were smoothed using a low pass Butterworth filter with a cut-off frequency of $6 \mathrm{~Hz}$. The $3 \mathrm{D}$ marker coordinates were then input in a post processing analysis software (OrthoTrack, Motion Analysis Corp.) to calculate the joint kinematics, the joint center position approximations, and the spatiotemporal parameters.

Variables have been chosen from the literature review that were considered to relate to functional deficits exhibited by individuals candidates for TKA or relevant biomechanical variables typically related to initiation and propagation of osteoarthritis.

Variables were classified into 2 categories. Parameters that were suspected to influence gait characteristics included body mass index (BMI), knee pain during walking (KP) and distance covered in 6 minutes (D6). Knee pain (KP) while performing a 6 minute walk test was measured in the knee undergoing surgical intervention using a 10 cm visual analog scale (VAS) completed by each subject immediately following completion of the 6 minute walk test. Subjects were requested to indicate on the VAS the severity of knee pain they experienced in the affected knee while performing the walking task. The VAS was anchored at the terminal points of the scale by the terms "No Pain" and "Extreme Pain". At the end of the 6 minutes, the test administrator recorded the distance (D6) covered by the subject to the nearest 1 foot mark. The value for this functional task was determined by the total distance walked in feet. The weight and height measures of each subject was used to calculate the Body Mass Index (BMI), defined as $\mathrm{BMI}=$ Weight $($ in $\mathrm{kg}) /$ Height $^{2}$ (in meters). This index provides a relative index 
of obesity (Whitney and Rolfes, 1999). Normal weight is define as $18<\mathrm{BMI}<25$, overweight as $25<\mathrm{BMI}<30$, obese as $30<\mathrm{BMI}<40$ and severely obese as $\mathrm{BMI}>40$.

Gait characteristics constituted the second category of parameters and included selected knee and ankle kinematic variables as well as selected spatiotemporal parameters related to heelstrike event and the loading response phase of gait. Gait speed (GS) was calculated as an average across 2 strides in order to eliminate the effect of differences that can exist between both limbs due to unilateral impairment. The offset marker (located on the shoulder blade) horizontal displacement over a two strides period was divided by the time elapsed to perform these two strides. Gait speed was expressed in meter per second $(\mathrm{m} / \mathrm{s})$. The maximum vertical displacement of the ankle marker occurring during swing phase of gait was termed (Zank) and was expressed in millimeters (mm). The vertical velocity of the ankle marker was obtained using the central difference method on 3 data points. The pre-heelstrike vertical velocity (Żank) was obtained by reading the maximum prior to heelstrike on the ankle marker velocity curve over time and was expressed in meter per second $(\mathrm{m} / \mathrm{s})$. The posture at heelstrike was characterized by the impact ankle and knee angles, (IAA) and (IKA) respectively expressed in degree. Loading response maximum ankle dorsi-plantar flexion angle (LRAA) and loading response maximum knee flexion angle (LRKA) were also considered for analysis. Timing of the previous two events $\left(T_{L R A A}\right)$ and $\left(T_{L R K A}\right)$ was expressed in percentage of the gait cycle. Range of ankle motion from heelstrike to loading response maximum plantar flexion (ROMA) and range of knee motion from heelstrike to maximum loading response knee flexion (ROMK) were retained and expressed in degrees. All gait characteristic parameters were calculated 
at the beginning and the end of the 6 minute walk for the affected limb (e.g. limb scheduled for surgery).

\subsubsection{Data summarization}

Data selected for the study are summarized in this section. Table 1 presents the functional ability parameters retained, Table 3 presents the gait characteristics and fatigue indicators retained, calculated at the beginning and the end of the 6minute walk and Figure 3-Figure 5 plots the gait characteristics variables.

\begin{tabular}{|l|l|}
\hline Parameter Abbreviation & \multicolumn{1}{|c|}{ Parameter Definition } \\
\hline BMI & Body Mass Index \\
\hline KP & Knee pain experienced during the 6 minute walk \\
\hline D6 & Distance covered in 6 minute walk \\
\hline
\end{tabular}

Table 2. Functional ability parameters.

\begin{tabular}{|l|l|}
\hline \multicolumn{1}{|c|}{ Parameter Abbreviation } & \multicolumn{1}{c|}{ Parameter Definition } \\
\hline GS & Gait speed \\
\hline$Z_{\text {ank }}$ & Swing ankle maximum height \\
\hline$\dot{Z}_{\text {ank }}$ & Pre-heelstrike ankle vertical velocity \\
\hline IAA & Impact ankle dorsi-plantar flexion angle at heelstrike \\
\hline LRAA & Loading response maximum ankle plantar flexion angle \\
\hline$T_{\text {LRAA }}$ & Timing of ankle peak during loading response phase \\
\hline ROMA & Ankle range of motion during loading response phase \\
\hline IKA & Impact knee angle at heelstrike \\
\hline LRKA & Loading response maximum knee flexion angle \\
\hline$T_{\text {LRKA }}$ & Timing of knee peak during loading response phase \\
\hline ROMK & Knee range of motion during loading response phase \\
\hline
\end{tabular}

Table 3. Gait characteristic parameters. 

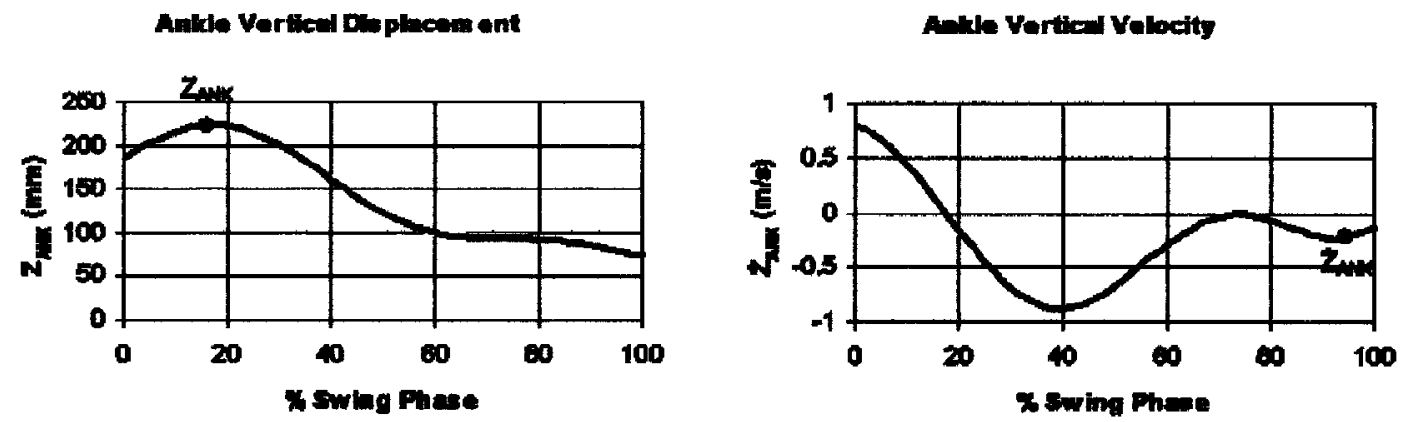

Figure 3. Ankle vertical trajectory and vertical velocity profile, definition of selected parameters.

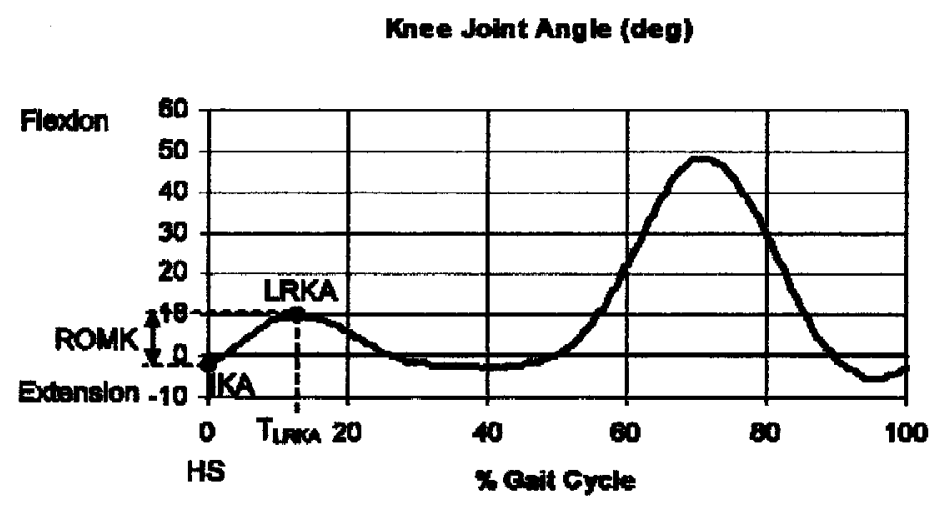

Figure 4. Knee joint angle and definition of selected knee parameters.

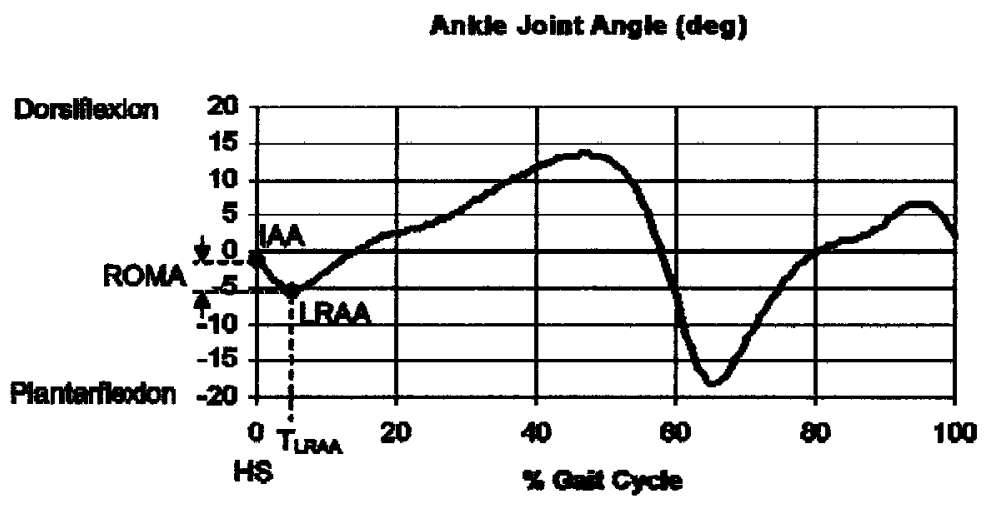

Figure 5. Ankle joint angle and definition of selected ankle parameters. 


\subsubsection{Statistical Analysis}

Paired T-tests were used to assess the differences in gait characteristic parameters between the beginning and the end of the 6 minute walk, for the involved limb.

\subsection{Results}

\subsubsection{Functional Ability Parameters}

Knee pain (KP), distance covered in 6 minute (D6) and body mass index (BMI) mean and standard deviation values are reported in Table 4. These parameters are used in this study to characterize the functional ability of our sample population.

\begin{tabular}{|c|c|}
\hline Knee pain (VA scale $0-10 \mathrm{~cm}$ ) & $4.3 \pm 2.5$ \\
\hline Distance covered in $6 \mathrm{~min}(\mathrm{ft})$ & $1399 \pm 267$ \\
\hline Body Mass Index BMI $\left(\mathrm{kg} / \mathrm{m}^{2}\right)$ & $32.3 \pm 6.5$ \\
\hline
\end{tabular}

Table 4. Knee pain, distance covered in 6 minute and body mass index values.

Patients experienced levels of pain during walking ranging from no pain $(0)$ to severe pain (8.2). The average ( $4.3 \pm 2.5)$ was similar to other studies .(Smith et al. 2004) reporting pain while walking experienced pre-surgery by knee OA patients scheduled for TKA.

Out of 26 patients, 15 were considered obese $(30<\mathrm{BMI}<40), 10$ were overweight $(25<\mathrm{BMI}<30)$ and 1 was in the normal range of weight $(18<\mathrm{BMI}<25)$. The average BMI (32.3 \pm 6.5$)$ was comparable to the average found in a population of 83 knee OA patients scheduled for TKA surgery (Kennedy et al.2006).

Patient's functional ability performance represented by the distance covered in 6 minute ranging from 1001 feet to 2117 feet. The average (1399 $\mathrm{ft} \pm 267$ ) was comparable to results found in a study of overweight and obese adults with knee OA (Brian et al. 2005) and in patients scheduled for TKA surgery preoperatively (Kennedy et al. 2006). 


\subsubsection{Gait Characteristic Parameters}

A summary of mean, standard deviation, and $\mathrm{P}$ values for gait characteristic parameters at the beginning and end of the 6 minute walk are reported in Table 5. Each parameter is discussed in the following sections.

\begin{tabular}{|l|c|c|c|}
\hline \multicolumn{1}{|c|}{ Parameters } & At start & After 6 min & T-test \\
\hline Gait speed $(\mathrm{GS})$ & $1.26 \mathrm{~m} / \mathrm{s} \pm 0.26$ & $1.22 \mathrm{~m} / \mathrm{s} \pm 0.24$ & 0.205 \\
\hline Swing ankle maximum height. $\left(\mathrm{Z}_{\text {ank }}\right)$ & $223 \mathrm{~mm} \pm 22$ & $220 \mathrm{~mm} \pm 21$ & $0.005^{* *}$ \\
\hline Pre-heelstrike ankle vertical velocity $\left(\dot{Z}_{\text {ank }}\right)$ & $-0.211 \mathrm{~m} / \mathrm{s} \pm 0.088$ & $-0.185 \mathrm{~m} / \mathrm{s} \pm 0.063$ & $0.017^{*}$ \\
\hline Impact ankle dorsi-plantar flexion angle (IAA) & $-0.6^{\circ} \pm 5.1$ & $-2.0^{\circ} \pm 4.8$ & $0.003^{* *}$ \\
\hline LR maximum ankle plantar flexion (LRAA) & $-9.4^{\circ} \pm 4.6$ & $-10.4^{\circ} \pm 4.5$ & $0.010^{*}$ \\
\hline Timing of ankle peak during LR phase $\left(\mathrm{T}_{\text {LRAA }}\right)$ & $7.8^{\circ}\left(\%_{\mathrm{GC}}\right) \pm 1.6$ & $7.1^{\circ}\left(\%_{\mathrm{GC}} \pm 1.1\right.$ & $0.004^{* *}$ \\
\hline Ankle ROM during LR phase (ROMA) & $8.9^{\circ} \pm 3.0$ & $8.4^{\circ} \pm 3.0$ & $\mathbf{0 . 1 4 1}$ \\
\hline Impact knee angle (IKA) & $-2.3^{\circ} \pm 5.5$ & $-2.1^{\circ} \pm 6.0$ & 0.704 \\
\hline LR maximum knee flexion (LRKA) & $9.3^{\circ} \pm 7.3$ & $9.5^{\circ} \pm 7.9$ & 0.622 \\
\hline Timing of knee peak during LR phase $\left(\mathrm{T}_{\text {LRKA }}\right)$ & $14.8(\% \mathrm{GC}) \pm 2.9$ & $15.0^{\circ}(\% \mathrm{GC}) \pm 2.7$ & 0.423 \\
\hline Knee ROM during LR phase (ROMK) & $11.6^{\circ} \pm 5.3$ & $11.6^{\circ} \pm 5.5$ & 0.629 \\
\hline
\end{tabular}

**significance $(\mathrm{P}<0.005)$, *significance $(\mathrm{P}<0.05)$

Table 5. Summary of gait characteristic parameters (mean, St dev, and $P$ values) at the beginning and end of the 6 minute walk.

\subsubsection{Gait Speed}

Walking velocities were somewhat higher at the beginning $(1.26 \mathrm{~m} / \mathrm{s} \pm 0.26)$ and at the end $(1.22 \mathrm{~m} / \mathrm{s} \pm 0.24)$ of the 6 minute walk than values commonly reported (Kaufman et al. 2001, McGibbon and Krebs 2002, Smith et al.2004) for knee OA patients. This difference is probably due to the fact that in our study, patients were asked to cover as much distance as they can in 6 minute instead of to walk at their preferred selected walking speed. The patients were able to maintain walking velocity throughout the 6 minute walk test and gait speed was not significantly different $(P=0.2)$ from the beginning and the end of the 6 minute walk. 


\subsubsection{Ankle Trajectory and Pre-Heelstike Vertical Velocity}

The ankle trajectory exhibited clear characteristics of what was termed "loader" population (Radin et al.1991, Gill and O'Connor 2003). Only one subject could be classified as a "glider" at the beginning of the 6 minute walk but fell in the category of loaders at the end of the 6 minute walk. Patients lifted slightly their ankle at the end of swing phase in preparation for heelstrike (Figure 6a). This characteristic in late swing is shown more clearly in the ankle vertical velocity profile (Figure 6b). Typical ankle trajectory and ankle vertical velocity profile are shown in Figure 6. At the beginning and the end of the 6 minute walk values of Zank and Zank were comparable to those found by Gill et O'Connor (2003) for their "loader" group. However, Zank and Żank were significantly reduced after 6 minute walk $(P=0.017$ and $P=0.005$ respectively) compared with initial walking values.
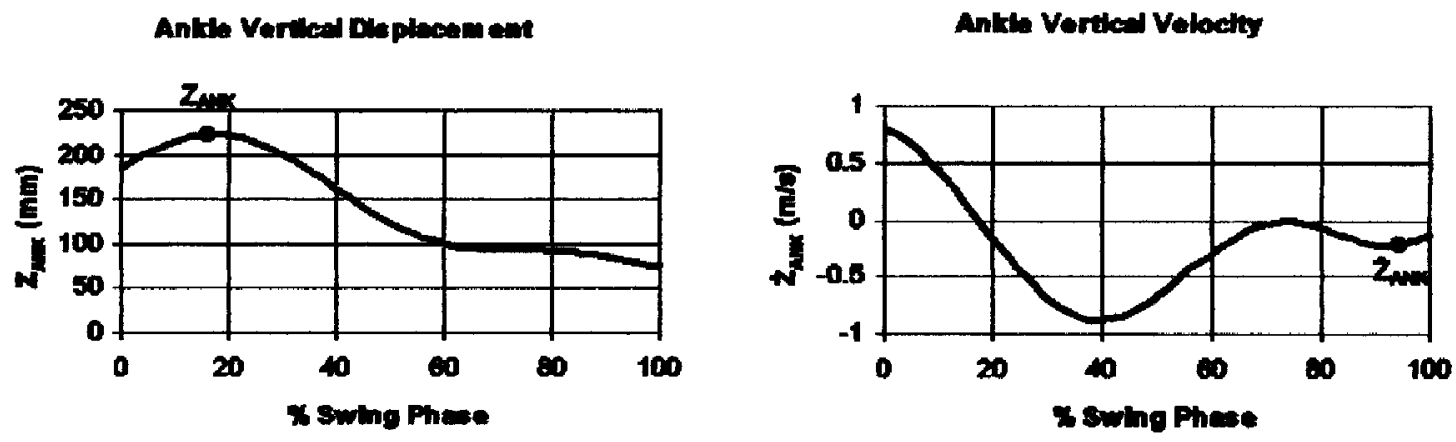

Figure 6. (a) Ankle vertical trajectory and (b) vertical velocity profile.

\subsubsection{Knee Kinematics}

Knee parameter values are summarized in Table 5. Typical knee joint angles and selected knee parameters are presented in Figure 4. Patients landed with a slightly hyper extended knee at heelstrike at the beginning $\left(-2.3^{\circ} \pm 5.5\right)$ and end $\left(-2.1^{\circ} \pm 6.0\right)$ of the 6 minute walk. These values are comparable to those found in knee joint pain patients 
(Radin et al.1991) and in knee osteoarthritis patients of various severity (Mundermann et al.2005). Patients exhibited a reduced stance knee flexion at the beginning $\left(9.3^{\circ} \pm 7.3\right)$ and end $\left(9.5^{\circ} \pm 7.9\right)$ of the 6 minute walk, characteristic of knee OA patients (Radin et al.1991, Schnitzer et al.1993, Kaufman et al.2001, Gok et al. 2002). Knee range of motion from heelstrike to peak stance knee flexion was also within the range of typical values found in OA patients. Timing of stance peak flexion was in the range of normal gait (Perry 1992).

None of the knee gait characteristic parameters were significantly different at the beginning and at the end of the 6 minute walk. Patients landed with a similar knee impact angle at heelstrike $(\mathrm{P}=0.704)$, exhibited similar loading response maximum knee flexion $(\mathrm{P}=0.622)$, similar timing for this event $(\mathrm{P}=0.423)$ and similar range of knee motion from heelstrike to maximum loading response knee flexion $(P=0.629)$ at the beginning and end of the 6 minute walk.

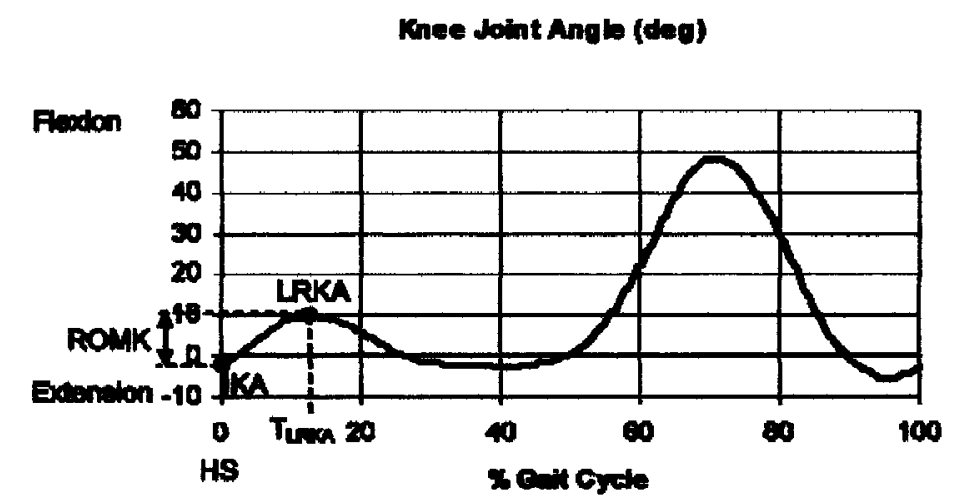

Figure 7. Knee joint angle and definition of selected knee parameters.

\subsubsection{Ankle Kinematics}

Ankle parameters values are summarized in Table 5. Typical Ankle joint angles and selected ankle parameters are presented in Figure 8. Initial ankle contact angle at 
heelstrike and maximum loading response plantar flexion were consistent with values reported for normal gait (Perry 1992). Individuals landed with the ankle at neutral or slightly plantar flexed and then underwent an arc of around 10 degrees plantar flexion. Timing for this event was consistent with the literature (Perry 1992) and happened at about $7 \%$ of the gait cycle.

However, all gait characteristic parameters related to the ankle except ankle range of motion from heelstrike to maximum loading response plantar flexion $(P=0.14)$ were significantly different from the beginning and the end of the 6 minute walk. Ankle position at heelstrike and at maximum during loading response phase of gait was significantly more plantarflexed $(\mathrm{P}=0.003$ and $\mathrm{P}=0.01$ respectively) after the 6 minute walk. Maximum loading response ankle platar flexion was reached significantly earlier in the gait cycle $(P=0.004)$ after 6 minute walk.

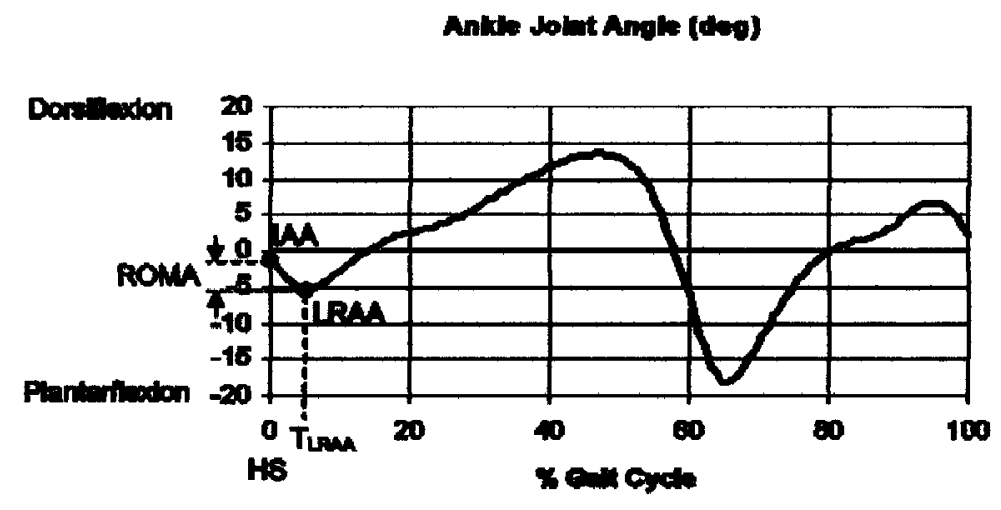

Figure 8. Ankle joint angle and definition of selected ankle parameters.

\subsection{Discussion}

Overweight is a strong risk factor for knee OA (Manninen et al. 1996, McAlindon et al. 1996, Kaufman et al.2001). Several studies have emphasized that individuals with a high BMI are at higher risk of developing knee OA (Schouten et al. 1992, Hochberg et al. 
1995, Felson et al. 1997). The distribution of our study population confirms these previous studies since $96 \%$ of patients were overweight or obese (BMI $\geq 25$ ).

Patients maintained their walking velocity throughout the 6 minute walk however subtle but statistically significant changes at the ankle were present after 6 minute walk. First, patients landed with a more plantar flexed posture at heelstrike after 6 minute than when they started walking. This variation was only $1.5^{\circ}$ on average but results are consistent between patients $(P=0.003)$. Increase in initial plantar flexion at heelstrike reduced the potential for heel rocker and has been associated with compensatory mechanism for a weak quadriceps (Perry 1992) commonly seen in knee OA population (Lewek et al. 2004, Hassan et al. 2001,O'Reilly et al. 1998, Slemenda et al.1997, Fisher and Pendergast 1997). The foot still contacts the floor by the heel but in a flatter posture. Gerritsen et al. (1995) have demonstrated that body configuration at initial contact has a considerable influence on the impact peak force and the loading rate. A higher loading rate at the tissue level may lead to the initiation (Ewers et al. 2002) or progression (Kerin et al. 2003) of the surface fissures in cartilage, similar to that seen in OA cartilage, which may ultimately lead to a faster rate of progression of OA. In their study on heel-toe running (Gerritsen et al. (1995)), foot angle had the greatest effect on both loading rate and impact forces (on average $85 \mathrm{~N}$ per degree of change). Both, peak force and loading rate increase when the initial foot angle was smaller, corresponding to a flatter landing. In our study, knee contact angle was unchanged from the beginning and end of the 6 minute walk while the ankle was more plantarflexed at heelstrike after 6 minutes. Based on Gerritsen et al. (1995) findings, it is reasonable to expect that our patients experienced higher loading rate and higher peak force due to this subtle change in ankle plantar 
flexion at landing after 6 minutes. If left uncorrected, these changes associated with excessive repetitive loading will cause further joint damage (Miyazaki et al. 2002).

The second subtle but significant difference found in our study was in ankle vertical velocity at heelstrike. After 6 minute, ankle pre-heelstrike velocity was reduced even if the value was still in the range typically exhibited by "loaders"(Radin et al. 1991). Gerritsen et al. (1995) also demonstrated that touchdown velocity of the heel was an excellent predictor of both peak force and loading rate. In their study on heel-toe running, an increase of touchdown velocity of $0.1 \mathrm{~m} / \mathrm{s}$ produced on average $212 \mathrm{~N}$ increase in peak force. Touchdown velocity of the heel is directly correlated to ankle vertical velocity at heelstrike since the ankle foot system corresponds to a rigid system at a given time. Hence, based on Gerritsen et al. (1995) findings, a reduced ankle vertical velocity at heelstrike after 6 minute walk will have the effect of reducing peak force experienced at heelstrike. Gill and $O^{\prime}$ Connor (2003) found comparable results in a population free of osteoarthritis symptoms. Increased vertical velocity of the ankle marker just prior to heelstrike was associated with higher loading rate and higher peak force at heelstrike. In our case, a lower ankle vertical velocity of the ankle marker after 6 minutes will result in reduced peak force and reduced loading rate at heelstrike.

If we combine the previous 2 findings in our study, results suggest that a weak quadricep tend to increase loading at the knee by letting the ankle land more plantar flexed at heelstrike but patients manage by some compensatory mechanisms to counteract these deleterious actions by reducing their impact velocity, in an attempt to reduce the loads across the knee. However without quantified data on loading rate and peak loading force we are missing important information on the magnitude of these compensations. 
Patients did not lift their leg as high in preparation for heelstrike after 6 minute walk when compared to initial values when they started walking. O'Connor et al. (2003) explained in a simulation study that with a constant walking velocity, not lifting the ankle as high will cause the foot to overshoot the target ground if no compensatory mechanism were applied. In their study, loaders applied corrective moment at the end of swing phase to bring the foot into contact with the floor at the target position which leads to an increased approach velocity of the foot and then results in higher peak force and loading rate. Our subjects exhibited similar corrective compensation at the end of swing phase but reduced vertical approached velocity while the leg is not lifted as high in preparation for heelstrike. These differences might come from the fact that their experimental study was performed on asymptomatic younger subjects. End stage knee OA patients have symptoms of pain and have been described as adopting gait strategies attempting to reduce pain and loads across the knee (Kaufman et al. 2001). These characteristics add an additional level of gait compensation that needs to be accounted for while interpreting the results. In another study Radin et al. (1991) found no difference between intermittent knee pain group with no symptoms of osteoarthritis and no pain group for the maximal swing ankle height but significant difference in vertical velocity just prior heelstrike associated with higher loading rate and peak force. These results suggest that maximum ankle height reach during swing phase cannot explain alone loading rate and peak loading force at heelstrike, but may explain gait adaptation when combined with the previously cited parameters.

Among other findings in our study, the maximum loading response peak ankle plantar flexion was significantly higher and happened, earlier in the gait cycle after 6 
minute walk compared with values for patients starting the 6 minute walk. Premature ankle plantar flexion is a compensatory mechanism used by people with weak quadriceps and/or people with knee pain to block tibial advancement, so initial contact by the heel does not stimulate the normal rocker action and loading response knee flexion is avoided (Perry et al.1992). Similarly, patients voluntarily increase plantar flexion as a mean of protecting a weak quadriceps from loading response knee flexion. Our results suggest that, after 6 minute walk, patients increase their mechanisms aimed at reducing pain in the knee and protect weak quadriceps.

Knee motion was characterized by a reduced loading response knee flexion and a hyper extended knee posture at heelstrike. Loading response knee flexion is avoided by the same mechanisms used for quadriceps weakness or pain. The purpose is to escape the shear force that accompanies joint motion (Perry et al.1992). A second objective is to reduce the compressive force from a contracting quadriceps. Patients use this substitution to preserve a good walking speed and endurance (Perry et al.1992). This strategy appears to be efficient as they were able to maintain their gait speed throughout the 6 minute walk. Knee flexion that follows loading the limb provides valuable shock absorption and reduced loading response knee flexion also means reduced shock absorption capability. Andriacchi and Mundermann (2006) found a strong relationship between anteriorposterior cartilage thickness ratio and knee hyperextension at heelstrike suggesting that knee hyperextension may be critical. Knee hyperextension at heelstrike is a common symptom present with quadriceps weakness and a compensatory mechanism to stabilize the knee. Knee OA patient frequently have an increased knee laxity (Fitzgerald et al. 2004, Sharma et al. 1999) which can cause increased instability. Locking the knee at the 
critical moment of heelstrike when high loads are transmitted is a mechanism that aims at increasing safety and stability. Although a reduced knee flexion at heelstrike will diminish shock absorption capability of the lower limb, it is not the primary requirement of end stage knee OA patients.

The knee exhibited typical knee OA pattern, but no significant differences were found in any of the knee parameters between the beginning and the end of the 6 minute walk. This could have happened for two reasons. First, our study population was constituted of $96 \%$ overweight or obese people. Marker placements are more difficult on large individuals and reconstitution of joint centers are less accurate because markers are further away from anatomical landmarks. Also, wands placed on the shank experienced oscillations due to movement of the large thigh mass. This could have induced errors and inaccuracy. Hence, small differences in knee motion might have been overshadowed by these errors. Another explanation could be, as suggested by Lewek et al. (2006), that because of the presence of instability in knee OA patients the central nervous system is unable to deviate from a few similar joint positions. Recent work has demonstrated that knee instability is a significant problem in patients with knee OA (Fitzgerald et al.2004), as instability can result as an inability to control excessive joint laxity. Heiderscheit (2000) stated that a reduction in knee motion variability could lead to an inability to adequately adjust to perturbations (i.e fatigue) and attenuate impact shocks. Lewek et al. (2006) found also a reduced stride to stride variability of knee motion in knee OA patients compared with normal subjects. They hypothesized that subjects may have learned to use only knee motions that minimized pain, effectively eliminating movement options. Similarly Hamill et al. (1999) suggested that pain could contribute to the overuse 
of similar, less painful knee joint motion. Heiderscheit (2000) demonstrated that runners exposed to external (high grass) or internal (fatigue) changes land with a more flexed knee at heelstrike to be able to adjust more easily to changes, and increase their shock absorption capability in preparation to uncertain changes. In our study, patients would be unable to adapt to fatigue by adopting a more flexed knee position at heelstrike because this will create a greater instability and increase the risk of fall due to the difficulty to control the knee due to laxity problem. An inability to change knee motion from the beginning and the end of the 6 minute walk may be interpreted as an inability to adapt to fatigue. As the knee seem unable to adapt (possibly because of pain, or joint laxity and requirement of stability during loading response phase of gait), adaptation may be present at the adjacent joint (the ankle). As the knee and the ankle are the two most efficient mechanisms to absorb shock at heelstrike, if patients cannot adapt at the knee they adapt at the ankle as reflected by our ankle parameters. They seem to choose ankle strategies to adapt to fatigue after 6 minute walk and try to relieve the load at a painful knee rather than adopt knee strategies in an attempt to maintain stability and performance.

\subsection{Conclusion}

The findings of this study indicate that compensatory mechanisms are present after a 6 minute walk in end stage knee OA patients. Even if individuals were able to maintain gait speed throughout the 6 minutes, subtle changes in vertical velocity of the ankle marker just prior to heelstrike, and maximum height reached by the ankle during swing are indicators of loading pattern changes which in turn impacts OA evolution. Results suggest that a weak quadriceps tend to increase loading at the knee by letting the ankle land more plantar flexed at heelstrike but patients manage by some compensatory 
mechanisms to counteract these deleterious actions by reducing their impact velocity, in an attempt to reduce the loads across the knee. After 6 minute walk, patients increase their mechanisms aimed at reducing pain in the knee and protect weak quadriceps. However without quantified data on loading rate and peak loading force we are missing important information on the magnitude of these compensations. No variability in knee parameters from the beginning and the end of the 6 minute walk may suggest an inability of the knee to adapt possibly because of laxity and pain. Patients are using ankle strategies to maintain speed rather than knee strategies in an attempt to stabilize a painful and unstable knee at heelstrike and reduce the load across the knee.

The results of this study may need to be interpreted with caution, at this time, since the sample size is somewhat small. Future investigation in this area hopes to establish means for utilizing these biomechanical variables as fatigue indicators, which could help assess end stage knee OA treatment outcomes (exercise program efficacy and TKA outcomes). 


\section{CHAPTER 3}

\section{EXERCISE EFFECTS ON PROLONGED \\ GAIT AMONG END STAGE KNEE OA PATIENTS}

\subsection{Introduction}

Information related to functional ability, mechanical factors, loading response phase of gait, ankle and knee parameters and fatigue, are presented in chapter 2 introduction.

For managing pain, exercise is among the most common conservative management approaches. It is important to recognize the involvement of muscle in OA because muscle can be exercised to improve strength, endurance, and skill, even in very old people. Therefore, rehabilitation programs that address muscle dysfunction can prevent or alleviate some of the problems associated with knee OA. A substantial number of clinical trials have indicated that various exercise interventions can enhance measures of functional capacity among patients with knee OA. Most exercise interventions such as walking programs (Messier et al. 1997, Minor et al. 1989, Peterson et al. 1993), muscle strengthening programs (Fisher et al. 1997, Peterson et al. 1993, Fisher et al. 1993), aquatic programs (Messier et al. 1997), and general therapy (Fisher et al. 1993), have demonstrated global improvements in pain reduction, walking speed, distance, muscle strength, and gait kinematics. Also, incorporated into rehabilitation programs, exercise aimed at improving reaction time, balance and coordination, can improve functional joint stability and proprioception (Hurley et al. 1998), restore shock absorption capacity, and 
protect against further joint damage (Johansson et al. 1991, O'Connor et al. 1985, 1998). Moreover, exercise programs aimed at improving quadriceps strength and overall physical performance can potentially reduce compensations due to the onset of mild fatigue appearing after a 6 minute walk (chapter 2).

The hypothesis tested in the present study was based on the presumption that a 6 minute walk represents a fatiguing activity for end stage knee OA patients. We hypothesized that a 4 to 8 week exercise program will modify the gait pattern and measures of functional ability adopted by end stage knee OA patients at the beginning of the 6 minute walk as well as the compensatory mechanisms at the end of the walk compared to the initial walking trial. Gait kinematics were analyzed with particular interest to phenomenon happening around heelstrike and loading response phase of gait, at the knee and ankle joints, initially and after a 6 minute walk. Functional ability measures included, pain and distance covered in 6 minute.

\subsection{Methods}

The methods utilized in the first sub-study (chapter 2) were employed in the present sub-study. Only additional components specific to this study and not already reported in the previous study are presented in this section. Refer to method section in chapter 2 for experimental protocol, population, study design, and variables.

\subsubsection{Population}

The study population described in chapter 2 was used in the present study. Subjects were also excluded if they reported any health problem that prohibits moderate exercise or if they indicated, on their background questionnaire, involvement in an exercise program more than one time per week during the previous month. From the 26 subjects 
initially recruited in the first study, 5 subjects dropped out. The remaining 20 subjects were randomized into an Exercise group and a Control group.

\subsubsection{Design}

A trial was conducted in which subjects who were eligible and agreed to participate underwent baseline testing at (T0) (described in chapter 2) and then were randomly assigned to either an Exercise group or a usual care group (control). Subjects in the exercise group were directed to participate in three sessions of exercise per week, one supervised and 2 unsupervised, for 4 to 8 weeks prior to their TKA surgery. Each subject's knee pain during walking, distance covered in 6 minutes and selected gait kinematic and kinetic characteristics were collected 4 to 8 weeks preoperatively (baseline testing T0) and 1 week prior to their scheduled TKA (T1). The testing times have been chosen for the following reason: 4 to 8 weeks of exercise has been demonstrated to result in significant improvements in functional capacity, muscle strength and performance of functional tasks among older adults with OA of the knee (Deyle et al. 2000, Fransen et al. 2001).

\subsubsection{Exercise Treatment Group}

Subjects assigned to the exercise treatment group were given a prehabilitation training booklet which explained all 5 components of the exercise training program including warm up, resistance exercises, flexibility exercises, step training and a cool down.

The exercise training booklet was based upon previous guidelines for older adult exercise programs (Topp et al. 1996). Each of the 5 components in the exercise training has, in previous investigations, been demonstrated to improve one or more of the 
outcome variables following 4 to 8 weeks of training among older adults (Deyle et al. 2000, Fransen et al. 2001, Kraemer et al. 2001, Topp 2002).

Each session of prehabilitation consisted of 5 minutes of warm up exercises, 20 minutes of resistance training exercises, 15 minutes of flexibility exercises, 15 minutes of step training and 5 minutes of cool down exercises. Previous studies with older functionally limited adults and subjects with symptomatic osteoarthritis of the knee indicated that this initial level of training is within the training capacity of the anticipated sample of adults with OA of the knee (Topp et al. 2002, Topp et al. 2001, Topp et al. 1993, Topp et al. 1996, Woolley et al. 1999, Topp et al. 2000, King et al. 2001). In the unlikely event that a subject could not achieve this initial level of training the program intensity and progression were adjusted to be consistent with their initial level of strength, flexibility and ability to complete the exercises.

One of the critical components of any exercise training program is the principle of specificity. This principle of training stipulates that the more closely the training mimics the evaluation method the greater the improvement in the evaluation method as a result of the training (Fleck et al. 1997). None of the components of the exercise program were the same as the functional tasks that was evaluated. The exercise training program involved exercises designed to improve strength, flexibility and coordination which are critical components of the functional task being evaluated as outcome variables. Subjects in the exercise treatment group were included in the analysis regardless of their compliance with the exercise program which is consistent with the intent-to-treat analysis plan. 


\subsubsection{Control Group}

Subjects assigned to the control group were not given any intervention other than their usual pre-operative care over the duration of the study. Control subjects were told not to change their usual level of activity prior to their TKA surgery.

\subsection{Statistical Analysis}

Univariate analysis of variance for $\mathrm{T} 1$ values with co variation on $\mathrm{T} 0$ values and group effect are used to evaluate the effects of exercise program on pain, functional ability and selected gait parameters. Results are presented for tests of between subjects effects (group effect).

\subsection{Results}

\subsubsection{Functional Ability Parameters and Gait Parameters at the Beginning of the Walk}

Results of between subjects tests of significance (group effect) are presented in Table 6 for D6, KP and gait parameters at the beginning of the walk. Three parameters showed significant differences from $\mathrm{T} 0$ (baseline testing) to $\mathrm{T} 1$ (testing prior to surgery) between the groups when accounted for initial values at T0. These parameters are distance covered in 6 minute $(D 6, P=0.005)$, gait speed (GS_start, $P=0.003$ ) and vertical velocity of the ankle marker just prior heel strike at the beginning of the walk (Zank_start, $\mathrm{P}=0.020$ ). Two parameters showed a trend, however significant differences could not be established. Those parameters are knee pain experienced during walking $(\mathrm{KP}, \mathrm{P}=0.071)$ and time (normalized to gait cycle) from heel strike to maximum knee angle during loading response, measured at the beginning of the walk (TLRKA_start, $\mathrm{P}=$ 0.059). All the other parameters do not show significant differences. 


\begin{tabular}{|c|c|}
\hline Parameters & $\mathbf{P}$ \\
\hline Distance covered in 6 minute (D6) & $0.005^{* *}$ \\
\hline Knee pain (KP) & 0.071 \\
\hline Gait Speed at start (GS_start) & $0.003^{* *}$ \\
\hline Swing Ankle maximum height @start ( $Z_{\text {ank_start })}$ & 0.901 \\
\hline Pre-heelstrike Ankle vertical velocity @start ( $\dot{Z}_{\text {ank__start })}$ & $0.020^{*}$ \\
\hline Impact Ankle dorsi-plantar flexion angle @start (IAA_start) & 0.187 \\
\hline LR maximum Ankle plantarflexion @start(LRAA_start) & 0.268 \\
\hline Timing of ankle peak during LR phase $@$ start ( $\left.T_{\text {LRAA_start }}\right)$ & 0.272 \\
\hline Ankle ROM during LR phase @start (ROMA_start) & 0.580 \\
\hline Impact Knee angle @start (IKA_start) & 0.960 \\
\hline LR maximum Knee flexion@start (LRKA_start) & 0.283 \\
\hline Timing of knee peak during LR phase @start( $T_{\text {LRKA__ }}$ start $)$ & 0.059 \\
\hline Knee ROM during LR phase @start (ROMK_start) & 0.220 \\
\hline
\end{tabular}

Table 6. Tests of between subject effects significance for D6, KP, and gait parameters at the beginning of the walk.

Detail results for parameters showing significant group effects or trends are presented in the following sections.

- $\underline{\text { D6 }}$

Distance covered in 6 minute exhibited a significant group effect between $\mathrm{T} 0$ and T1 $(\mathrm{P}=0.005)$. Patients in the exercise group were able to walk further distance on average after the exercise program than at baseline testing (Exercise group: D6 @ T0= $1498 \mathrm{ft} \pm 89 ; \mathrm{D} 6 @ \mathrm{~T} 1=1564 \mathrm{ft} \pm 73$ ), while patients in the control group did not cover as much distance as they were able to at baseline testing (Control group: D6 @ T0= $1394 \mathrm{ft} \pm 89 ; \mathrm{D} 6$ @ $\mathrm{T} 1=1303 \mathrm{ft} \pm 73$ ), (Table 7, Figure 9). 


\begin{tabular}{|l|c|c|c|c|c|}
\hline \multirow{2}{*}{ Group } & \multirow{2}{*}{ Time } & \multirow{2}{*}{ Mean D6 (ft) } & \multirow{2}{*}{ Std. Error } & \multicolumn{2}{|c|}{ 95\% Confidence Interval } \\
\cline { 4 - 6 } & & & Lower Bound & Upper Bound \\
\hline \multirow{2}{*}{ Control } & T0 & 1394.450 & 89.090 & 1207.280 & 1581.620 \\
\cline { 2 - 6 } & T1 & 1303.000 & 73.531 & 1148.516 & 1457.484 \\
\hline \multirow{2}{*}{ Exercise } & T0 & 1498.400 & 89.090 & 1311.230 & 1685.570 \\
\cline { 2 - 6 } & T1 & 1564.750 & 73.531 & 1410.266 & 1719.234 \\
\hline
\end{tabular}

Table 7. D6 mean, std error, lower and upper bound values.

Mean Distance Covered in 6 Minutes

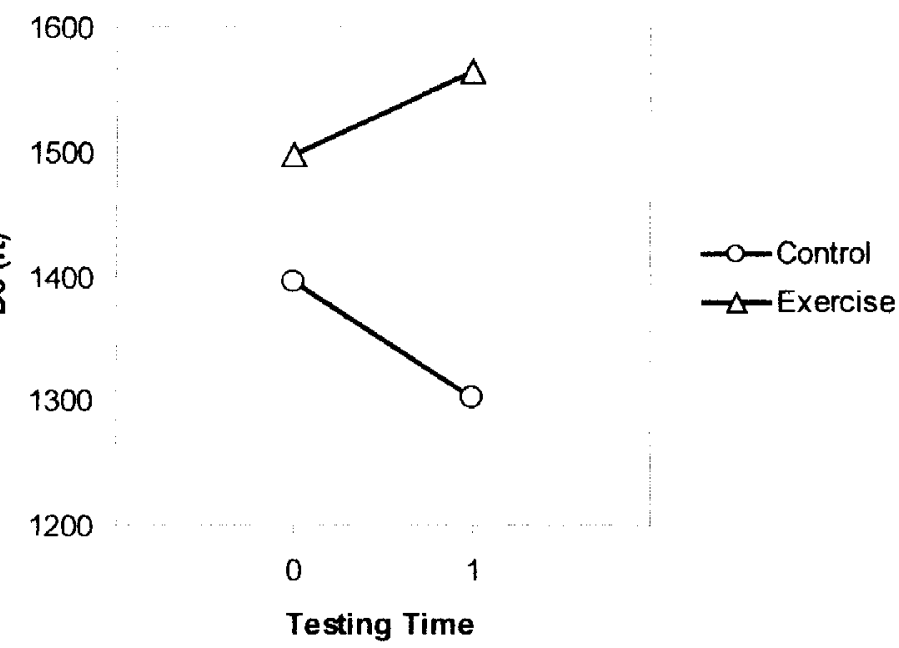

Figure 9. Mean variation of D6 between T0 and T1 for control and exercise group.

- $\underline{\mathrm{KP}}$

Patients in the exercise group experienced similar levels of pain in average between $\mathrm{T} 0$ and $\mathrm{T} 1(\mathrm{KP} @ \mathrm{~T} 0=3.425 \pm 0.77, \mathrm{KP} @ \mathrm{~T} 1=3.685 \pm 0.732)$, while patients in the control group seemed to experience more pain on average at $\mathrm{T} 1$ than they did at baseline testing T0 $(\mathrm{KP} @ \mathrm{~T} 0=4.6 \pm 0.77, \mathrm{KP} @ \mathrm{~T} 1=6.02 \pm 0.732)($ Table 8, Figure 10). However this difference was not significant $(P=0.071)$. 


\begin{tabular}{|c|c|c|c|c|c|}
\hline \multirow{2}{*}{ Group } & \multirow{2}{*}{ Tìme } & \multirow{2}{*}{$\begin{array}{c}\text { Mean KP } \\
|0-10|\end{array}$} & \multirow{2}{*}{ Std. Error } & \multicolumn{2}{|c|}{$95 \%$ Confidence Interval } \\
\hline & & & & Lower Bound & Upper Bound \\
\hline \multirow{2}{*}{ Control } & TO & 4.600 & .770 & 2.981 & 6.219 \\
\hline & $\mathrm{Tl}$ & 6.020 & .732 & 4.482 & 7.558 \\
\hline \multirow{2}{*}{ Exercise } & T0 & 3.425 & .770 & 1.806 & 5.044 \\
\hline & $\mathrm{Tl}$ & 3.685 & .732 & 2.147 & 5.223 \\
\hline
\end{tabular}

Table 8. KP mean, std error, lower and upper bound values.

Mean Knee Pain

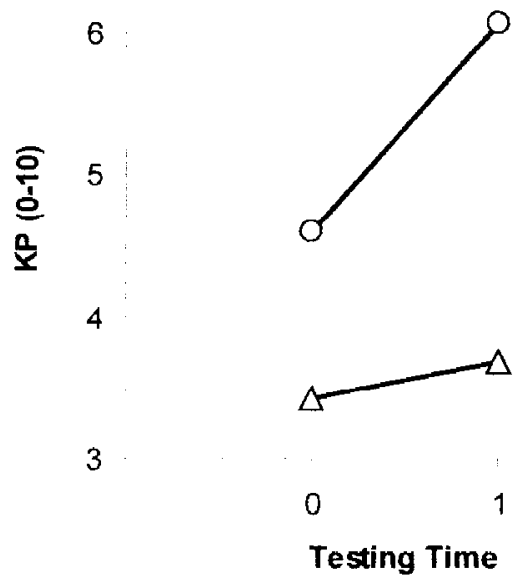

Figure 10. Knee pain mean variations between $\mathrm{T} 0$ and $\mathrm{T} 1$ for control and exercise group.

- GS_start

Gait speed at the beginning of the walk exhibited a significant group effect between T0 and T1 $(\mathrm{P}=0.003)$. The exercise group increased their initial gait speed on average from T0 to T1 (Exercise group: GS_start @ T0 $=1.374 \mathrm{~m} / \mathrm{s} \pm 0.084$, GS_start @ $\mathrm{T} 1=$ $1.496 \mathrm{~m} / \mathrm{s} \pm 0.066$ ), while the control group decreased their initial gait speed on average from T0 to T1 (Control group: GS_start @ T0 $=1.249 \mathrm{~m} / \mathrm{s} \pm 0.084$, GS_start @ $\mathrm{T} 1=$ $1.210 \mathrm{~m} / \mathrm{s} \pm 0.066$ ) (table Table 9, Figure 11. GS_start mean variations between T0 and $\mathrm{T} 1$ for control and exercise group.). 


\begin{tabular}{|l|c|c|c|c|c|}
\hline \multirow{2}{*}{ Group } & \multirow{2}{*}{ Time } & \multirow{2}{*}{$\begin{array}{c}\text { Mean GS } \\
\text { start (m/s) }\end{array}$} & \multirow{2}{*}{ Std. Error } & \multicolumn{2}{|c|}{$95 \%$ Confidence Interval } \\
\cline { 5 - 6 } & & 1.249 & .084 & Lower Bound & Upper Bound \\
\hline \multirow{2}{*}{ Control } & $\mathrm{T} 0$ & 1.210 & .066 & 1.072 & 1.425 \\
\cline { 2 - 6 } & $\mathrm{T} 1$ & 1.374 & .084 & 1.197 & 1.348 \\
\hline \multirow{2}{*}{ Exercise } & $\mathrm{T} 0$ & 1.496 & .066 & 1.357 & 1.551 \\
\cline { 2 - 6 } & $\mathrm{T} 1$ & &
\end{tabular}

Table 9. GS start mean, std error, lower and upper bound values.

Mean Starting Gait Speed

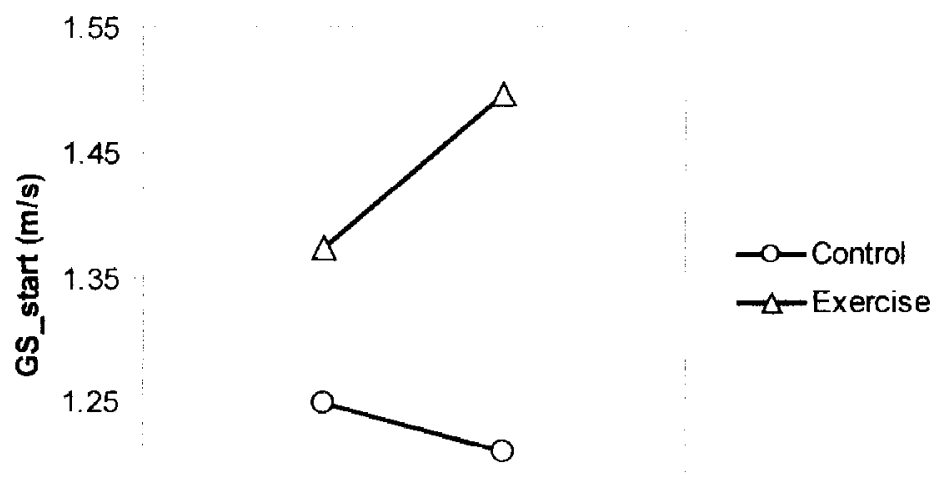

1.15

0
Testing Time

Figure 11. GS_start mean variations between $\mathrm{T} 0$ and $\mathrm{T} 1$ for control and exercise group.

- Zank start

Vertical velocity of the ankle marker just prior heelstrike exhibited a significant group effect between $\mathrm{T} 0$ and $\mathrm{T} 1(\mathrm{P}=0.02)$. Patients in the exercise group impacted the floor just prior heel strike at the beginning of the walk with a higher vertical velocity of the ankle marker after the exercise program compared to baseline values (Żank_start@ $\mathrm{T} 0=-0.225 \mathrm{~m} / \mathrm{s} \pm 0.028$, Zank_start $@ \mathrm{~T} 1=-0.252 \mathrm{~m} / \mathrm{s} \pm 0.027)$, while patients in the control group reduced their vertical velocity prior heelstrike at $\mathrm{T} 1$ compared with their T0 values (Żank_start@ $@ \mathrm{~T} 0=-0.228 \mathrm{~m} / \mathrm{s} \pm 0.028$, Żank_start @ $\mathrm{T} 1=0.2176 \mathrm{~m} / \mathrm{s} \pm 0.027$ ) (Table 1, Figure 12). 


\begin{tabular}{|l|c|c|c|c|c|}
\hline \multirow{2}{*}{ Group } & \multirow{2}{*}{ Time } & Mean Żank & \multirow{2}{*}{ Std. Error } & \multicolumn{2}{|c|}{ 95\% Confidence Interval } \\
\cline { 5 - 6 } & & start (m/s) & & Lower Bound & Upper Bound \\
\hline \multirow{2}{*}{ Control } & $\mathrm{T} 0$ & -0.228 & 0.028 & -0.288 & -0.168 \\
\cline { 2 - 6 } & $\mathrm{Tl}$ & -0.176 & 0.027 & -0.233 & -0.118 \\
\hline \multirow{2}{*}{ Exercise } & $\mathrm{T} 0$ & -0.225 & 0.028 & -0.285 & -0.165 \\
\cline { 2 - 6 } & $\mathrm{Tl}$ & -0.252 & 0.027 & -0.309 & -0.194 \\
\hline
\end{tabular}

Table 10. Zank_start mean, std error lower and upper bound values.

\section{Mean Ankle Vertical Velocity}

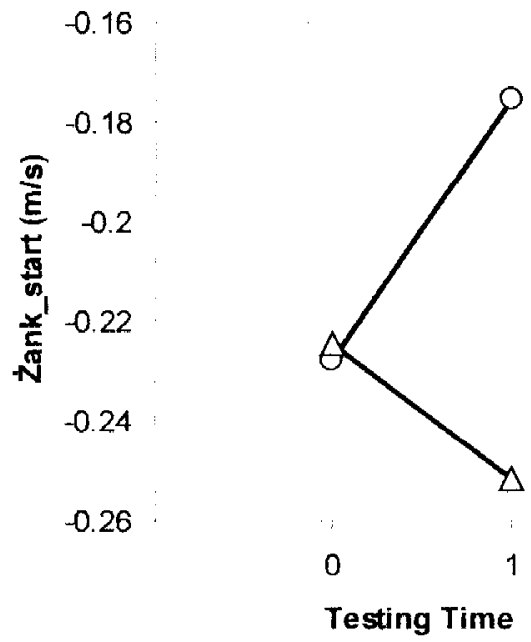

Figure 12. Zank mean variations between T0 and $\mathrm{T} 1$ for control and exercise group.

- TLRKA start

After the exercise program, patients in the exercise group increased their time (normalized to gait cycle) from HS to maximum LR knee flexion angle at the beginning of the walk compared to T0 values (TLRKA_start@T0 $=15.6 \pm 0.98 \% \mathrm{GC}$, TLRKA_start@ $@ \mathrm{~T} 1=16.1 \pm 0.70 \% \mathrm{GC}$ ), while patients in the control group decreased their time from T0 to T1 (TLRKA_start@ $@$ T0=14.6 $\pm 0.98 \% \mathrm{GC}, \mathrm{TLRKA} \_$start $@$ T1 $=$ $13.9 \pm 0.70 \% \mathrm{GC}$ ) (Table 11, Figure 13). However this difference was not statistically significant $(\mathrm{P}=0.059)$. 


\begin{tabular}{|c|c|c|c|c|c|}
\hline \multirow{2}{*}{ Group } & \multirow{2}{*}{ Time } & \multirow{2}{*}{$\begin{array}{c}\text { Mean } \\
\text { TLRKA } \\
(\% \mathrm{GC}) \\
\end{array}$} & \multirow{2}{*}{ Std. Error } & \multicolumn{2}{|c|}{ 95\% Confidence Interval } \\
\hline & & & & Lower Bound & Upper Bound \\
\hline \multirow{2}{*}{ Control } & T0 & 15.600 & .985 & 13.530 & 17.670 \\
\hline & T) & 16.100 & .698 & 14.633 & 17.567 \\
\hline \multirow{2}{*}{ Exercise } & $\mathrm{TO}$ & 14.600 & .985 & 12.530 & 16.670 \\
\hline & T1 & 13.900 & .698 & 12.433 & 15.367 \\
\hline
\end{tabular}

Table 11. TLRKA_start mean, std error, lower and upper bound values.

Mean Time to Max Loading Response

Knee Angle at Start of Walk

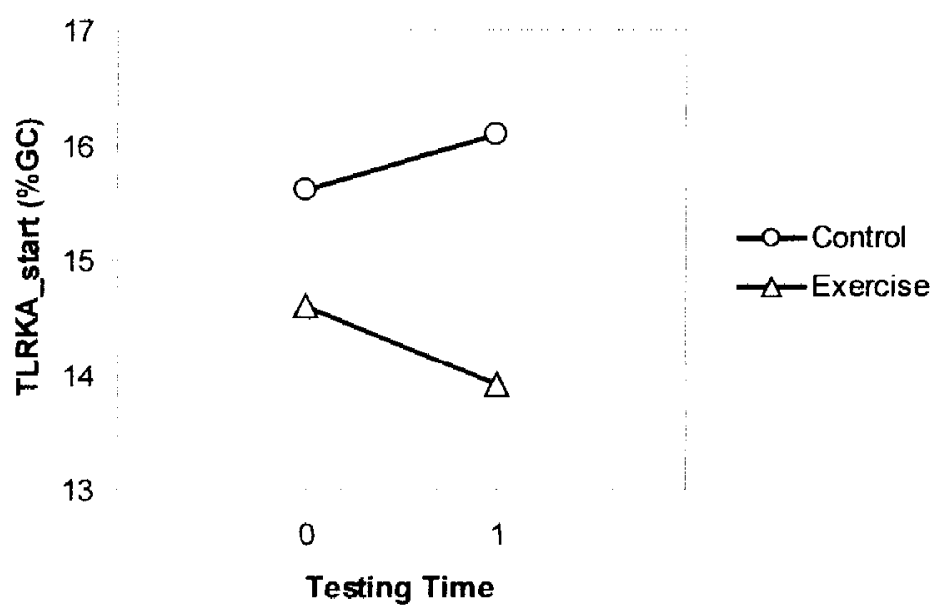

Figure 13. TLRKA_start mean variation between $\mathrm{T} 0$ and $\mathrm{T} 1$ for control and exercise group.

\subsubsection{Parameter Changes between Start and End of the Walk}

Results for parameter changes between the beginning and the end of the walk are presented in Table 12. Two of the parameters changes between the beginning and the end of the walk exhibited significant differences between T0 and T1 between groups when accounted for initial values at baseline testing. Those parameters are loading response maximal ankle angle (LRAA_change, $P=0.042)$ and impact ankle angle (IKA_change, $\mathrm{P}=0.011$ ). One parameter showed a trend, time (normalized to gait cycle) from heel strike to maximum loading response knee angle (TLRKA_change, $P=0.059$ ), however 
significant differences could not be established. All the other parameter changes did not show any significant differences.

\begin{tabular}{|c|c|}
\hline Parameter Changes (start-end) & $\mathbf{P}$ \\
\hline Gait Speed change (GS_change) & 0.292 \\
\hline Swing Ankle maximum height change ( $\left.Z_{\text {ank__change }}\right)$ & 0.712 \\
\hline Pre-heelstrike Ankle vertical velocity change ( $\dot{Z}_{\text {ank }}$ change) & 0.726 \\
\hline Impact Ankle dorsi-plantar flexion angle change (IAA_change) & 0.175 \\
\hline LR maximum Ankle plantarflexion change(LRAA_change) & $0.042^{*}$ \\
\hline Timing of ankle peak during $L R$ phase change ( $\left.T_{\text {LRAA change }}\right)$ & 0.916 \\
\hline Ankle ROM during L.R phase change (ROMA_change) & 0.903 \\
\hline Impact Knee angle change (IKA_change) & $0.011^{*}$ \\
\hline LR maximum Knee flexion change (LRKA change) & 0.225 \\
\hline Timing of knee peak during $L R$ phase change $\left(T_{L R K A}\right.$ change $)$ & 0.059 \\
\hline Knee ROM during LR phase change (ROMK change) & 0.290 \\
\hline
\end{tabular}

Table 12. Tests of between subjects effects significance for fatigue indicators (parameters changes between the beginning and the end of the walk).

More detail results for parameter changes showing significant group effects or a trend are presented in the following sections.

- LRAA change

Loading response maximum ankle angle change between the beginning and the end of the walk exhibited a significant group effect from $\mathrm{T} 0$ to $\mathrm{T} 1(\mathrm{P}=0.042)$. At baseline testing both groups exhibited a similar increase in loading response plantar flexion between the beginning and the end of the walk (@T0: LRAA_change control $=0.9^{\circ} \pm$ 0.6 , LRAA_change exercise $=1^{\circ} \pm 0.6$ ), while at $\mathrm{T} 1$, the exercise and the control group exhibited a different pattern (Table 13, Figure 14). At T1, Patients in the exercise group exhibited a significantly greater increase in plantar flexion during the loading response phase of gait, between start and end of walk, than the control group who had only a minor decrease in plantar flexion (LRAA_change@ $\mathrm{T} 1$ control $=0.26^{\circ} \pm 0.5$, LRAA_change@ $\mathrm{T} 1$ exercise $\left.=1.46^{\circ} \pm 0.5\right)($ Table 14$)$ 


\begin{tabular}{|l|c|c|c|c|c|}
\hline \multirow{2}{*}{ Group } & \multirow{2}{*}{ Time } & \multirow{2}{*}{$\begin{array}{c}\text { Mean LRAA } \\
\text { change ( }\end{array}$} & \multirow{2}{*}{ Std. Error } & \multicolumn{2}{|c|}{ 95\% Confidence Interval } \\
\cline { 5 - 6 } & & .903 & .602 & Lower Bound & Upper Bound \\
\hline \multirow{2}{*}{ Control } & $\mathrm{T} 0$ & .259 & .496 & -.361 & 2.167 \\
\cline { 2 - 6 } & $\mathrm{T} 1$ & 1.005 & .602 & -.783 & 1.301 \\
\hline \multirow{2}{*}{ Exercise } & $\mathrm{T} 0$ & 1.457 & .496 & .415 & 2.269 \\
\cline { 2 - 6 } & $\mathrm{T} 1$ & &
\end{tabular}

Table 13. LRAA_change mean, std error, lower and upper bound values (positive values of LRAA_ change indicates a decrease in plantar flexion).

\begin{tabular}{|c|c|c|c|c|c|c|}
\hline \multirow{2}{*}{ Group } & \multirow{2}{*}{ Time } & \multirow{2}{*}{ Start/End } & \multirow{2}{*}{$\begin{array}{c}\text { Mean } \\
\text { LRAA }\left(^{\circ}\right)\end{array}$} & \multirow{2}{*}{ Std. Error } & \multicolumn{2}{|c|}{ 95\% Confidence Interval } \\
\hline & & & & & Lower Bound & Upper Bound \\
\hline \multirow{4}{*}{ Control } & \multirow{2}{*}{ T0 } & start & -7.945 & 1.312 & -10.702 & -5.188 \\
\hline & & end & -8.848 & 1.334 & -11.650 & -6.046 \\
\hline & \multirow{2}{*}{$\mathrm{Tl}$} & start & -9.580 & 1.252 & -12.210 & -6.950 \\
\hline & & end & -9.839 & 1.327 & -12.626 & -7.052 \\
\hline \multirow{4}{*}{ Exercise } & \multirow{2}{*}{ T0 } & start & -10.387 & 1.312 & -13.144 & -7.630 \\
\hline & & end & -11.392 & 1.334 & -14.194 & -8.590 \\
\hline & \multirow{2}{*}{$\mathrm{T} 1$} & start & -9.311 & 1.252 & -11.941 & -6.681 \\
\hline & & end & -10.768 & 1.327 & -13.555 & -7.981 \\
\hline
\end{tabular}

Table 14. LRAA mean, st error, lower and upper bound values.

Mean Loading Response Ankle Angle at Beginning and End of Walk for TO and T1

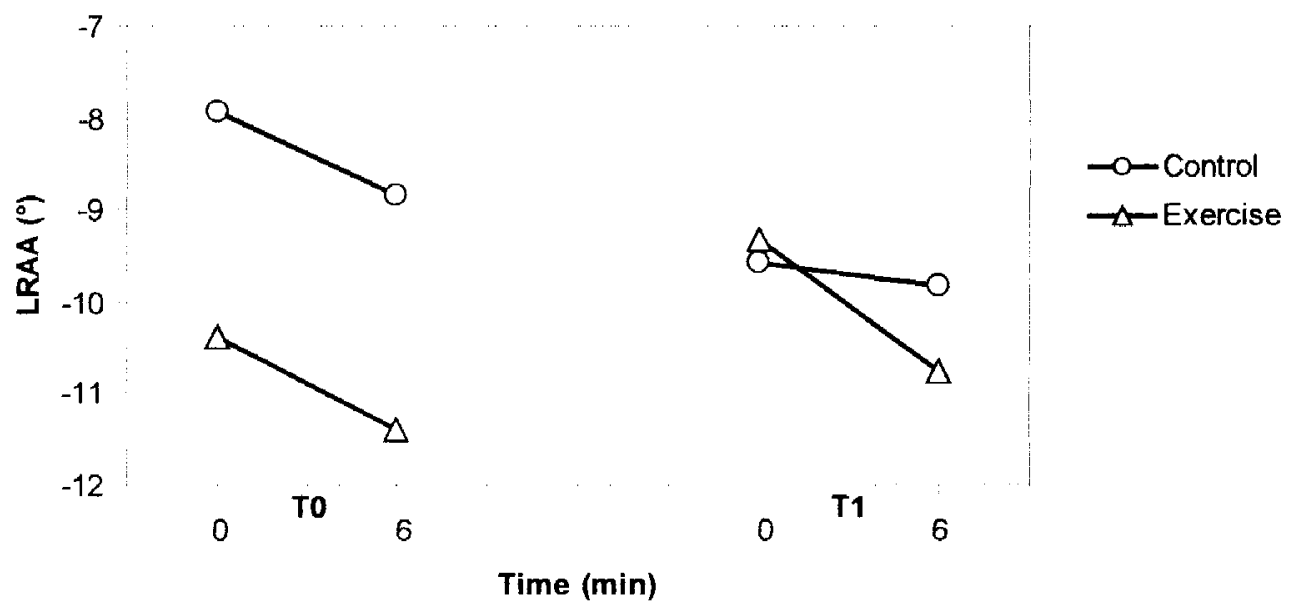

Figure 14. LRAA mean variations at $\mathrm{T} 0$ and $\mathrm{T} 1$ between start and end of walk. 
- IKA change

Between the beginning and the end of the walk, changes in impact knee angle exhibited a significant group effect between $\mathrm{T} 0$ and $\mathrm{T} 1(\mathrm{P}=0.011)$. Patients in the exercise group had on average, a more extended knee at heelstrike after the exercise program when compared to the control group. At T0 (IKA_change control $=-0.24^{\circ} \pm$ 0.78 , IKA_change exercise $\left.=-0.78^{\circ} \pm 0.78\right)$, while at T1 (IKA_change control $=-1.6^{\circ} \pm$ 0.91, IKA_change exercise $\left.=1.67^{\circ} \pm 0.91\right)($ Table 15$)$. At T0, both group landed with a slightly less extended knee after 6 minute walk than when they started walking. At T1 after the exercise program, the control group kept the same pattern as at $\mathrm{T} 0$, while the exercise group changed pattern and landed with a more extended knee after the 6 minute walk (Table 16, Figure 15).

\begin{tabular}{|c|c|c|c|c|c|}
\hline \multirow{2}{*}{ Group } & \multirow{2}{*}{ Time } & \multirow{2}{*}{$\begin{array}{c}\text { Mean IKA } \\
\text { change (") }\end{array}$} & \multirow{2}{*}{ Std. Error } & \multicolumn{2}{|c|}{ 95\% Confidence Interval } \\
\hline & & & & Lower Bound & Upper Bound \\
\hline \multirow{2}{*}{ Control } & T0 & -.235 & .777 & -1.867 & 1.397 \\
\hline & $\mathrm{Tl}$ & -1.597 & .911 & -3.511 & .317 \\
\hline \multirow{2}{*}{ Exercise } & $\mathrm{TO}$ & -.773 & .777 & -2.405 & .859 \\
\hline & $\mathrm{Tl}$ & 1.670 & .911 & -.244 & 3.584 \\
\hline
\end{tabular}

Table 15. IKA change mean, std error, lower and upper bounds values (Negative values of IKA_change correspond to a decrease in knee hyperextension between the beginning and the end of the walk and positive values correspond to an increase in knee flexion between the beginning and the end the walk).

\begin{tabular}{|c|c|c|c|c|c|c|}
\hline \multirow{2}{*}{ Group } & \multirow{2}{*}{ Time } & \multirow{2}{*}{ Start/End } & \multirow{2}{*}{$\begin{array}{c}\text { Mean } \\
\text { IKA ( })\end{array}$} & \multirow{2}{*}{ Std. Error } & \multicolumn{2}{|c|}{$95 \%$ Confidence Interval } \\
\hline & & & & & Lower Bound & Upper Bound \\
\hline \multirow{4}{*}{ Control } & \multirow{2}{*}{ T0 } & start & -1.206 & 1.250 & -3.831 & 1.419 \\
\hline & & end & -.971 & 1.334 & -3.773 & 1.831 \\
\hline & \multirow{2}{*}{$\mathrm{T} 1$} & start & -.926 & 1.362 & -3.787 & 1.935 \\
\hline & & end & .671 & 1.788 & -3.086 & 4.428 \\
\hline \multirow{4}{*}{ Exercise } & \multirow{2}{*}{ T0 } & start & -1.800 & 1.250 & -4.425 & .825 \\
\hline & & end & -1.027 & 1.334 & -3.829 & 1.775 \\
\hline & \multirow{2}{*}{$\mathrm{T} 1$} & start & -1.380 & 1.362 & -4.241 & 1.481 \\
\hline & & end & -3.050 & 1.788 & -6.807 & .707 \\
\hline
\end{tabular}

Table 16. IKA mean, std error, lower and upper bounds values. 


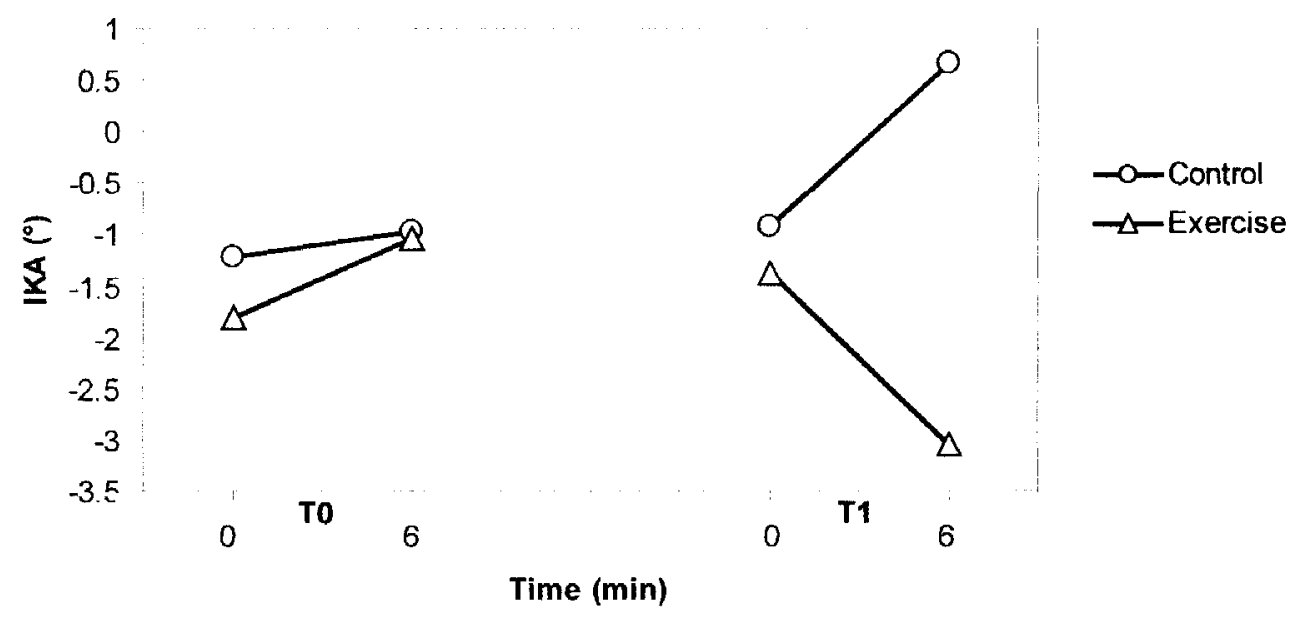

Figure 15. IKA mean variations at $\mathrm{T} 0$ and $\mathrm{T} 1$ between start and end of walk.

\subsection{Discussion}

This study investigated the effects of a 4 to 8 week exercise program for end stage knee OA patients on knee pain, functional ability, gait parameters and fatigue gait indicators after a 6 minute walk. The exercise program improved functional ability reported as the distance covered in 6 minutes, gait speed, and to some extent pain level. Evidence is accruing that demonstrates the benefits of exercise as reducing pain and improving function in knee OA patients (Van Baar et al. 1999, Fransen et al. 2002, Hurley 2003, Sisto et al. 2006, Lange et al. 2008). Results of this study support these findings.

However studies investigating the effectiveness of exercise programs concentrate on outcome variables that relieve the symptoms of knee OA such as pain and difficulty performing daily activity. Nonetheless, these studies overlook a very important point: by what means is this improvement in physical ability achieved? By increasing their functional ability score (distance covered in 6 minute), patients intrinsically increased 
their walking speed. Increasing gait speed has been shown to increase the biomechanical forces at the knee joint (Collins and Whittle 1989, Voloshin 2000, Schnitzer et al. 2003). Chen (1998), suggested that the easiest way to reduce loading rate is to slow down. Chen et al. (2003) reinforced the idea that walking slowly with lower heelstrike transient might be an effective preventive measure against knee OA. Based on the latest suggestions that faster walking speeds increase loading conditions at the knee, it is reasonable to question whether or not improved physical ability (walking speed), would be a beneficial outcome for end stage knee $\mathrm{OA}$ patients. This question remains unanswered without investigations of loading conditions at the knee.

A study by Gill and O'Connor (2003) has shown that subtle changes in the kinematics of the swing leg just prior to heelstrike has large implications on the impact velocity at heelstrike and thus, on the loading conditions at the knee. These differences in gait pattern which are not perceptible by the naked eye seem to have a substantial impact on the disease progression. Similarly in the present study, differences in ankle vertical velocity just prior to heelstrike are present between the exercise group and the control group after the exercise program. All patients could be classified as "loaders" as defined by Radin et al. (1991), based on their high vertical velocity of the ankle marker just prior to heelstrike. However, the exercise group exhibited higher ankle approach velocity after the exercise program (T1), than at baseline testing (T0), while the control group exhibited a reduced ankle approach velocity compared with their baseline testing values. The difference in pain level experienced by both groups might partly explain these differences. Patients were asked to stop their pain medications a week before surgery which corresponded to T1 testing. The exercise program might have had some beneficial 
effect on pain management by strengthening the muscles used at controlling the knee stability. The exercise group did not experience a higher level of pain at T1 than at T0 while the control group tended to have an increased level of pain at $\mathrm{T} 1$. The difference in pain level at T1 may have contributed to an adaptation in gait strategy adopted by the control group. Pain acts as a protective mechanism to alleviate knee loads and reduce the deleterious effect of impulse loading at heelstrike. "Gliding" instead of "digging" into the ground at heelstrike will reduce the knee load and the pain level. Patients in the control group seem to have adopted a strategy characterized by a reduced walking velocity and a reduced ankle approach velocity in an attempt to alleviate the load and the pain at the knee due to heelstrike impact. Pain was probably not as much of a concern for the exercise group who did not change their "digger" gait pattern. Furthermore, it appears that without the pain protective mechanism and with the strengthening benefit of the exercise program, patients in the exercise group were able to walk faster and impacted the ground with a higher vertical velocity at heelstrike, putting their knees at higher risk for joint degeneration and with a faster rate of disease progression. In addition, research has shown that existing knee $\mathrm{OA}$ condition in one knee was an important risk factor for developing knee $\mathrm{OA}$ in the other knee. Thus, it seems reasonable to expect that with the gait pattern exhibited by patients in the exercise group they will have an increased risk of developing $\mathrm{OA}$ in the non affected leg.

There are additional evidences in this present study's results in favor of the current hypothesis that patients in the exercise group might be putting their knees at increased risk. A trend in the results showed that the control group took a longer time to reach the maximum of knee flexion during loading response (TLRKA) at testing prior to surgery 
(T1) than at baseline testing ( $\mathrm{T} 0$ ), while the exercise group reduced this timing after the exercise period. This difference in TLRKA is possibly due to the difference in pain level experienced by the two groups and a level of confidence factor. The concept of functional instability has recently been identified as a problem in a significant proportion of individuals with knee OA (Fitzgerald et al. 2004). This idea was reinforced by the result in a study by Maly (2009) who stated that "pain indicated to participants that they should not trust their knees during challenging activities". The author introduced the concept of "careful mobility" and showed qualitative and quantitative evidences that people with knee OA demonstrate a careful gait that goes beyond just reduced walking speed. The control group in the present study experienced a higher level of pain than the exercise group and exhibited a slower walking speed. Spending more time to reach the maximum of knee flexion during loading response might be another indication of a careful gait. Patients in the control group adopted a strategy to slow down the rate of knee loading by taking more time to reach the peak of knee flexion during loading response. Their priority was to reduce the pain that rapid loading rate produces. The loading response phase of gait requires a great deal of coordination and is a very challenging phase for stability. Knee OA patients have been described as "microklutzs" and they may be trying to unconsciously compensate for this micro-incoordination. By taking more time during the loading response phase of gait, they managed to reduce the speed at which they contacted the ground at heelstrike (Zank), and thus might have experienced reduced impact loading at the knee. The concept of careful mobility has been linked to the level of pain. While the control group demonstrated a careful gait, the exercise group might have felt more confident as they experienced less pain. This can be reflected by the shorter time 
exhibited by patients in the exercise group after the exercise training to reach the maximum knee flexion during loading response. Patients attempted to load their knees faster in order to reach their goal of increased distance covered in 6 minute.

Variations of gait variables between the beginning and the end of the 6 minute walk (fatigue indicators) explained strategies adopted by end stage knee OA patients. Some fatigue indicators highlighted important adaptation mechanisms that were overlooked by a single walking trial. Additional indications that the exercise group exacerbated their condition were present after the 6 minute walk. Impact knee angle pattern of change (IKA_change) was different for the two groups. After 6 minute walk, patients in the exercise group landed with a considerably more extended knee angle at T1. Faster walking speeds require more stability at heelstrike. greater knee extension at heelstrike was thus adopted by patients in the exercise group in order to achieve the stability required to maintain faster walking speed. However a fully extended knee at heelstrike reduces shock absorption mechanisms. Gerritsen et al. (1995) found that a greater leg angle corresponding to a more extended knee at touchdown resulted in a higher impact peak force, and knee flexion was found to play a major role in shock absorption by the knee extensor muscles. The low level of pain experienced by the exercise group in the present study might have prevented the protective pain feedback mechanism that will allow preserving good shock absorption at heelstrike. Their priority was to maintain fast walking speed and cover as much distance as they could and not walk in a manner that will reduce pain and conserve shock absorption mechanisms. Furthermore, knee hyperextension is a characteristic of overstriding (Gutekunst et al. 2010). Overstriding is an abnormal gait pattern defined by a stride length greater than the preferred stride 
length. When tired, an individual is more likely to develop an abnormal gait. Also muscular fatigue leads to decreased shock absorption, and may lead to injuries. After 6 minute walk, patients in the exercise group displayed the altered gait pattern of overstriding. Overstriding produces heelstrike with the knee extended and thus decreases shock absorption (Mercer et al. 2003). Decrease shock absorption leads to microtrauma. Thus it seems reasonable to believe that people in the exercise group while increasing their walking speed are forced to adopt a strategy aimed at locking the knee at heelstrike to preserve stability and walking speed. This mechanism has among its consequences increased loading conditions at the knee, and thus it exposes patients to faster rate of joint degeneration after the exercise program. In the other hand, at $\mathrm{T} 1$ the control group increased their knee flexion at heelstrike after the 6 minute walk. Their pain level was higher and they likely adopted a strategy aimed at reducing the load across the knee in an attempt to lower the pain experienced at heelstrike. This requirement predominated and patients in the control group adopted a strategy that could conciliate pain relief and stability which is slower walking speed.

Another gait parameter provided some additional information on the strategies used to cope with fatigue by patients in both groups after the 6 minute walk. After the exercise program (T1), patients in the exercise group reached a considerably more plantarflexed ankle position during loading response (LRAA_change) after the 6 minute walk than when they started walking. Patients voluntarily increased plantarflexion as a mean of protecting a weak quadriceps from loading response knee flexion. As they get fatigued, patients increased their mechanisms aimed at reducing pain in the knee and protect weak quadriceps. This more plantarflexed position during loading response adopted by the 
exercise group could be described as a person trying to overstride. They attempted to land with their leg further out in front of their body. Overstriding has been described as a gait alteration that can cause lower leg injuries. Patients in the exercise group are also landing with a higher vertical velocity of the ankle marker prior to heelstrike which means that they are overshooting the target ground position. Such gait patterns are expected to produce higher loads at the knee and could exacerbate knee OA condition.

Results in Messier et al. (2008) study suggested that greater knee strength is associated with larger knee load. Thus, they raised the question of whether greater knee strength improves shock absorption or exacerbate knee joint loads and lead to injury. Similarly, in the present study, physical ability was improved and by that mean possibly knee strength. An accumulation of indices leaded us to believe that patients in the exercise group adopted a gait pattern that could increase loads at the knee. It seems thus reasonable to ask the question of whether improving physical ability will improve knee OA condition or will cause further knee degeneration and initiate the onset of the disease on the opposite leg. Further investigations with measures of the loading conditions at the knee will be necessary to answer this question. Patient gait retraining is emerging as a strategy to delay knee OA surgery, provide relief of pain and also delay the onset of OA in the adjacent joints. The results of the present study suggested that exercise programs should include a component of gait retraining in order to improve physical function along with changing gait pattern towards reduced loading conditions at the knee. Without this important component, exercise might be exacerbating phenomenon that caused OA initially since improvement in physical function and pain level by exercise regimen might be masking further joint degeneration. Radin et al. (2004) has gotten patients to stop 
being "Microklutz" (as defined in Radin et al. 1991). They obtained preliminary results with the use of biofeedback to train patients to reduce the rate of loading at the knee. However gait retraining is not used widely and yet needs further investigation.

\subsection{Conclusion}

Results showed that a 4 to 8 weeks exercise program was effective at improving physical function in end stage knee $\mathrm{OA}$ patients and at reducing to some extent knee pain. However, gait pattern adopted by patients in the exercise group suggested that the improvement in physical function and pain level by exercise regimen might be masking further joint degeneration. Further investigations on knee loading conditions are needed to verify this suspicion. Investigation of gait pattern after a 6 minute walk suggested that investigation of fatigue gait adaptation could reveal important information that a single gait trial was unable to detect.

In order to reduce the load across the knee along with improving functional ability and reducing pain, exercise programs might need a gait retraining component with a feedback mechanism. There is an important amount of literature supporting that exercise improves functional ability and reduces knee pain. However consequences on loading conditions at the knee have been overlooked. There is a need for changing the way exercise training is done. Gait training with feedback should be a critical part of any exercise program for knee OA patients. Without this, there is evidence that patients suffering from severe knee $\mathrm{OA}$ are unable to deviate from a gait pattern exacerbating joint damage. 


\section{CHAPTER 4}

\section{PREHABILITATION EFFECTS ON PRONGUED \\ GAIT AMONG TKA PATIENTS}

\subsection{Introduction}

Conservative treatments for $\mathrm{OA}$ of the knee include weight loss, exercise, and medication. These approaches, however, are means for managing OA. They do not provide cures for the disease, nor do they address the physiological cause of the symptoms. Commonly, these treatments provide only limited relief of the symptoms and surgical interventions are recommended (Brady et al. 2000).

Total knee arthroplasty (TKA) addresses the actual problem and replaces the nonfunctional joint with a prosthetic device. This procedure has been proven to be efficient in relieving pain and improving functional ability and quality of life (Fortin et al. 1999, Harris et al. 1990, Liang et al. 1990, Rissanen et al. 1995, Tierney et al. 1994, Van Essen et al. 1998, Williams et al. 1997). However, TKA commonly involves prolonged rehabilitation (Dieppe et al. 1999, Callahan et al. 1994).

Physical function was identified by a consensus of research experts in OA as one of the most important dimensions to be measured when evaluating intervention effectiveness (Bellamy et al. 1997). Locomotor ability, which is defined as the aptitude of a person to walk, is one of the most important physical functions. Locomotor ability can be quantified in many different ways. Gait parameters and fatigability while performing walking, are some examples of pertinent walking functional ability quantifications. 
According to patients and rehabilitation specialists, locomotor ability is of the highest relevance when looking at outcomes of TKA surgery for patients with knee OA since most patients reported difficulties walking. Moreover, this locomotor activity reflects changes in physical function (Barr et al. 1994).

The rate of recovery from a TKA is dependent upon a number of factors. Previous investigators have described preoperative pain and functional capacity including the ability to complete functional tasks to be consistent predictors of recovery from a TKA (Escalante et al. 1997, Sharma et al. 1996, Anouchi et al. 1996). The measures of knee pain and the ability to complete functional tasks, have been shown to be meaningful, and can be improved by various exercise interventions among patients with knee OA (Topp et al. 2002, Ettinger et al. 1997), even after as little as 4 to 8 weeks of moderate intensity training (Deyle et al. 2000, Ries et al. 1996). It is consequently speculated that a prehabilitation program, aimed at enhancing pre-surgical functional ability levels, will improve post-surgical outcomes.

A limited number of studies have examined the effects of preoperative exercise interventions upon surgical outcomes. Whitney et al. (2002) found that prehabilitation improves distance covered in 6 minute. Studies by D'Lima et al. (1996) and Rodgers et al. (1998), however, concluded that 6 weeks of preoperative physical therapy had no effect on measures of functional capacity following joint replacement surgery. Thus, the question of whether or not exercise, when directed towards improving functional capacity prior to orthopedic surgery, can enhance surgical recovery, remains unanswered.

An increased fatigue is reported by patients with OA. However, this fatigue has not been characterized and quantified. Syed et al. (2000) hypothesized that the changes in 
gait pattern due to fatigue in obese knee OA patients will lead to an altered knee kinematic pattern at heelstrike and consequently decrease the shock absorption. This scenario will result in an increased rate of loading causing articular cartilage damage (Radin et al. 1991). Knee OA patients exhibit significant quadriceps weakness (Slemenda et al. 1997, Fisher et al. 1991). Fatigue due to muscle weakness leads to shorter periods of eccentric contraction and thus in decreased shock absorbency. Thus, it is reasonable to anticipate that fatigue will be reduced in knee OA patients who participate in an exercise program focusing on muscle strengthening.

Results from chapter 2 demonstrated that exercise improved functional ability (distance covered in 6 minute) and to some extent pain levels in end stage knee OA patients. The exercise program did affect gait characteristics of end stage knee OA patients prior to their elective TKA surgery.

The hypothesis tested in the present study was that at one month after TKA surgery, gait characteristics related to shock absorbency and functional status parameters (knee pain and distance covered in 6 minute) would be significantly improved for patients participating in the prehabilitation protocol compared with patients in the control group who had only usual care.

\subsection{Methods}

The testing protocol, population, experimental design, and outcome variables described in chapters 2 and 3 were implemented for the present study. Additional components that are specific to this study and not already reported in the previous two studies are presented in this section. 


\subsubsection{Design}

The exercise program is termed prehabilitation, as it occurs prior to TKA surgery, whereas rehabilitation occurs after a clinical. Subjects who were eligible and agreed to participate underwent baseline testing 4 to 8 weeks prior to surgery (T0) (described in chapter II) and then were randomly assigned to either an Exercise group or a usual care group (control). Subjects underwent a subsequent testing one week prior to their TKA surgery (T1) (described in chapter III). Following the TKA surgery all subjects in the treatment and control groups participated in a standardized rehabilitation program for 4 weeks. Subjects underwent a third testing one month after their TKA surgery (T2). Each subject's knee pain during walking, distance covered in 6 minutes, and selected gait kinematic and kinetic characteristics were collected at $\mathrm{T} 0, \mathrm{~T} 1$ and $\mathrm{T} 2$.

The testing times were chosen for the following reasons. Exercise for 4 to 8 weeks has been demonstrated to result in significant improvements in functional capacity, muscle strength, and performance of functional tasks among older adults with OA of the knee (Deyle et al. 2000, Fransen et al. 2001). At one month postoperatively, TKA patients are commonly able to complete functional tasks such as walking and thus should be able to complete the 6 minute walk test.

\subsubsection{Statistical Analysis}

Univariate analysis of variance for $\mathrm{T} 2$ values with co variation on $\mathrm{T} 0$ values were used to evaluate the effects of exercise program on post-TKA outcome variables (pain, functional ability, and selected gait parameters). Results are presented for tests of between subjects effects (group effect). 


\subsection{Results}

\subsubsection{Functional Ability Parameters and Gait Parameters at the Beginning of the Walk}

Results of between subjects tests of significance (group effect) are presented in

Table 17 for D6, KP and gait parameters at the beginning of the walk. No parameters showed significant differences from T0 (baseline to T2 (1 month post surgery) between the groups when accounting for initial values at $\mathrm{T} 0$.

\begin{tabular}{|c|c|}
\hline Parameters & $\mathbf{P}$ \\
\hline Distance covered in 6 minute (D6) & 0.934 \\
\hline Knee pain (KP) & 0.934 \\
\hline Gait Speed at start (GS_start) & 0.429 \\
\hline Swing Ankle maximum height @start ( $Z_{\text {ank_start) }}$ & 0.832 \\
\hline Pre-heelstrike Ankle vertical velocity @start ( $\dot{Z}_{\text {ank_start })}$ & 0.962 \\
\hline Impact Ankle dorsi-plantar flexion angle @start (IAA start) & 0.769 \\
\hline LR maximum Ankle plantarflexion@start(LRAA_start) & 0.864 \\
\hline Timing of ankle peak during LR phase @start ( $\mathrm{T}_{\mathrm{LRAA}}$ start) & 0.480 \\
\hline Ankle ROM during LR phase @start (ROMA_start) & 0.919 \\
\hline Impact Knee angle@start (IKA_start) & 0.744 \\
\hline LR maximum Knee flexion @start (LRKA_start) & 0.486 \\
\hline 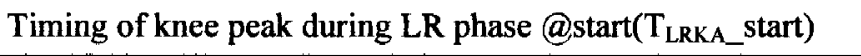 & 0.722 \\
\hline Knee ROM during LR phase @start (ROMK_start) & 0.804 \\
\hline
\end{tabular}

Table 17. Tests of between subject effects significance for D6, KP, and gait parameters at the beginning of the walk.

\subsubsection{Parameter Changes between Start and End of the Walk}

Results for parameter changes between the beginning and end of the walk and group effects are presented in Table 18. None of the parameters exhibited significant differences between the groups. 


\begin{tabular}{|c|c|}
\hline Parameter Changes (start-end) & $\mathbf{P}$ \\
\hline Gait Speed change (GS_change) & 0.277 \\
\hline Swing Ankle maximum height change ( $Z_{\text {ank }}$ change $)$ & 0.786 \\
\hline Pre-heelstrike Ankle vertical velocity change ( $\dot{Z}_{\text {ank__hange }}$ ) & 0.547 \\
\hline Impact Ankle dorsi-plantar flexion angle change (IAA_change) & 0.442 \\
\hline LR maximum Ankle plantarflexion change(LRAA_change) & 0.954 \\
\hline Timing of ankle peak during $L R$ phase change ( $\left.T_{\text {LRAA_change }}\right)$ & 0.845 \\
\hline Ankle ROM during LR phase change (ROMA_change) & 0.344 \\
\hline Impact Knee angle change (IKA_change) & 0.916 \\
\hline LR maximum Knee flexion change (LRKA_ change) & 0.226 \\
\hline Timing of knee peak during LR phase change ( $\left.T_{\text {LRKA_change }}\right)$ & 0.581 \\
\hline Knee ROM during LR phase change (ROMK_change) & 0.476 \\
\hline
\end{tabular}

Table 18. Tests of between subjects effects significance for fatigue indicators (parameters changes between the beginning and the end of the walk).

\subsection{Discussion}

This study investigated the effects of a 4 to 8 week prehabilitation program on postTKA outcomes among patients seeking relief from knee OA. No group effect could be demonstrated on either the functional ability parameters or the gait parameters.

The exercise program was associated with increased functional ability and improved pain level to some extent prior to surgery (chapter 3). Other significant effects that were reported in chapter 3 suggested that exercise modified certain gait parameters prior to surgery among patients scheduled for TKA.

The present study results suggested that the pre-surgery exercise program effects did not remain after TKA surgery. This could have happened for several reasons. After surgery, both groups were following the same rehabilitation exercise program. Rehabilitation post surgery is known to significantly improve recovery rate and function ( Minns Lowe 2007). One month post TKA surgery (T2), patients in the control group might have caught up with the exercise group. In order to improve, the level of exercise needs to be higher than the capabilities of the patients. The rehabilitation was not higher 
in intensity than the prehabilitation. Patients in the exercise group might have reached a plateau with the prehabilitation exercises prior to surgery, and they were not able to improve post surgery with the rehabilitation program due to the plateauing effect. The control group might have started to catch up on their performance level one month after surgery. The exercise group might have needed to elevate their level of rehab in order to get full benefit or their prehab program.

Another possibility for explaining the lack of significance in the results post TKA was that the prehab program did not include any gait retraining component. Patients in the exercise group did not have an improved gait pattern prior to surgery. Increased strength without any particular attention to walking characteristics will not change their gait pattern. Adding a gait retraining component to the prehab protocol may benefit the rate of recovery and help patients to keep the prehab benefits even post TKA surgery.

\subsection{Conclusion}

The present study was not able to demonstrate any benefits of an exercise program prior to TKA surgery to improve functional ability, pain, and gait characteristics post TKA. Further investigations, that add gait retraining components to the prehab protocol, as well as a stronger rehab program may maintain the benefits of exercise prior to surgery. 


\section{CHAPTER 5}

\section{SUMMARY AND CONCLUSIONS}

The present overall study investigated the walking biomechanics of end stage knee OA and TKA patients. Pre-operatively, end stage knee OA patients have the symptoms of pain, limited functional ability, and exhibit deviations from a normal gait pattern. Assessment of changes in gait biomechanics from the beginning and end of a 6 minute walk, raises the question of whether a single walking trial, typically performed in clinical studies, is enough to understand compensation mechanisms used by knee OA patients in daily living.

Patients maintained their walking velocity throughout the 6 minute walk. However, subtle but statistically significant differences at the ankle were present after a 6 minute walk. Results suggest that end stage knee OA patients may be experiencing higher loading conditions at the knee after a short walk duration (6 min). These adaptations appearing after a 6 minute walk could potentially have a serious impact on the disease progression, as well as, the onset of OA in the opposite leg and adjacent joints. In order to adapt to fatigue after a 6 minute walk, end stage knee OA patients appear to adopt ankle strategies alleviating the load from a painful knee, rather than knee strategies, causing greater instability and reduced performances. Stability appears to be a critical element in end stage knee OA walking requirements. End stage knee OA patients are expected to walk a shorter distance and a single walking trial for gait analysis may be insufficient to assess gait compensations due to fatigue in daily activities. A 6 minute walk for end stage 
knee OA patients appears to be a sufficient amount of time to reveal adaptations due to fatigue.

In light of the initial results on end stage knee OA walking biomechanics, the present study included investigation of the effects of a 4 to 6 weeks exercise program on TKA outcomes. Exercise therapy was effective at improving function and reducing pain to a certain extent for end stage knee OA patients pre-surgery. However, assessment of the walking biomechanics raised the question of whether improving physical ability improved knee $\mathrm{OA}$ condition or caused further knee joint degeneration and possibly the onset of $\mathrm{OA}$ in the opposite leg. Control patients with higher levels of pain and lower physical ability performances than exercisers, exhibited a more careful gait pattern with lower speed and gait parameter reflecting potentially lower impact at heelstrike which may be more beneficial for knee OA conditions. Whereas, the exercisers' walking characteristics showed evidence of an overstriding gait pattern with potentially reduced shock absorption mechanisms that can lead to lower leg injuries. Gait patterns adopted by patients in the exercise group suggested that improvements in physical function and pain level by routine exercise may mask further joint degeneration. Further investigations on knee loading conditions are needed to verify this suspicion.

Investigation of walking biomechanics one month after surgery suggested that the effects of the pre surgery exercise program did not remain after TKA surgery. Even if patients in the exercise group had increased physical ability performances and experienced less pain just prior to surgery compared to the control group, one month after surgery there was no difference between the groups. The lack of a significant effect of the exercise program on gait changes post surgery may indicate that the exercise regimen 
prior to surgery requires an additional component such as gait retraining. Increased strength without any particular attention to walking characteristics will not change gait pattern. Adding a gait retraining component to the prehab protocol may improve the rate of recovery and help patients to maintain the prehab benefits even post TKA surgery. There is evidence that patients suffering from severe knee $\mathrm{OA}$ are unable to deviate from a gait pattern, exacerbating joint damage.

\section{Suggestions for Future Study}

To confirm the results of the present study, a larger sample size should be used. Additionally, a comparison with healthy age matched control subjects could help to identify what parameter changes between the beginning and end of the walk are specific to knee OA condition. Recording the pain level at the beginning of the walk as well as at the end of the walk, will permit correlation analysis to identify if the pain or fatigue is responsible for gait changes appearing during the 6 minute walk. Addition of force plate data will allow for calculation of the peak force at the knee as well as the ground reaction loading rate. Correlation of those parameters with the vertical height of the ankle marker during late swing and pre-heelstrike vertical velocity will give very insightful information on the loading condition of the knee at heelstrike and during the loading response phase of gait.

Future study should also include a rehabilitation program post surgery adjusted to each patient personal level in order to allow the benefits of the prehabilitation program to be carried out post surgery. An additional component of gait retraining with biofeedback in the prehab as well as in the rehab will ensure that gait characteristics are returning to a normal pattern as the patient's physical ability is improving. 


\section{REFERENCES}

Administration on Aging. (2001). Elder action: action ideas for older persons and their families. http://www.aoa.gov/aoa/eldranctn/fitfact.html.

Akima H., Kubo K., Kanchisa H., Suzuki Y., Gunji A., \& Funkunaga T. (2000). Legpress resistance training during 20 days of 6 degrees head-down-tilt bed rest prevents muscle deconditioning. European Journal of Applied Physiology 82(1-2), $30-8$.

American College of Rheumatology Subcommittee on Osteoarthritis Guidelines. (2000). Recommendations for the medical management of osteoarthritis of the hip and knee. Arthritis Rheumatism 43, 1905-15.

Andriacchi TP., Galante JO., \& Fermier RW. (1982). The influence of total knee replacement design on walking and stair climbing. Journal of Bone \& Joint Surgery $64,1328-35$.

Andriacchi TP. (1993). Functional analysis of pre and post knee surgery, total knee arthroplasty and ACL reconstruction. Journal of Biomechanical Engineering 115 , $575-81$.

Andriacchi TP., Mundermann A., Smith RL., Alexander EJ., et al. (2004). A framework for the in vivo pathomechanics of osteoarthritis at the knee. Annals of Biomedical Engineering 32, 447-57.

Andriacchi TP., Briant PL., Bevill SL., \& Koo S. (2006). Rotational changes at the knee after ACL injury cause cartilage thinning. Clinical Orthopaedics and Related Research 442, 39-44.

Andriacchi T. \& Mundermann A. (2006). The role of ambulatory mechanics in the initiation and progression of knee osteoarthritis. Current Opinions in Rheumatology $18,514-8$.

Anouchi Y., McShane M., Kelly F., Elting J., \& Stiehl J. (1996). Range of motion in total knee replacement. Clincial Orthopaedics and Related Research 311(10), 87-92.

Baker KR., Xu L., Zhang Y., Nevitt M., Niu J., Aliabadi P., Yu W., and Felson, D. (2004). Quadriceps weakness and its relationship to tibiofemoral and patellofemoral knee osteoarthritis in Chinese. Arthritis and Rheumatism 50(6), 1815-21. 
Bamman MM., Hunter GR., Stevens BR., Guilliams ME., \& Greenisen MC. (1997). Resistance exercise prevents plantar flexor deconditioning during bed rest. Medicine and Science in Sports and Exercise 29(11), 1462-8.

Bamman MM., Clarke MS., Feeback DL., Talmadge RJ., Stevens BR., Lieberman SA., \& Greenisen MC. (1998). Impact of resistance exercise during bed rest on skeletal muscle sarcopenia and myosin isoform distribution. Journal of Applied Physiology 84(1), 157-63.

Banks SA., Markovich GD., Hodge WA. (1997). The mechanics of knee replacement during gait. American Journal of Knee Surgery 4, 261-267.

Barr S., Bellamy N., Buchanan WW., Chalmers A., Ford PM., Kean WF., et al. (1994). A comparative study of signal versus aggregate methods of outcome measurement based on the WOMAC Osteoarthritis Index: Western Ontario and McMaster Universities Osteoarthritis index. Journal of Rheumatol 21, 2106-12.

Bellamy M., Kirwan J., Boers M., Brooks P., Stand V., Tugwell P., et al. (1997). Recommendations for a core set of outcome measures for future phase III clinical trials in knee, hip and hand osteoarthritis: consensus development at OMERACT III. Journal of Rheumatology 24, 799-802.

Benedetti MG., Catani F., Bilotta TW., Marcacci M., Mariani E., \& Giannini S. (2003). Muscle activation pattern and gait biomechanics after total knee replacement. Clinical Biomechanics 18, 871-6.

Berman AT., Zarro VJ., Bosacco SJ., et al. (1987). Quantitative gait analysis after unilateral or bilateral total knee replacement. Journal of Bone \& Joint Surgery 69, 1340-5.

Block JA. \& Shakoor N. (2009). The biomechanics of Osteoarthritis: implications for therapy. Current Rheumatology Reports 11(1), 15-22.

Bobbert MF., Yeadon MR. \& Nigg BM. (1992). Mechanical analysis of the landing phase in heel-toe running. Journal of Biomechanics 25, 223-4.

Brady O., Masri B., Garbuz D. \& Duncan C. (2000). Rheumatology: 10. Joint replacement of the hip and knee - when to refer and what to expect. Canadian Medical Association Journal 163(10), 1285-91.

Brandt, K. Heilman, M., Slemenda, C., et al. (1999). Quadriceps strength in women with radiographically progressive osteoarthritis of the knee and those stable radiographic changes. Journal of Rheumatology 26, 2431-7.

Brinkman JR. \& Perry J. (1985). Rate and range of knee motion during ambulation in healthy and arthritis subjects. Physical Therapy 65, 1055-60.

Burckhardt CS. (1990). Chronic Pain. Nursing Clinics of North America 25(4), 63-870. 
Callahan, C., Drake, B., Heck, D. \& Dittus, R. (1994). Patient outcomes following tricompartmental tota; knee replacement: a meta analysis. Journal of the American Medical Association 271, 1349-57.

Caraffa A., Projetti M., \& Rizzo A.G. (1996). Prevention of anterior cruciate ligament injuries in soccer: A prospective controlled study of proprioceptive training. Knee Surgery in Sports 4, 19-21.

Chandler JM., Duncan PW., Kochersberger G., \& Studenski S. (1998). Is lower extremity strength gain associated with improvement in physical performance and disability in frail, community-dwelling elders? Archives of Physical Medicine and Rehabilitation 79, 24-30.

Chen PQ., Cheng CK., Shang HC., et al. (1991). Gait analysis after total knee replacement for degenerative arthritis. Journal of Formosan Medical Association $90,160-6$.

Chen WL. (1998). Impulsive loading in Gonarthrosis. Doctor of Philosophy Thesis. University of Oxford, Oxford.

Chen WL., O'Connor JJ., \& Radin EL. (2003). A comparison of the gaits of Chinese and caucasian women with particular reference to their heelstrike transients. Clinical Biomechanics 18, 207-13.

Chen CP., Chen MJ., Pei YC., Lew HL., Wong PY., \& Tang SF. (2003). Sagittal plane loading response during gait in different age groups and in people with knee osteoarthritis. American Journal of Physical Medicine and Rehabilitation 82(4), 307-12.

Collins JJ. \& Whittle MW. (1989). Influence of gait parameters on the loading of the lower limb. Journal of Biomedical Engineering 11, 409-12.

Deyle G., Henderson N., Matekel R., Ryder M., Garber M., \& Allison S. (2000). Effectiveness of manual physical therapy and exercise in osteoarthritis of the knee. Annals of Internal Medicine 132(3), 173-81.

Dieppe P., Basler HD., Chard J., Croft P., Dixon J., Hurley M., Lohmander S., \& Raspe H. (1999). Knee replacement surgery for osteoarthritis: effectiveness, practice variations, indications and possible determinants of utilization. [Review] [90 refs]. Rheumatology 38(1), 73-83.

Dixon JS. \& Bird HA. (1981). Reproductibility along a $10 \mathrm{~cm}$ vertical visual analogue scale. Annals of the Rheumatic Diseases 40, 87-9.

D'Lima D., Colwell C., Morris B., Hardwick M., \& Kozin F. (1996). The effect of preoperative exercises on total knee replacement outcomes. Clinical Orthopaedics and Related Research 326, 174-82. 
Doherty M., Holt M., MacMillan P., Watt I., \& Dieppe P. (1986). A reappraisal of 'analgesic hip.' Annals of the Rheumatic Diseases 45, 272-6.

Downie WW., Leatham PA., Rhind VM., Wright V., Branco JA., \& Anderson JA. (1978). Studies with pain rating scales. Annals of the Rheumatic Diseases 37, 37881.

Enoka RM. (1994). Neuromechanical basis of kinesiology ( $2^{\text {nd }}$ ed.). Champaign, IL. Human Kinetics.

Escalante A. \& Beardmore T. (1997). Predicting length of stay after hip or knee replacement for rheumatoid arthritis. Journal of Rheumatology 24, 146-52.

Ettinger W., Davis M., Neuhaus J., \& Mallon K. (1994). Long-term physical functioning in persons with knee osteoarthritis from NHANES I: Effects of comorbid medical conditions. Journal of Clinical Epidemiology 47(7), 809-15.

Ettinger W.H., Burns R., Messier S.P., Applegate W., Rejeski W. J., Morgan T., Shumaker S., Berry M.J., O'Toole M., Monu J., \& Craven T. (1997). A randomized trial comparing aerobic exercise and resistance exercise with a health education program in older adults with knee osteoarthritis. Journal of American Medical Association 227, 25-32.

Felson DT., Zhang Y. (1998). An update on the epidemiology of knee and hip osteoarthritis with a view to prevention. Arthritis Rheumotology. 41, 1343-55.

Finch E., Walsh M., Thomas SG., \& Woodhouse LJ. (1998). Functional ability perceived by individuals following total knee arthroplasty compared to age matched individuals without knee disability. Journal of Orthopaedic and Sports Physical Therapy 27, 255-63.

Fisher NM., Pendergast DR., Gresham GE., \& Calkins E. (1991). Muscle rehabilitation: its effect on muscular and functional performance of patients with knee osteoarthritis. Archives of Physical Medicine and Rehabilitation 72(6), 367-74.

Fisher NM, Gresham GE, Abrams M, Hicks J, Horrigan D, \& Pendergast DR. (1993). Quantitative effects of physical therapy on muscular and functional performance in subjects with osteoarthritis of the knees. Archives of Physical Medicine and Rehabilitation 74, 840-7.

Fisher NM, White SC, Yack HJ, Smolinski RJ, \& Pendergast DR. (1997). Muscle function and gait in patients with knee osteoarthritis before and after muscle rehabilitation. Disability Rehabilitation 19, 47-55

Fisher NM. \& Pendergast DR. (1997). Reduced muscle function in patients with osteoarthritis. Scandinavian Journal of Rehabilitation Medicine 29, 213-21. 
Fitzgerald GK., Piva SR., et al. (2004). Reports of joint instability in knee osteoarthritis: its prevalence and relationship to physical function. Arthritis and Rheumatism 51(6), 941-6.

Fleck SJ. \& Kraemer WJ. (1997). Designing resistance training programs ( $2^{\text {nd }}$ ed.). Champaign, IL: Human Kinetics.

Fortin PR., Clarke AE., Joseph L., Liang MH., Tanzer M., Ferland D., Phillips C., Partridge AJ., Belisle P., Fossel AH., Mahomed N., Sledge CB., \& Katz JN. (1999). Outcomes of total hip and knee replacement. Preoperative functional status predicts outcomes at six months after surgery. Arthritis and Rheumatism 42, 1722-8.

Fortin PR., Penrod JR., Clarke AE., St-Pierre Y., Joseph L., Belisle P., Liang MH., Ferland D, Phillips C., Mahomed N., Tanzer M.,. Sledge CB., Fossel AH, \& Katz JN. (2002). Timing of total joint replacement affects clinical outcomes among patients with osteoarthritisof the hip and knee. Arthritis and Rheumatism 46, 332730.

Fransen M, Margiotta E, Crosbie J, \& Edmunds J. (1997). A revised group of exercise program for osteoarthritis of the knee. Physiotherapy Research Institute 2, 30-41.

Fransen M., Crosbie J., \& Edmonds J. (2001). Physical therapy is effective for patients with osteoarthritis of the knee: a randomized controlled clinical trial. Journal of Rheumatology 28(1), 156-64.

Fransen M, McConnell S, \& Bell M. (2002). Therapeutic exercise for people with OA of the hip and knee: a systematic review. Journal of Rheumatology 29, 1737-45.

Gerritsen KG., van den Bogert AJ., \& Nigg BM. (1995). Direct dynamics simulation of the impact phase in heel-toe running. Journal of Biomechanics 28(6), 661-8.

Gill HS. \& O'Connor JJ. (2003). Heelstrike and pathomechanics of osteoarthrosis: a simulation study. Journal of Biomechanics 36, 1617-24.

Gill HS. \& O'Connor JJ. (2003). Heelstrike and pathomechanics of osteoarthrosis: a pilot gait study. Journal of Biomechanics 36, 1625-31.

Gok H.,Ergin S., \& Yavuzer G. (2002).Kinetic and kinematic characteristic of gait in patients with medial knee arthrosis. Acta Orthopaedica Scandinavica 73, 647-52.

Guccione AA., Felson DT., Anderson JJ., Anthony JM., Zhang Y., Wilson PW., KellyHayes M., Wolf PA., Kreger BE., \& Kannel WB. (1994). The effects of specific medical conditions on the functional limitations of elders in the Framingham Study. American Journal of Public Health 84(3), 351-8.

Gutekunst DJ., Frykman PN., \& Seay JF. (2010). Over-stridding during "fixed-cadence" load carriage leads to increased ground reaction forces. American Society of Biomechanics Conference Providence, RI August 18-21. 
Guyatt GH., Sullivan MJ., Thompson PJ., Fallen EL., Pugsley SO., Taylor DW. Et al. (1985). The 6-minute walk: a new measure of exercise ability in patients with chronic heart failure. Canadian Medical Association Journal 132, 919-23.

Hagberg M. (1981). Muscular endurance and surface electromyogram in isometric and dynamic exercise. Journal Applied Physiology 51, 1-7.

Hamill J., van Emmerik RE., et al. (1999). A dynamical systems approach to lower extremity running injuries. Clinical Biomechanics 14(5), 297-308.

Harada ND., Chiu V., \& Stewart AL. (1999). Mobility-related function in older adults: assessment with a 6-minute walk test. Archives of Physical Medicine and Rehabilitation 80(7), 837-41.

Harris WH. \& Sledge CB. (1990). Total hip and total knee replacement (2). New England Journal of Medice 323, 801-7.

Hassan, B. Mockett, S., \& Doherty M. (2001). Static postural sway, proprioception, and maximal voluntary quadriceps contraction in patients with knee osteoarthritis and normal control subjects. Annals of the Rheumatic Diseases 60, 612-8.

Heiderscheit BC. (2000). Movement variability as a clinical measure for locomotion. Journal of Applied Biomechanics 16, 419-27.

Heidt RS., Sweeterman LM., Carlonas R L., Traub JA., \& Tekulve FX. (2000). Avoidance of soccer injuries with preseason conditioning. American Journal of Sports Medicine 28(5), 659-62.

Hilding MB., Ryd L., Toksvig-Larsen S., Mann A., \& Stenstrom A. (1999). Gait affects tibial component fixation. Journal of Arthroscopy 14, 589-93.

Hilding MB, Lanshammar H, \& Ryd L. (1996). Knee joint loading and tibial component loosening, RSA and gait analysis in 45 osteoarthritic patients before and after TKA. Journal of Bone and Joint Surgery (British) 78(1), 66-73.

Hochberg MC., Lethbridge-Cejku M., et al. (1995). The association of body weight, body fatness, and body fat distribution with osteoarthritis of the knee: data from the Baltimore Longitudinal Study of Aging. Journal of Rheumatology 22 (3), 488-93.

Hodgkinson R. \& Woolf D. (1973). A five-year clinical trial of indomethacin in osteoarthritis of the hip. Practitioner 210, 392-6.

Hurley MV. \& Newham DJ. (1993). The influence of arthrogenous muscle inhibition on quadriceps rehabilitation of patients with early, unilateral osteoarthritic knees. British Journal of Rheumatology 32, 127-31.

Hurley, M., (1997). The effects of joint damage on muscle function, proprioception and rehabilitation. Manual Therapy 2, 11-7. 
Hurley MV, Rees J, \& Newham DJ. (1998). Quadriceps function, proprioceptive acuity and functional performance in healthy young, middle-aged and elderly subjects. Age Ageing; 27, 55-62.

Hurley, MV. (1998). Quadriceps weakness in osteoarthritis. Current Opinion in Rheumatology 10, 246-50.

Hurley MV. (1999). The role of muscle weakness in the pathogenesis of osteoarthritis. Rheumatic Disease Clinics of North America 25(2), 283-98.

Hurley MV. (2003). Muscle dysfunction and effective rehabilitation of knee osteoarthritis: What we know and what we need to find out. Arthritis and Rheumatism 49 (3), 444-52.

Hurwitz D., Ryals A., Block J., Sharma L., Schnitzer T., \& Andriacchi T. (2000). Knee pain and joint loading in subjects with osteoarthritis of the knee. Journal of Orthopeadic Research 18(4), 572-9.

Jensen M., Karoly P., \& Braver S. (1986). The measurement of clinical pain intensity: a comparison of six methods. Pain 27, 117-26.

Johansson H, Sjolander P, \& Sojka P. (1991). A sensory role for the cruciate ligaments. Clinical Orthopaedics and Related Research 268, 161-78.

Jones BH., Cowan DN., \& Knapik JJ. (1994). Exercise, training and injuries. Sports Medicine 18(3), 202-14.

Jordan J., Luta G., Renner J., Dragomir A., Hochberg M., \& Fryer J. (1997). Knee pain and knee osteoarthritis severity in self-reported task specific disability: the Johnston County Osteoarthritis Project. Journal of Rheumatology 24(7), 1344-9

Jorgensen L., Jacobsen BK., Wilsgaard T., \& Nagnus JH. (2000).Walking after stroke: Does it matter? Changes in bone mineral density within the first 12 months after stroke. A longitudinal study. Osteoporosis International 11(5), 381-7.

Kalb C. (1999). The jock vs. the clock: weekend athletes and the perils of middle age. Newsweek May 24, 76-81.

Kaufman KR., Hughes C., Morrey BF., Morrey M., An KN. (2001). Gait characteristics of patients with knee osteoarthitis. Journal of Biomechanics 34, 907-12.

Keays SL., Bullock-Saxton J., \& Keays AC., (2000). Strength and function before and after anterior cruciate ligament reconstruction. Clinical Orthopaedics and Related Research 373, 174-83.

Kennedy DM., Hanna SE., Stratford PW., Wessel J., \& Gollish JD. (2006). Preoperative function and gender predict pattern of functional recovery afterhip and knee arthroplasty. Journal of Arthroplasy 21(4) 559-66. 
King KL., Morgan AL., McNevin N., Fahlman MM., Boardley D., Topp R., \& Doherty KD. (2001). Functional ability in the elderly after a 16-week exercise program: A preliminary study. Paper presented at The Midwest Regional Chapter of the American College of Sports Medicine, October 14-16.

Kraemer WJ., Keuning M., Ratamess NA., Volek JS., et al. (2001). Resistance training combined with bench-step aerobics enhances woman's health profile. Medical Science in Sports and Exercise 33(2), 529-69.

Kremer E., Atkinson JH., \& Ignelzi RJ. (1981). Measurement of pain: patient preference does not confound pain measurement. Pain 10, 241-8.

Kroll MA., Otis JC., Sculco TP., et al. (1989). The relationship of stride characteristics to pain before and after total knee arthroplasty. Clinical Orthopaedics and Related Research 239, 191-5.

Lafortune MA., Lake MJ., \& Hennig EM. (1996). Differntial shock transmissino response of the human body to impact severity and lower limb posture. Journal of Biomechanics 29(12), 1531-7.

Lafortune MA., Hennig EM., \& Lake MJ. (1996). Dominant role of interface over knee angle for cushioning impact loading and regulating initial leg stiffness. Journal of Biomechanics 29(12), 1523-9.

Lange AK., van Wanseele B., \& Flatarone Singh MA. (2008). Strenght training for treatment of osteoarthritis of the knee: a systematic review. Arthritis and Rheumatism 59(10), 1488-94.

Langenfeld H., Schneider B., Grimm W., Beer M., Knoche M., Riegger G., \& Kochsiek K. (1990). The six-minute walk - an adequate exercise test for pacemaker patients? Pacing and Clinical Electrophysiology 13(12-2), 1761-5.

Lawrence RC., Felson DT., Helmick CG., et al. (2008). Estimates of the prevalence of arthritis and other rheumatic condition in the United States. Part II. Arthritis and Rheumatism 58, 26-35.

Lee TH., Tsuchida T., Kitahara H., \& Moriya H. (1999). Gait analysis before and after unilateral total knee arthroplasty. Study using a linear regression model of normal controls- Women without arthroplasty. Journal of Orthopaedic Science 4, 13-21.

Lewek, M., Rudolph, K., \& Snyder-Mackler, L. (2004). Quadricps femoris muscle weakness and activation failure in patients with symptomatic knee osteoarthritis. Journal of Orthopaedic Research 22, 110-5.

Lewek MD., Scholz J., Rudolph KS., \& Snyder-Mackler L. (2006). Stride-to-stride variability of knee motion in patients with knee osteoarthritis. Gait and Posture 23, $505-11$. 
Liang MH., Fossel AH., \& Larson MG. (1990). Comparisons of five health status instruments for orthopedic evaluation. Medical Care 28, 632-42.

Maly MR. (2009). Linking biomechanics to mobility and disability in people with knee osteoarthritis. Exercise Sports Science Review 37(1), 36-42.

Manninen P., Riihimäki H., Heliövaara M., \& Mäkelä P. (1996). Overweight, gender and knee osteoarthritis. International Journal of Obesity and Related Metabolic Disorders: Journal of the International Association for the Study of Obesity 20(6), 595-7.

McAlindon TE., Cooper C., Kirwan JR., \& Dieppe PA. (1993). Determinants of disability in osteoarthritis of the knee. Annals of the Rheumatic Diseases 52, 258-62.

McAlindon T., Zhang Y., Hannan M., Naimark A., Weissman B., Castelli W., \& Felson D. (1996). Are risk factors for patellofemoral and tibiofemoral knee osteoarthritis different?. Journal of Rheumatology 23(2), 332-7.

Mercer JA., DeVita P., Derrick TR., \& Bates BT.(2003). Individual effects of stride length and frequency on shock attenuation during running. Medicine and Science in Sports and Exercise 35(2), 307-13.

Messier SP., Loeser RF., Hoover JL., Semble EL., \& Wise CM. (1992). osteoarthritis of the knee: effects on gait, strength, and flexibility. Archives of Physical Medicine and Rehabilitation 73, 29-36.

Messier, S.P., Thompson, C.D. \& Ettinger, W.H. (1997). Effects of long term aerobic or weight training regimens on gait in an older osteoarthritic population. Journal of Applied Biomechanics 13, 205-25.

Messier SP., Legault C., Schoenlank CR., Newman JJ., Martin DF., \& DeVita P. (2008). Risk factors and mechanisms of knee injury in runners. Medicine and Science in Sports and Exercise 40(11), 1873-9.

Michael K. (2000). Relationship of skeletal muscle atrophy to functional status: a systematic research review. Biology Research Nursing 2(2), 117-31.

Miyazaki T., Wada M., Kawahara H., Sato M., Baba H., \& Shimada S. (2002). Dynamic load at baseline can predict radiographic disease progression in medial compartment knee osteoarthritis. Annals of the Rheumatic Diseases 61, 617-22.

Mizrahi J., Voloshin AS., Russek D., Verbitsky O., \& Isakov E. (1997). The influence of fatigue on EMG and impact acceleration in running. Basic Applied Myology 7(2), 119-26.

Mundermann A., Dyrby CO., Hurwitz DE., Sharma L., \& Andriacchi TP. (2004). Potential strategies to reduce medial compartment loading in patients with knee osteoarthritis of varying severity. Arthritis and Rheumatism 50(4), 1172-8. 
Mundermann A., Dyrby CO., \& Andriacchi TP. (2005). Secondary gait changes in patients with medial compartment knee osteoarthritis: increased load at the ankle, knee and hip during walking. Arthritis and Rheumatism 52, 2835-44.

National Center for Health Statistics (NCHS) (1992). National Hospital Discharge Survey 1990-1992. American Academy of Orthopaedic Surgeons, Department of Research and Scientific Affairs, Park Ridge Ill.

Newman N. \& Ling RSM. (1985). Acetabular bone destruction related to non-steroidal anti-inflammatory drugs. Lancet II, 11-13.

Nordesjo LO., Nordgren B., Wigren A., \& Kolstad K. (1983). Isometric strength and endurance in patients with severe rheumaroid arthritis or osteoarthrosis in the knee joints. Scandanavian Journal of Rheumatology 12, 152-56.

O'Connor BL, Palmoski MJ, \& Brandt KD. (1985). Neurogenic acceleration of degenerative joint lesions. Journal of Bone and Joint Surgery 67, 562-72.

Ohnhaus EE. \& Adler R. (1975). Methodological problems in the measurement of pain: a comparison between the verbal rating scale and the visual analogue scale. Pain 1, 379-84.

Oliveria SA., Felson DT., Reed J., Cirillo PA., \& Walker AM. (1995). Incidence of symptomatic hand, hip, and knee osteoarthritis among patients in a health maintenance organization. Arthritis and Rheumatism 38(8), 1134-41.

O'Reilly SC., Jones A., Muir KR., Doherty M. (1998). Quadriceps weakness in knee osteoarthritis: the effect on pain and disability. Annals of the Rheumatic Diseases $57,588-94$.

Orthopedic Network News. (2002) Hip and knee implant review. CMS MedPar. www.orthopedicnetworknews.com.

Ouellet D. \& Moffet H. (2002). Locomotor deficits before and two months after knee arthroplasty. Arthritis and Rheumatism 47 (5), 484-93.

Parent E. \& Moffet H. (2003). Preoperative predictors of locomotor ability two months after total knee arthroplasty for severe osteoarthritis. Arthritis and Rheumatism 49 (1), 36-50.

Peat G, McCarney R, \& Croft P. (2001). Knee pain and osteoarthritis in older adults: a review of community burden and current use of primary health care. Annals of the Rheumatic Diseases 60, 91-7.

Perry J. (1992). Gait analysis: normal and pathological function. Thorofare, NJ. Slack Inc. 
Perry J. (1998). The contribution of dynamic electromyography to gait analysis. $R R D S$ Gait Analysis in the Science of Rehabilitation Monograph 002, 33-48.

Peterson MGE., Kovar-Toledano PA., Otis JC., Allegrante JP., Mackenzie CR., Gutin B., et al. (1993). Effect of walking program on gait characteristics in patients with osteoarthritis. Arthritis Care and Research 6, 11-6.

Petrella RJ. \& Barha C. (2000). Home based exercise therapy for older persons with knee osteoarthritis: a randomized clinical trial. Journal of Rheumatology 27, 2215-21.

Phipps WJ., Cassmeyer VL., Sands JK., \& Lehman NM. (1994). Medical-Surgical Nursing: Concepts and Clinical Practice $\left(4^{\text {th }}\right.$ ed.). St. Louis, MO: Mosby-Year Book.

Praemer A., Furner S., \& Rice DP. (1999). Musculoskelatal Conditions in the United States $\left(2^{\text {nd }}\right.$ ed.). Rosemont, IL, American Academy of Orthopaedic Surgeons.

Price D., McGrath P., Rafii A., \& Buckingham B. (1983). The validation of visual analogue scales as ratio scale measures for chronic and experimental pain. Pain 17, 45-56.

Price LG., Hewett JE., Kay DR., \& Minor MA. (1988). Five-minutes walking test of aerobic fitness for people with arthritis. Arthritis Care Research 1, 33-7.

Radin EL., Whittle MW., Yang KH., Jefferson R., Rodgers MM., Kish VL., \& O'Connor JJ. (1986). The heelstrike transient, its relationship with the angular velocity of the shank, and effects of quadriceps paralysis. In: Lantz SA., King AI. (Eds.), Advances in Bioengineering. American Society of Mechanical Engineering, New York, 121123.

Radin EL, Yang KH, Riegger C, Kish VL, \& O'Conner JJ. (1991). Relationship between lower limb dynamics and knee joint pain. Journal of Orthopaedic Research 9, 398405.

Radin EL. Schaffler MB., Gibson G., \& Tashman S. (1995). Osteoarthritis as the result of repetitive trauma. Osteoarthritis disorders. Journal of the American Academy of Orthopaedic Surgeons 13, 197-203.

Radin EL. (2004). Who gets osteoarthritis and why? Journal of Rheumatology 31(70) 10 15.

Rashad S., Low F., Revell P., Hemingway A., Rainsford K., \& Walker F. (1989). Effect of non-steroidal anti-inflammatory drugs on the course of osteoarthritis (letter). Lancet II, 1149.

Rejeski WJ., Ettinger WHJ., Schumaker S., James P., Burns R., \& Elam JT. (1995). Assessing performance-related disability in patients with knee osteoarthritis. Osteoarthritis Cartilage 3, 157-67. 
Ries M., Philbin E., Groff G., Sheesley K., Richman J., \& Lynch F. (1996). Improvement in cardiovascular fitness after total knee arthroplasty. Journal of Bone and Joint Surgery 78A(11), 1696-701.

Rissanen P., Aro S., Slatis P., Sintonen H., \& Paavolainen P. (1995). Health and quality of life before and after hip or knee arthroplasty. Journal of Arthroplasty 10, 169-75.

Rodgers J., Garvin K., Walker C., Morford D., Urban J., \& Bedard J. (1998). Preoperative physical therapy in primary total knee arthoplasty. Journal of Arthoplasty 13(4), 414-21.

Rogind H, Bibow-Nielson B, Jensen B, Moller HC, Frimodt-Moller H, \& Bliddal H. (1998). The effects of a physical training program on patients with osteoarthritis of the knees. Archive of Physical and Medical Rehabilitation 79, 1421-7.

Ronningen H. \& Langeland N. (1979). Indomethacin treatment in osteoarthritis of the hip joint. Acta Orthopaedica Scandinavica 50, 169-74.

Schipplein OD. \& Andriacchi TP. (1991) Interaction between active and passive knee stabilizers during level walking. Journal of Orthopaedic Research 9, 113-9.

Schnitzer TJ. (1993). Effect of piroxicam on gait in patients with osteoarthritis of the knee. Arthritis and Rheumatism 36(9), 1207-13.

Sharma L., Sinacore J., Daugherty C., Kuesis D., Stulberg S., Lewis M., Baumann, G., \& Chang R. (1996). Prognostic factors for functional outcome of total knee replacement: a prospective study. Journal of Gerontology: Medical Sciences $51 \mathrm{~A}(40), 152-7$.

Sharma L., Hayes KW., Felson DT., Buchanan TS., Kirwan-Mellis G., Lou C., Pai YC., $\&$ Dunlop DD. (1999). Does laxity alter the relationship between strength and physical function in knee osteoarthritis. Arthritis and Rheumatism 42(1), 25-32.

Sharma, L., Dunlop, D., Cahue, S., et al. (2003). Quadriceps strength and osteoarthritis progression in malaligned and lax knees. Annals of Internal Medicine 138, 613-9.

Sisto SA. \& Malanga G. (2006). Osteoarthritis and therapeutic exercise. American Journal of Physical Medicine and Rehabilitation 85(11), 69-78.

Slemenda C, Brandt KD, Heilman DK, Mazzuca S, Braunstein EM, Katz BP, et al. (1997). Quadriceps weakness and osteoarthritis of the knee. Annals of Internal Medicine 127, 97-104.

Slemenda C. Heilman DK., Brandt KD., Katz BP., Mazzuca SA., Braunstein EM., et al. (1998). Reduced quadriceps strength relative to body weight: a risk factor for knee osteoarthritis in women? Arthritis and Rheumatism 41, 1951-9. 
Smith CA. (1994). The warm-up procedure: To stretch or not to stretch. A brief review. Journal of Orthopedic Sports and Physical Therapy 19(1), 12-7.

Smith AJ., Lloyd DG., \& Wood DJ. (2004). Pre-surgery knee joint loading patterns during walking predict the presence and severity of anterior knee pain after total knee arthroplasty. Journal of Orthopaedic Research 22, 260-6.

Stillwell KM., Forman DE., McElwain D., Simpson C., \& Garber CE. (1996). The 6 minute walk test for evaluation of functional capacity in elderly adults. Medicine and Science in Sports \& Exercise 28(5), 152.

Syed IY. \& Davis BL. (2000). Obesity and osteoarthritis of the knee: hypotheses concerning the relationship between ground reaction forces and quadriceps fatigue in long-duration walking. Medical Hypotheses 54(2), 182-5.

Teichtahl, A., Wluka, A., \& Cicuttini, F. (2007). Abnormal biomechanics: a precursor or result of knee osteoarthritis? British Journal of Sports Medicine 37, 289-90.

Tierney WM., Fitsgerald JF., Heck DA., Kennedy JM., Katz BP., Melfi CA., et al. (1994). Knee replacement patient outcomes team. Tricompartmental knee replacement: a comparison of orthopaedic surgeon's self reported performance rates with surgical indications, contraindications, and expected outcomes. Clinical Orthopaedics and Related Research 305, 209-17.

Topp R., Mikesky A., Wigglesworth J., Edwards J. (1993). The effect of a 12-week dynamic strength training program on gait velocity and balance of older adults. The Gerontologist 33(4), 501-6.

Topp R., Mikesky A., Dayhoff N., \& Holt W. (1996). Effect of resistance training on strength, postural stability, and gait speed of older adults. Clinical Nursing Research $5(4), 407-27$.

Topp R., Woolley S., Khuder S., \& Bruss A. (2000). Predictors of four functional tasks in patients with osteoarthritis of the knee. Orthopaedic Nursing 19(5), 49-58.

Topp R., Woolley S., Pifer M., Khuder S., Hornyak J., \& Kahaleh B (2001). The effect of strength training on pain during functioning among patients with OA of the knee. Midwest Nursing Research Society's Annual Conference, Cleveland, Ohio March 36.

Topp R., Ditmyer D., King K., Doherty K., \& Hornyak J. (2002). The effect of bed rest and the potential of prehabilitation on ICU patients. AACN Clinical Issues: Advanced Practice in Acute and Critical Care 13(2), 263-76.

Topp R., Woolley S., Hornyak J., Khuder S., \& Kahaleh B. (2002). The effect of dynamic versus isometric strength training on pain and functioning among adults with osteoarthritis of the knee. Archives of Physical Medicine and Rehabilitation 83(9), 1187-95. 
Van Essen GJ., Chipchase LS., O'Connor D., \& Krishnan J. (1998). Primary total knee replacement: short term outcomes in an Australian population. Journal of Quality in Clinical Practice 18, 135-42.

Van Lent MET., Drost MR., and Widenberg FA. (1994). EMG profiles of ACL-deficient patients during walking: the influence of mild fatigue. International Journal of Sports Medicine 15(8), 508-14.

Verbitsky O., Mizrahi J., Voloshin A., Triger U., \& Isakov E. (1998). Shock transmission and fatigue in humans running. Journal of Applied Biomechanics 14, 300-11.

Voloshin A. (2000). The influence of walking speed on dynamic loading on the human musculoskeletal system. Medicine and Science in Sports and Exercise 32(6), 11561159.

Wang AW., Gilbey HJ., \& Ackland TR. (2002). Preoperative exercice programmes improve early return of ambulatory function after total hip arthroplasty: a randomized, controlled trial. American Journal of Physical Medicine and Rehbiltation 81, 801-6.

Weidenhielm L., Mattsson E., Broström LA., \& Wersäll-Robertsson E. (1993). Effect of preoperative physiotherapy in unicompartmental prosthetic knee replacement. Scandinavian Journal of Rehabilitation Medicine 25(1), 33-9.

Whitney EN. \& Rolfes SR. (1999). Understanding nutrition. Belmont, CA. West/Wadsworth.

Whitney J. D. \& Parkman, S. (2002). Preoperative physical activity, anesthesia and analgesia: effects of early postoperative walking after total hip replacement. Applied Nursing Research 15(1), 19-27.

Wijgman A.J., Dekkers G.H., Waltje E., Krekels T., \& Arens H.J. (1994). No positive effect of preoperative exercise therapy and teaching in patients to be subjected to hip arthroplasty. Ned Tijdschr Geneeskd 138, 949-52.

Williams JI., Llewellyn TH., Arshinoff R., Young N., Naylor CD., Ontario hip and knee replacement team project. (1997). The burden of waiting for hip or knee replacements in Ontario. Journal of Evaluation in Clinical Practice 3, 59-68.

Wilson SA., McCann PD., Gotlin RS., et al. (1996). Compreshensive gait analysis in posterior-stabilized knee arthroplasty. Journal of Arthroplasty 11, 359-67.

Woolley S., Topp R., Khuder S., Kahaleh B., \& Commager J. (1999). Function: which factors predict ability in OA patients. Biomechanics 17(1), 77-84. 


\title{
CURRICULUM VITAE
}

\author{
Danielle Biton
}

2919 Westfield Rd

Louisville, KY 40220

(502) 459-4234

d0bito01@louisville.edu

\section{PROFESSIONAL BACKGROUND}

\section{Education}

Ph.D. in Mechanical Engineering, University of Louisville, expected December 2010. Dissertation title "Walking Biomechanics of End Stage Knee OA and TKA patients."

DEA in Biomechanics and Physiology of Movement. University of Paris 11, Orsay, France, 1997.

Maitrise in Mechanical Engineering. University Joseph Fourier, Grenoble, France, 1996.

Licence in Mechanical Engineering, University Joseph Fourier, Grenoble, France, 1994.

\section{Experience}

1997-2000 Assistant Research Engineer in Biomechanics. AFM (Neuromuscular Disorder Association), Pitie Salpetriere Hospital, Paris, France. Managed the Elite Movement Analysis Laboratory. Calibrated Elite motion analysis system. Collected kinetic, kinematic, and electromyographic data and performed analysis on the data. Developed clinical research protocols to quantify muscular strength of various pathologies. Conducted studies on walking patterns of healthy and pathologic children and adults.

1996-1997 Graduate Research Assistant in Biomechanics. Physiology of Movement Laboratory, Paris, France. Studied walking initiation from a seated position. Analyzed anticipatory postural adjustments (APA) and preformed motion analysis in terms of motor program using force plates and electromyography equipment.

1996 Research Assistant. RESACT Sport Laboratory in collaboration with INRIA (National Institute of Research in Computer Service and Automation), Grenoble, France. Analyzed the influence of slope on human walking parameters. Implemented a threedimensional walking pattern for an anthropomorphous robot design project. 
1996 Research Assistant. INPG Laboratory (Polytechnic National Institute of Grenoble), Grenoble, France. Investigated the suitability of various composite materials for fabrication of skis by optimizing performance indices.

1992-1996 Tutor. Parent Association, Sassenage, France. Tutored middle school and high school students in physics, mathematics, and French.

\section{Languages}

French: mother tongue

\section{Specialties}

Biomechanics and motion analysis.

\section{Publications}

Journals and Reviewed Series

Quesada, P.M., Durham, M.P., Topp, R.V., Swank, A.M. and Biton, D., "Quantitative Assessment of Balance Performance On a Passively Unstable Surface," Occupational Ergonomics, 7(1), 3-10, 2007.

\section{Conference Proceedings}

Biton, D., Quesada, P., Nyland, J., Durham, M., Angeli, C., Topp, R., and Swank, A. "Heel Strike Dynamics during 6 Minute Walk Test among End Stage Knee OA Patients," The $20^{\text {th }}$ International Society of Biomechanics Congress, Cleveland, Ohio, USA, August $1-5,2005$.

Biton, D., Quesada, P., Angeli, C., Nyland, J., Topp, R., and Swank, A. "Fatigue during Gait among End Stage Knee Osteoarthritis Patients," 2005 Summer Bioengineering Conference, Vail, Colorado, USA, June 22-26, 2005. 